\title{
INTERACTIVE EFFECTS OF ALCOHOL AND DIABETES DURING PREGNANCY ON THE RAT FETUS \\ By
}

Yi Lin

B. Sc. (Public Health) Tianjin Medical Institute, 1983

A THESIS SUBMITTED IN PARTIAL FULFILLMENT OF

THE REQUIREMENTS FOR THE DEGREE OF

MASTER OF SCIENCE

in

THE FACULTY OF GRADUATE STUDIES

SCHOOL OF FAMILY AND NUTRITIONAL SCIENCES, DIVISION OF HUMAN NUTRITION

We accept this thesis as conforming to the required standard

THE UNIVERSITY OF BRITISH COLUMBIA

August 1992

(C) Yi Lin, 1992 
In presenting this thesis in partial fulfilment of the requirements for an advanced degree at the University of British Columbia, I agree that the Library shall make it freely available for reference and study. I further agree that permission for extensive copying of this thesis for scholarly purposes may be granted by the head of my department or by his or her representatives. It is understood that copying or publication of this thesis for financial gain shall not be allowed without my written permission.

Human Nutrition

The University of British Columbia

2075 Wesbrook Place

Vancouver, Canada

V6T 1Z1

Date:

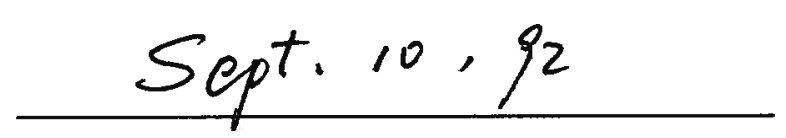




\begin{abstract}
Substantial literature indicates that maternal diabetes has teratogenic effects on the fetus and that consumption of alcohol during gestation is also teratogenic to the fetus. In the present study, Sprague-Dawley female rats were used to test whether small amounts of alcohol administered during organogenesis has an effect on the outcome of pregnancy in nondiabetic rats; to confirm the teratogenic effect of diabetes on fetuses; and to establish whether there is an interaction between alcohol and diabetes on the outcome of pregnancy. All rats were fed Purina rat chow and tap water ad libitum. Diabetes was induced by tail vein administration of streptozotocin ( $60 \mathrm{mg} / \mathrm{kg}$ body weight) one week before mating. Alcohol was administered during organogenesis (days 6-11 of gestation) intragastrically. The incidence and types of external and skeletal malformations were recorded in the fetuses of all treatment groups on day 21 of gestation. In addition, the fetal development was followed by assessing the ossification of the skeleton on gestational day 21 with the aid of alizarin red S and alcian blue 8GS staining.

The results of this investigation support the view of previous studies that maternal diabetes is teratogenic to the offspring in terms of significantly increased malformation rates, and retarded fetal development (smaller fetal weight, bigger placenta, and retarded skeletal ossification compared to controls).

Consumption of a small amount of alcohol $(2 \mathrm{~g} / \mathrm{kg} /$ day) during organogenesis (days 6-11 of gestation) did not seem to intoxicate the dams, the body weight gain was at a normal rate, and there was a bigger fetal/placental ratio compared to controls. In terms of skeletal development, alcohol exposure seemed to enhance bone development. However, there were a few fetuses with absence of ossification centers in the hyoid bone
\end{abstract}


and the short 13th rib which were significantly different from other treatment groups. Whether this represents retarded skeletal development is not clear.

In the present study, a significant interaction between maternal diabetes and alcohol administration during organogenesis was observed. The fetal external malformation rate was significantly increased in diabetic rats exposed to alcohol compared to diabetic rats not exposed to alcohol. Furthermore, more fetuses had poorly ossified thoracic vertebral centers, poorly ossified cervical arches, and poorly ossified supraoccipital bone in diabetic rats exposed to alcohol than in diabetic rats not exposed to alcohol. These observations suggest that a small amount of alcohol consumption during organogenesis could possibly exacerbate the embryotoxic effects of maternal diabetes. 
$\begin{array}{ll}\text { Abstract } & \text { ii }\end{array}$

List of Tables $\quad$ viii

List of Figures $\quad$ x

Acknowledgement $\quad$ xi

1 Introduction 1

1.1 Evidence that alcohol is teratogenic . . . . . . . . . . . 1

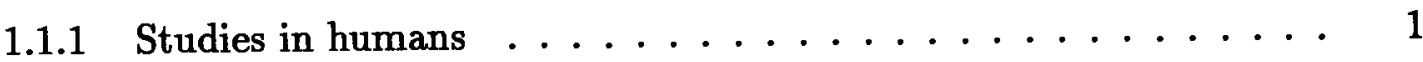

1.1.2 Studies in animals ..................... 5

1.2 Evidence that diabetes is teratogenic ................ 11

1.2.1 Studies in humans ....................... 11

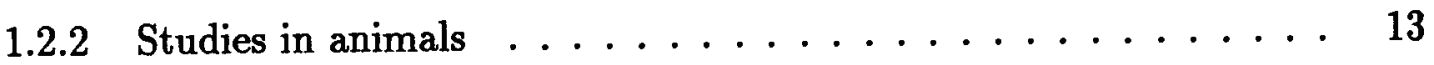

1.2.3 The teratogenic period of diabetic pregnancy . . . . . . . 14

1.2.4 The proposed mechanisms . . . . . . . . . . 15

1.3 Evidence for an interaction between alcohol and other factors . . . . . . 17

1.4 Evidence for an interaction between alcohol and diabetes . . . . . . 20

1.5 Skeletal examination in experimental teratology studies . . . . . . . . 21

1.6 The purpose of the study . . . . . . . . . . . . . . 23

2 Methods $\quad 24$

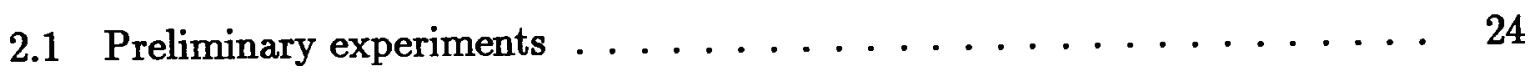


2.2 Experimental methods . . . . . . . . . . . . . . 25

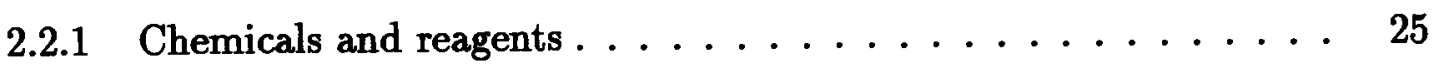

2.2 .2 Animals and diets . . . . . . . . . . . . 25

2.2.3 Induction of diabetes . . . . . . . . . . . 25

2.2 .4 Breeding . . . . . . . . . . . . . 26

2.2.5 Administration of alcohol $\ldots \ldots \ldots \ldots \ldots \ldots$

2.2 .6 Blood alcohol assay $\ldots \ldots \ldots \ldots \ldots \ldots \ldots \ldots$

2.2 .7 Body weight record $\ldots \ldots \ldots \ldots \ldots \ldots \ldots \ldots$

2.2 .8 Blood glucose measurement $\ldots \ldots \ldots \ldots \ldots \ldots \ldots$

2.2 .9 Termination of gestation $\ldots \ldots \ldots \ldots \ldots \ldots$

2.2 .10 Skeletal staining $\ldots \ldots \ldots \ldots \ldots \ldots \ldots \ldots$

2.2 .11 Skeletal examination $\ldots \ldots \ldots \ldots \ldots \ldots \ldots$

2.2 .12 Food record $\ldots \ldots \ldots \ldots \ldots \ldots \ldots \ldots \ldots \ldots$

2.2 .13 Statistical analysis $\ldots \ldots \ldots \ldots \ldots \ldots \ldots \ldots \ldots$

3 Results $\quad 34$

3.1 Calorie and water consumption $\ldots \ldots \ldots \ldots \ldots \ldots \ldots$

3.2 Reproductive performance . . . . . . . . . . . . 38

3.3 Body weight and weight gain of dams during pregnancy . . . . . . . 39

3.4 Blood glucose concentrations . . . . . . . . . . . . . 42

3.5 Peak blood alcohol levels . . . . . . . . . . . . . . . . . 44

3.6 Outcome of pregnancy . . . . . . . . . . . . . 44

3.7 Fetal weight, placental weight and fetal weight/placental weight ratio . . 45

3.8 External malformations . . . . . . . . . . . . . . . 49

3.9 Skeletal malformations $\ldots \ldots \ldots \ldots \ldots \ldots \ldots \ldots \ldots \ldots \ldots$

3.10 Skeletal ossification and variants . . . . . . . . . . . 54 
3.10.1 Metacarpus, metatarsus $\ldots \ldots \ldots \ldots \ldots \ldots \ldots$

3.10 .2 Sternum . . . . . . . . . . . . . 56

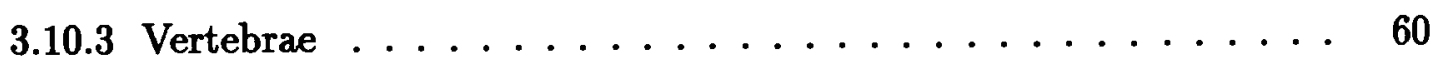

3.10 .4 Skull $\ldots \ldots \ldots \ldots \ldots \ldots \ldots \ldots \ldots$

3.10 .5 Other skeletal variants $\ldots \ldots \ldots \ldots \ldots \ldots \ldots \ldots$

3.10 .6 Bone areas . . . . . . . . . . . . . . 69

4 Discussion $\quad 71$

4.1 Calorie and water consumption $\ldots \ldots \ldots \ldots \ldots \ldots$

4.2 Reproductive performance . . . . . . . . . . . . 72

4.3 Weight gain $\ldots \ldots \ldots \ldots \ldots \ldots \ldots \ldots \ldots \ldots \ldots$

4.4 Outcome of pregnancy $\ldots \ldots \ldots \ldots \ldots \ldots \ldots \ldots$

4.5 Fetal and placental weights . . . . . . . . . . . 76

4.6 Malformations . . . . . . . . . . . . . . 78

4.7 The proposed mechanisms for malformations . . . . . . . . 79

4.8 Skeletal ossification . . . . . . . . . . . . . . . 82

4.8.1 Number of ossification centers . . . . . . . . . . 83

4.8.2 Skeletal variations . . . . . . . . . . . . . . . 84

4.8.3 Ossification of the skull . . . . . . . . . . . 86

4.8 .4 Bone areas . . . . . . . . . . . . . 87

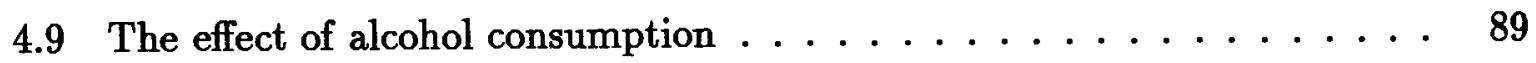

4.10 Summary and conclusion . . . . . . . . . . . . 89

$\begin{array}{lr}\text { Appendices } & 91\end{array}$

$\begin{array}{ll}\text { A Photographs } & 91\end{array}$

$\begin{array}{lr}\text { B Chi-square tests, P values } & 102\end{array}$ 
C Two way ANOVA statistical effects diabetes vs alcohol, $P$ values

D Tests of Simple Effect, $P$ values

Bibliography

108 


\section{List of Tables}

1.1 Principal Features of the Fetal Alcohol Syndrome Observed in 245 People Affected ..................... 3

1.2 Associated Features of the Fetal Alcohol Syndrome Observed in 245 People Affected ..................... 4

3.3 Average water and calorie intake per day during gestation in each treatment group $($ Mean $\pm \mathrm{SD}) \ldots \ldots \ldots \ldots \ldots \ldots \ldots$

3.4 Breeding and pregnancy rates of animals in each treatment group . . . 38

3.5 Body weight and weight gain of dams during gestation in each treatment group $(\operatorname{mean} \pm \mathrm{SD}) \ldots \ldots \ldots \ldots \ldots \ldots \ldots \ldots \ldots$

3.6 Blood glucose concentration of dams at different times during the experiment, in each treatment group $(\mathrm{mmol} / \mathrm{L}) \ldots \ldots \ldots \ldots \ldots$

3.7 Reproductive variables on day 21 of gestation in each treatment group . .

3.8 Fetal and placental weights on day 21 of gestation in each treatment group $(\operatorname{mean} \pm \mathrm{SD}) \ldots \ldots \ldots \ldots \ldots \ldots \ldots \ldots \ldots \ldots \ldots$

3.9 Numbers of fetuses with external malformations in each treatment group 51

3.10 Numbers of fetuses with skeletal malformations in each treatment group . 52

3.11 Development of ossification centers in metacarpus, metatarsus, and sternum in each treatment group $\ldots \ldots \ldots \ldots \ldots \ldots \ldots$

3.12 Skeletal variants observed in fetuses of each treatment group . . . . . 58

3.13 Mean numbers of poorly ossified centers in sternum, thoracic and lumbar vertebrae in each group $($ mean $\pm \mathrm{SD}) \ldots \ldots \ldots \ldots$ 
3.14 Frequencies of fetuses according to the most cephalic and most caudal vertebral ossification centers and the most caudal vertebral arches . . . 61

3.15 Ossification centers and foramen in skull . . . . . . . . 67

3.16 Ossified tissue areas $\left(\mathrm{mm}^{2}\right)$ measured in the selected bones (mean \pm SD) $\quad 70$ 


\section{List of Figures}

2.1 Skeletal districts for examining the ossification centers, skeletal variants

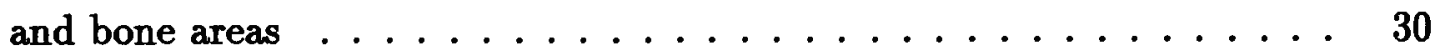

3.2 Daily mean calorie intake during pregnancy $\ldots \ldots \ldots \ldots \ldots$

3.3 Daily mean water intake during pregnancy $\ldots \ldots \ldots \ldots$

3.4 Maternal body weight changes during gestational period in 4 groups . . . 41

3.5 Interaction of diabetes at alcohol on maternal weight gain during D12-21 43

3.6 Interaction of alcohol at diabetes on maternal weight gain during D12-21 43

3.7 Interaction of diabetes at alcohol on fetal weight $\ldots \ldots \ldots \ldots$

3.8 Interaction of alcohol at diabetes on fetal weight $\ldots \ldots \ldots \ldots$

3.9 Interaction of diabetes at alcohol on $\mathrm{f} / \mathrm{p}$ ratio $\ldots \ldots \ldots \ldots$

3.10 Interaction of alcohol at diabetes on $\mathrm{f} / \mathrm{p}$ ratio $\ldots \ldots \ldots \ldots$

3.11 Observed irregular shapes of sternebral ossification centers $\ldots \ldots \ldots 57$

3.12 Ossification centers of cervical arches $\ldots \ldots \ldots \ldots \ldots$

3.13 Observed irregular shapes of vertebral ossification centers . . . . . 65 


\section{Acknowledgement}

I wish to thank my research supervisor, Dr. Melvin Lee, for his kind help and knowledgeable guidance throughout the course of this study. I am also deeply grateful to Dr. Muriel Harris for her constructive advice in writing my thesis. My thanks are happily extended as well to Dr. Linda McCargar, Dr. Joseph Leichter, and Dr. David Kitts for serving on my committee.

I would also like to thank Mrs. Virginia Green for her advice and assistance with statistical analysis of the data, Mr. Alistair Blachford for his instruction in the technique

of bone area measurement. My thanks also go to Mr. Zbysek Masin for his technical support in the animal room. 


\section{Chapter 1}

\section{Introduction}

\subsection{Evidence that alcohol is teratogenic}

The potential for damage to the offspring from prenatal alcohol exposure is now well established. A link between alcohol and birth defects had been strongly suspected since the 1700 s, with early scientific evidence gradually being accumulated during the 19th and early 20th centuries (Warner and Rosett, 1975).

In 1973, Jones et al. (1973a; 1973b) rediscovered an effect of alcohol on morphogenesis. In their two original articles, 11 cases were reported and these 11 children, all raised in a fetal environment provided by an alcoholic mother, had a similar pattern of craniofacial, limb and cardiovascular defects with prenatal-onset growth deficiency and developmental delay. They named this condition "fetal alcohol syndrome". The characterization of "fetal alcohol syndrome" by Jones et al. stimulated a great deal of research both in humans and laboratory animals.

\subsubsection{Studies in humans}

Within a few years after the original reports by Jones et al., several hundred case reports (Clarren and Smith, 1978) were published in the medical literature of many countries. A great deal of evidence supports the view that exposure to ethanol during gestation is associated with a variety of negative outcomes including perinatal death, compromised growth, and behavioral deficits. Fetal alcohol syndrome, the most severe end of the 
spectrum of effects of alcohol on the fetus, has been reported around the world with a frequency of one to three per 1,000 births based on local reports from various U.S. and European studies. Abel and Sokol, basing their estimate on 20 studies from Australia, Europe, and North America, found a worldwide incidence of 1.9 cases of FAS per 1,000 live births (Warren and Bast, 1988). It has been calculated that approximately $5 \%$ of all congenital anomalies may be attributable to prenatal alcohol exposure (Sokol et al., 1986).

However, not all affected infants present the full clinical picture at birth. Along the rest of the continuum toward normal are persons with every subcombination of fetalalcohol-syndrome anomalies. Each anomaly can independently vary in severity and grade into the normal range (Clarren and Smith, 1978). The abnormalities most typically associated with alcohol teratogenicity can be grouped into four categories: central nervous system dysfunctions; growth deficiencies; a characteristic cluster of facial abnormalities; and variable major and minor malformations. Tables $1.1 \& 1.2$ show the frequency of specific malformations within each category (Clarren and Smith, 1978).

The variability of phenotype probably results from variations in dose exposure and gestational timing offset by the genetic background of the individual fetus. Nearly all patients recognized as having the full fetal-alcohol-syndrome phenotype have been born to heavy daily alcohol users or relatively frequent intermittent heavy alcohol users (Clarren and Smith, 1978).

The critical amount of maternal alcohol intake needed during pregnancy to produce adverse fetal effects has not been definitely established. However, a definite risk has been established with an oral maternal intake of $90 \mathrm{ml}(3 \mathrm{oz})$ absolute alcohol (6 average-sized drinks) per day during pregnancy. This consumption level was derived from animal studies by noting the minimum blood alcohol concentration $(73 \mathrm{mg} / 100 \mathrm{ml}$ in mice) responsible for a teratological effect. The amount of alcohol consumption necessary to achieve that 
Table 1.1: Principal Features of the Fetal Alcohol Syndrome Observed in 245 People Affected

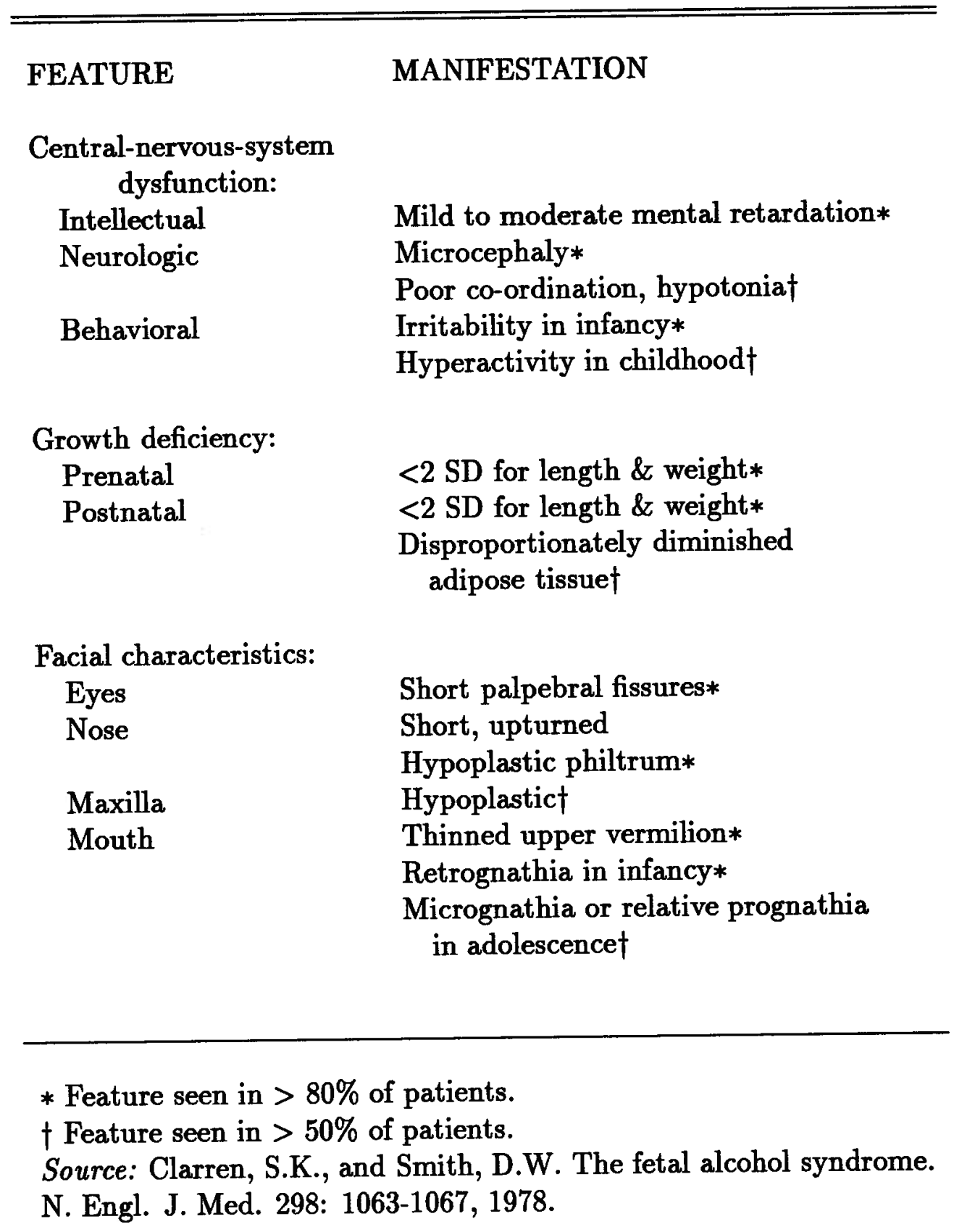


Table 1.2: Associated Features of the Fetal Alcohol Syndrome Observed in 245 People Affected

\begin{tabular}{|c|c|c|}
\hline AREA & FREQUENT* & OCCASIONAL $\dagger$ \\
\hline Eyes & $\begin{array}{l}\text { Ptosis, strabismus, } \\
\text { epicanthal folds }\end{array}$ & $\begin{array}{l}\text { Myopia, clinical microph- } \\
\text { thalmia, blepharophimosis }\end{array}$ \\
\hline Ears & Posterior rotation & Poorly formed concha \\
\hline Mouth & $\begin{array}{l}\text { Prominent lateral } \\
\text { palatine ridges }\end{array}$ & $\begin{array}{l}\text { Cleft lip or cleft palate, } \\
\text { small teeth with faulty enamel }\end{array}$ \\
\hline Cardiac & $\begin{array}{l}\text { Murmurs, especially } \\
\text { in early childhood, } \\
\text { usually atrial } \\
\text { septal defect }\end{array}$ & $\begin{array}{l}\text { Ventricular septal defect, } \\
\text { great-vessel anomalies, } \\
\text { tetralogy of Fallot }\end{array}$ \\
\hline Renogenital & Labial hypoplasia & $\begin{array}{l}\text { Hypospadias, small rotated } \\
\text { kidneys, hydronephrosis }\end{array}$ \\
\hline Cutaneous & Hemangiomas & Hirsutism in infancy \\
\hline Skeletal & $\begin{array}{l}\text { Aberrant palmar } \\
\text { creases, pectus } \\
\text { excavatum }\end{array}$ & $\begin{array}{l}\text { Limited joint movements, } \\
\text { especially fingers \& elbows, } \\
\text { nail hypoplasia, especially } 5 \text { th, } \\
\text { polydactyly, radioulnar synostosis } \\
\text { pectus carinatum, bifid xiphoid, } \\
\text { Klippel-Feil anomaly, scoliosis }\end{array}$ \\
\hline Muscular & & $\begin{array}{l}\text { Hernias of diaphragm, umbilicus } \\
\text { or groin, diastasis recti }\end{array}$ \\
\hline
\end{tabular}

* Reported in between $26 \& 50 \%$ of patients.

$\dagger$ Reported in between $1 \& 25 \%$ of patients.

Source: Clarren, S.K., and Smith, D.W. The fetal alcohol syndrome.

N. Engl. J. Med. 298: 1063-1067, 1978. 
blood alcohol concentration in a $130 \mathrm{lb}$. woman for a period of 6-8 hours was calculated to be $90 \mathrm{ml}$ of absolute alcohol (Maykut, 1979). Although confirmatory evidence is not yet available, it has been suggested that a continuum of fetal alcohol effects ranging from the normal state to abnormalities in growth and intellectual performance to congenital malformations occurs with increasing intake of alcohol (Maykut, 1979).

The period during pregnancy when alcohol is imbibed may be another determining factor in producing morphologic changes. It has been suggested that the first $3-4 \frac{1}{2}$ months of gestation may be the critical period for producing birth defects since rapid organ cell differentiation (e.g., brain, heart, eyes) occurs at this time. Intrauterine growth retardation may be exacerbated by alcohol consumption in later pregnancy (Maykut, 1979).

In addition, the effects of maternal alcohol exposure on the fetus may be related to the peak blood alcohol concentration, which varies from individual to individual. It has been noticed that there are racial differences in the rate of alcohol metabolism and also, alcohol metabolism may vary with age. Thus the variability of observed symptoms is probably due to differences in dose exposure at various gestational periods offset by genetic background of the particular fetus (Maykut, 1979).

\subsubsection{Studies in animals}

Animal studies and the development of appropriate animal models have provided a wealth of information about the effects of gestational alcohol exposure (Driscoll et al., 1990). Animal models are particularly important because of the opportunity to control for factors seldom accounted for in human studies (including control of timing and dose of alcohol exposure, control of nutrition through pair-fed controls, control of the postnatal environment through cross-fostering, and consideration of individual differences through cross-strain comparisons). Extensive animal studies have now demonstrated the specific 
teratogenic properties of ethyl alcohol in several species of animals, with many of the abnormalities being similar to those found in man (Clarren and Smith, 1978). The mouse (Chernoff, 1975; Randall et al., 1977), guinea pig (Papara-Nicholson and Telford, 1957), beagle dog (Ellis and Pick, 1976), rat (Sandor and Amels, 1971; Tze and Lee, 1975), and pigtail macaque (Elton and Wilson, 1977) are among the many species that have been studied as models for the teratogenicity of alcohol.

Decreased birth weight and litter size in offspring of alcohol-fed mice and rats have been found by many investigators (Chernoff, 1975; Martin et al., 1977b; Tze and Lee, 1975), although not by all (Sandor and Amels, 1971; Weathersbee and Lodge, 1978). Many morphological effects are also found, but these are not consistent across species. In the mouse, investigators have produced eye defects, cardiac and neural abnormalities, digit anomalies, and cardiovascular, urogenital, and head malformations by administering large doses of alcohol summarized by Streissguth, et al. (1980). In the rat, microcephaly and a shrivelled appearance have been noted by Tze and Lee (1975). However, apparent malformations were not observed in ethanol treated rats by many other researchers (Abel and Dintcheff, 1978a; Abel, 1978b; Abel, 1979a; Lee and Leichter, 1983; Testar et al., 1986).

Methodological differences among experiments of the time period during gestation when alcohol is administered, the dose, the route of administration, and the strain of animal used may contribute to the difficulties encountered in reproducing experimental results (Streissguth et al., 1980). The three commonly employed methods to administer alcohol are: placing alcohol in drinking water, oral intubation and liquid diet.

Ideally, potential teratogens should be administered to animals by the same route that exposure occurs in humans. For alcohol, the most obvious choice is the oral route. The simplest approach would be to place alcohol in the animal's drinking water. However, this method has several disadvantages. First, it produces only low blood alcohol levels, 
and it is the blood alcohol level, not the daily dose of alcohol administered, that appears to be important in producing fetal alcohol effects, since studies in different strains of mice have shown that prenatal death, malformations, and fetal weights were directly related to maternal blood alcohol levels (Chernoff, 1980). Second, animals usually reduce their fluid intake when the only fluid available is alcohol and, as a consequence, their food intake is also reduced, introducing suboptimal nutrition as a possible confounding factor (Rilely and Meyer, 1984).

To overcome these major defects, Testar et al. (1986) used a modified procedure for oral administration of alcohol. In their study, increasing amounts of ethanol were introduced into drinking water during the premating period and $25 \%$ ethanol in drinking water was offered during gestation in rats. Total energy intake in the alcohol group did not differ from that of controls, either before or during gestation, and this balance was produced by the progressive increment in alcohol derived calories and the correlated decrease in calories derived from food. During pregnancy, ethanol provided more than $30 \%$ of the total calories ingested by the rats. At the 21 st day of gestation, the maternal blood alcohol concentration was $147 \pm 18 \mathrm{mg} / \mathrm{dl}$.

In the liquid diet method, alcohol is mixed with a liquid diet and the mixture is provided as the animal's only source of calories. Presumably this method is nontraumatic to the animal, and is easy to administer. Theoretically, nutritional intake can be controlled and high blood alcohol levels can be achieved and maintained. Typically, in the rat, a diet providing $35 \%$ of the animal's daily caloric intake in the form of alcohol is administered during pregnancy. Blood alcohol levels $(\mathrm{BAL})$ of over $100 \mathrm{mg} / \mathrm{dl}$ are achieved during a substantial portion of the dark cycle when the rats consume the majority of their daily intake (Driscoll et al., 1990).

Disadvantages are that animals in the same group do not all consume the same amount of alcohol and their temporal patterns of intake also differ. Both factors influence blood 
alcohol levels and are not under the experimenter's control. Furthermore, diets that differ in nutritional composition might produce different blood alcohol levels even though they contain the same concentration and percent ethanol derived calories and the animals consume about the same daily dose of ethanol. For example, in a study by Wiener et al. (1981) two diets differing in protein content, but containing the same concentration of ethanol, were consumed in fairly similar amounts by pregnant rats. However, the animals on the diet with higher levels of protein achieved blood alcohol levels only about half as high as those on the diet lower in protein. Thus, even though animals are selfadministering the same daily dose of ethanol, this does not necessarily ensure equal blood alcohol levels when the nutritional composition of the diet differs. This problem was also encountered by Vavrousek-Jakuba et al. (1991). Since blood alcohol level appears to be critical in producing fetal alcohol effects, interpreting data in terms of the daily dose of ethanol consumed may lead to erroneous conclusion.

For oral intubation, the alcohol is mixed with a vehicle and administered directly to the stomach via a tube. The primary advantage of the intubation procedure is that the researcher has control over the dose of alcohol and time of administration. Each animal receives the same dose, at the same time, high blood alcohol levels can be obtained, but are transient. In rats, the doses administered are generally 4 to $8 \mathrm{~g} / \mathrm{kg} /$ day. Following intubation, peak BALs are often well over $200 \mathrm{mg} / \mathrm{dl}$ and rats are obviously intoxicated (Driscoll et al., 1990).

Disadvantages of this method are that intubation is probably stressful and involves daily handling of the dam, possibly confounding the results. Also, the concentration of alcohol and volume administered must be considered because of the potentially irritating properties of high concentrations of alcohol and the effects of volume on absorption (Rilely and Meyer, 1984).

Again, due to differences in metabolism among species, the BAL, rather than the 
absolute dose of alcohol, provides a more meaningful estimate of compound bioavailability (Driscoll et al., 1990; Kumar, 1982).

The following studies reviewed were based on different methodologies. In Lee and Leichter's study (1983), Sprague-Dawley rats received $10 \%$ ethanol $(\mathrm{v} / \mathrm{v})$ in drinking water for one week, $20 \%$ ethanol in drinking water for another 4 weeks before mating and $30 \%$ ethanol in drinking water throughout gestation. The mean serum alcohol level of these rats was $61 \pm 23 \mathrm{mg} \%$. They found the litter size and birth weight were lower in the rats of alcohol group than in the rats of both pair-fed and control groups.

In the study by Testar et al. (1986), Wistar rats were given alcohol in the drinking fluid. Before mating, the rats were given $10 \%$ ethanol in drinking fluid for one week, $15 \%$ for the second week, $20 \%$ for the third, and $25 \%$ for the fourth week. After mating, they were given $25 \%$ ethanol throughout gestation. The ethanol calories comprised over $30 \%$ of the total energy intake during pregnancy. Ethanol intake during pregnancy was more than $10 \mathrm{~g} / \mathrm{kg} /$ day. At the 21 st day of gestation, rats on ethanol had blood alcohol levels of $147 \pm 18 \mathrm{mg} / \mathrm{dl}$. There was a reduction in litter size and fetal weight in the ethanol group, but this was also found in pair-fed group. However, the fetal body length was reduced only in the ethanol group.

In studies using a liquid diet as the source of alcohol, ethanol provided $36 \%$ of total calories in almost every study. In the study by Weinberg et al. (1990), Sprague-Dawley rats were given liquid diet throughout gestation, the blood alcohol level reached 145 to $190 \mathrm{mg} / \mathrm{dl}$. They found a significantly lowered fetal weight in alcohol-exposed fetuses than in either pair-fed or ad libitum control fetuses.

In Abel's three consecutive studies (Abel and Dintcheff, 1978a; Abel, 1978b; Abel, 1979a) alcohol was given by stomach tube throughout gestation. In these studies, four different doses were used $(1.0,2.0,4.0$, and $6.0 \mathrm{~g} / \mathrm{kg} /$ day of ethanol). The peak blood alcohol levels produced by $2.0,4.0$, and $6.0 \mathrm{~g} / \mathrm{kg}$ doses were $80 \mathrm{mg} / 100 \mathrm{ml}, 150 \pm 15$ and 
$267 \pm 19 \mathrm{mg} / 100 \mathrm{ml}$, respectively. The lower doses of 1.0 and $2.0 \mathrm{~g} / \mathrm{kg}$, resulted in a reduction in litter size and litter weights in both ethanol treated and pair-fed control groups, but the difference between the ethanol treated and pair-fed control groups was not significant. With the higher doses of 4.0 and $6.0 \mathrm{~g} / \mathrm{kg}$, litter weight, but not litter size was reduced in ethanol-treated groups. Also, a dose-related reduction in litter weight at birth was observed.

In summary, most studies found a reduced litter weight and/or litter size in ethanol treated rats, but no apparent gross malformations were observed.

With respect to the findings in placental weight of alcohol treated animals, many researchers found a reduced fetal weight in ethanol treated rats, but an increased placental weight (Aufrere and Lebourhis, 1987; Weinberg et al., 1990). Others have reported variations in placental mass, but their observations are not all similar. In alcoholic women, an increase in placental mass was noticed by Kaminski et al. (Aufrere and Lebourhis, 1987) and in both mice and rats, a similar observation has been reported (Fisher et al., 1985; Gordon et al., 1985; Henderson et al., 1981; Jones et al., 1981; Leichter and Lee, 1984). However, in some cases, no change was reported (Abel, 1979b; Chernoff, 1977; Nelson et al., 1985), whereas in others a decrease in placental weight occurred (Aufrere and Lebourhis, 1987; Greizerstein and Aldrich, 1983; Kennedy, 1984). These discrepancies can be explained by differences in the experimental conditions used, including $\mathrm{BAL}$, duration of intoxication and stage of pregnancy. Indeed, if intoxication is severe and takes place during the last two-thirds of pregnancy, a decrease in placental weight is observed (Aufrere and Lebourhis, 1987; Greizerstein and Aldrich, 1983; Kennedy, 1984). Conversely, if intoxication takes place during the first one-third of pregnancy, placental weight is increased (Fisher et al., 1985; Gordon et al., 1985; Henderson et al., 1981; Jones et al., 1981). 


\subsection{Evidence that diabetes is teratogenic}

The first six decades of the insulin era clearly established that most, if not all, of the perinatal complications of pregnancies caused by diabetes are linked to faulty regulation of maternal metabolism and that they can be diminished by rigorous diabetes management (Freinkel, 1980). However, careful retrospective analyses disclosed that the 3- to 6fold increase in the incidence of birth defects had not been attenuated to any meaningful extent (Freinkel, 1988).

\subsubsection{Studies in humans}

The association between diabetes mellitus in women and congenital malformations in their offspring has been suspected since the nineteenth century. In 1885, LeCorché reported hydrocephalus in two infants of diabetic mothers. The prognosis for pregnant diabetic women prior to the discovery of insulin was poor, and few women delivered successfully (Mills, 1982).

It was not until better control of hyperglycemia, close monitoring in the last months of pregnancy, and early delivery for fetal distress were instituted that salvage rates in diabetic pregnancies improved substantially. At this point, the full impact of congenital malformations was appreciated (Mills, 1982).

The definitive clinical observations on the increased incidence of congenital fetal malformations in diabetic pregnancy were not made until 1964 by Molsted-Pedersen, Tygstrup and Pedersen (1964). These observations were later confirmed in many centers, both retrospectively (Glasgow et al., 1979; Kucera, 1971; Malins, 1979; Pedersen, 1977; Soler et al., 1976) and prospectively (Chung and Myrianthopoules, 1975). Most studies have shown that there is unquestionably an increased incidence of major congenital abnormalities in the infants of diabetic mothers (1988). 
Epidemiological data indicate that the risk of congenital malformations in diabetic pregnancies is three to four times higher than that in the nondiabetic population (Baird and Aerts, 1987; Eriksson, 1984a; Kitzmiller et al., 1978; Kucera, 1971; Mills, 1982; Molsted-Pedersen, 1980; Pedersen, 1979; Simpson et al., 1983; Soler et al., 1976), and the malformations affect all fetal organ systems (Kucera, 1971).

Diabetes in pregnancy is associated with a number of changes in embryo-fetal development such as altered growth rate and maturation of several organ systems and an increased rate of congenital malformation (Eriksson et al., 1989a).

Most studies show a generalized increase in malformations involving multiple organ systems. These include cardiovascular, genitourinary, musculoskeletal, and other malformations (Mills, 1982). Nevertheless, no single study has contained enough cases to determine whether or not the risk for each specific defect is significantly increased in diabetic pregnancies compared to the nondiabetic population.

Kucera (1971) tried to estimate relative risks using data from available literature for the 20 year period from 1945 through 1965. He reviewed data on 7,101 fetuses of diabetic women, of which 340 fetuses showed anomalies (4.79\%). This series was then compared with a normal "control" group obtained from WHO data with a total of 431,764 fetuses. This control group had 7,124 malformations $(0.65 \%)$. He found a higher incidence of anomalies in the offspring of diabetic women. Spinal anomalies, situs viscerum inversus, gross skeletal anomalies, pseudohermaphroditism, urological anomalies, and heart anomalies are all significantly more frequent in fetuses of diabetic pregnancies. One syndrome which seems particularly strongly associated with diabetes is the caudal regression syndrome. Caudal regression is a condition in which agenesis or hypoplasia of the femorae occurs in conjunction with agenesis of the lower vertebrae. It is very rare in the general population (Mills, 1982). Kucera (1971) found 9 cases with this syndrome in 7,101 infants of diabetic mothers. 


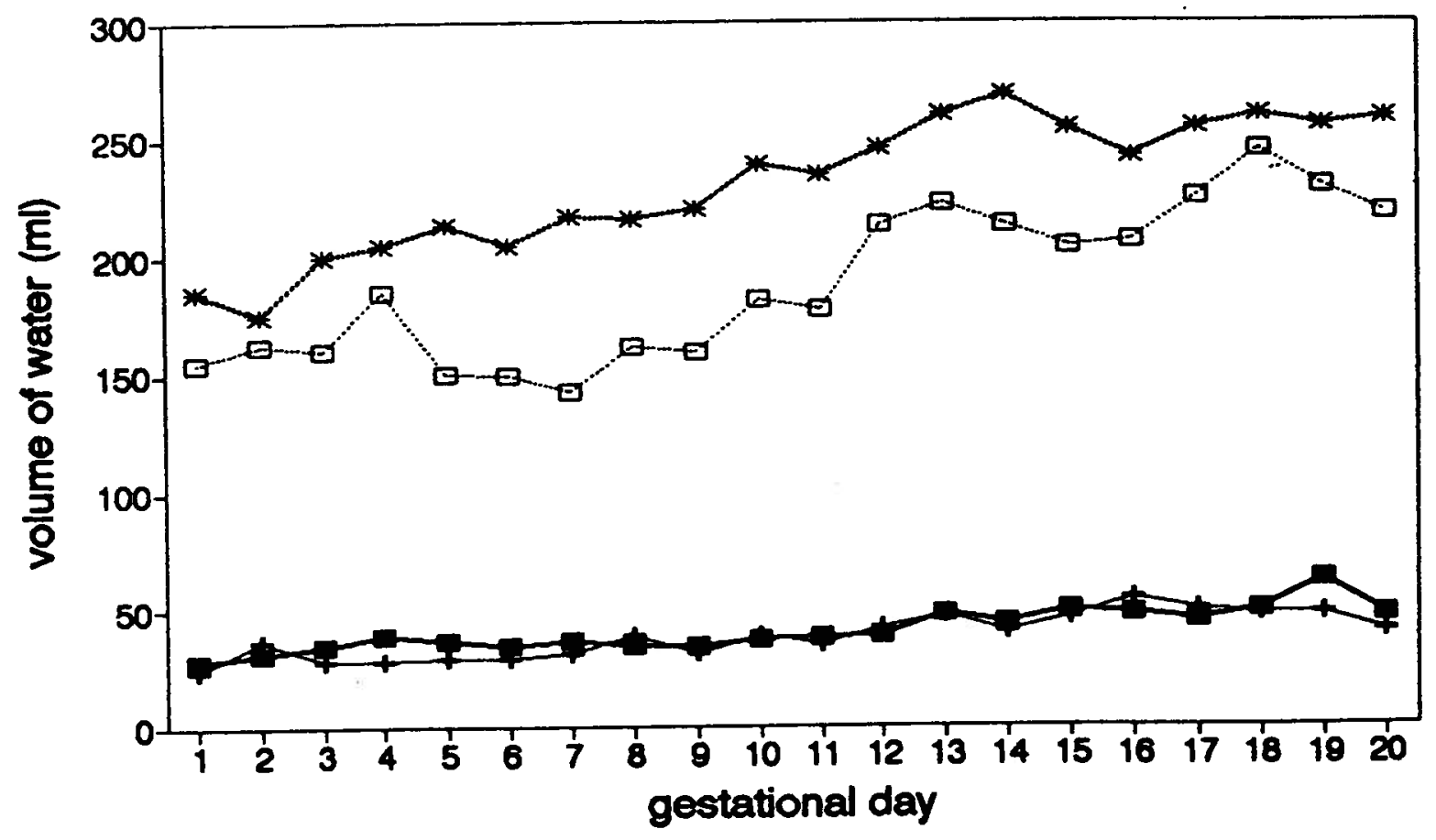

$\rightarrow-$ group $1+$ group $2 \rightarrow-$ group $3 \rightarrow$ group 4

Figure 3.3: Daily mean water intake during pregnancy 
Table 3.4: Breeding and pregnancy rates of animals in each treatment group

\begin{tabular}{lcccc}
\hline \hline Group & 1 & 2 & 3 & 4 \\
\hline No of rats initially & 9 & 10 & 18 & 13 \\
No of rats that bred & 9 & 10 & 16 & 13 \\
Breeding rate (\%) & \multicolumn{2}{c}{100} & & 93.5 \\
No of rats with live fetuses & 9 & $8^{a}$ & $11^{b}$ & $8^{c}$ \\
Pregnancy rate (\%) & 100 & 90 & 68.8 & 61.5 \\
No of rats excluded from study & 0 & 2 & 7 & 5 \\
\hline \hline
\end{tabular}

Group 1: Non-diabetic on water

Group 2: Non-diabetic on alcohol

Group 3: Diabetic on water

Group 4: Diabetic on alcohol

Breeding rate and pregnancy rate were not significantly different

among groups

Excluded rats:

${ }^{a}$ Group 2: 1 not pregnant and 1 had one resorption but no

live fetus on day 21

${ }^{b}$ Group 3: 2 not bred, 5 not pregnant on day 21

${ }^{c}$ Group 4: 5 not pregnant on day 21

interactions were observed, $\mathrm{p}<0.01)$.

\subsection{Reproductive performance}

There was no apparent difference between diabetic and nondiabetic rats in the proportion of animals with positive breeding (number of vaginal plugs). However, not all rats which had plugs subsequently produced litters. There was a trend that more diabetic rats with plugs failed to produce litters than was the case for nondiabetic animals, although the difference among groups was not statistically significant. Only rats containing live fetuses at autopsy were included in this study and subjected to subsequent examinations (table 3.4). 


\subsection{Body weight and weight gain of dams during pregnancy}

The average body weights of dams on days $1,6,12$, and 21 of gestation, as well as the average body weight gains from day 1 to day 5,6 to day 11 , and 12 to day 20 of gestation for each group are shown in table 3.5 and Figure 3.4. The mean body weights of the 4 experimental groups were not statistically different on day 1 of gestation. During gestation, diabetes, but not alcohol exposure, played the main role in the differences in body weight. Diabetic rats, whether consuming alcohol or water, had significantly lower body weights on days 6,12 , and 21 of gestation compared to nondiabetic rats $(\mathrm{p}<0.01)$. On day 21 , diabetic rats weighed about $90 \mathrm{~g}$ less than nondiabetic rats. No interaction between diabetes and alcohol exposure on body weight was observed on days 6,12 , or 21 of gestation.

From day 1 to day 5 of gestation, when alcohol was not administered, diabetic rats (groups $3 \& 4$ ) gained less weight than nondiabetic rats (groups $1 \& 2, \mathrm{p}<0.05$ ). From day 6 to day 11 of gestation, when rats in groups 2 and 4 consumed alcohol, diabetic rats gained significantly less weight than nondiabetic rats $(\mathrm{p}<0.001)$, but alcohol administration did not have a significant effect on body weight gain. It should be noted that there were huge variations of weight gains from day 6 to day 11 in groups 3 and 4 (table 3.5). In fact, 3 out of 11 rats in group 3 and 3 out of 8 rats in group 4 lost weight instead of gaining weight during this period of gestation. The reason for losing weight in these rats is not clear. It cannot be attributed to the administration of alcohol, because some of the group 3 rats (no alcohol administered) also lost weight during this period. Interestingly, from day 12 to day 20 of gestation, in addition to the diabetic effect on body weight gain $(\mathrm{p}<0.001)$, there was also a significant interaction between diabetes and alcohol (2-way ANOVA, $p<0.05)$. Alcohol alone did not have a significant effect on body weight gain.

Because the overall 2-way ANOVA showed a significant interaction between diabetes 
Table 3.5: Body weight and weight gain of dams during gestation in each treatment group (mean $\pm \mathrm{SD}$ )

\begin{tabular}{lcccc}
\hline \hline Group & 1 & 2 & 3 & 4 \\
\hline No of animals & 9 & 8 & 11 & 8 \\
Body wt on D1(g) & $253.6 \pm 11.8$ & $256.0 \pm 8.8$ & $246.6 \pm 12.4$ & $249.7 \pm 12.3$ \\
Body wt on D6(g)* & $275.1 \pm 9.3$ & $279.2 \pm 6.5$ & $264.1 \pm 16.9$ & $260.9 \pm 16.5$ \\
Body wt on D12(g)* & $305.7 \pm 13.3$ & $293.7 \pm 7.1$ & $271.5 \pm 26.0$ & $266.2 \pm 16.2$ \\
Body wt on D21(g)* & $382.3 \pm 28.5$ & $387.9 \pm 18.0$ & $309.2 \pm 38.2$ & $284.9 \pm 25.0$ \\
Wt gain D1-5(g)* & $21.5 \pm 5.9$ & $23.2 \pm 5.6$ & $17.5 \pm 12.1$ & $11.2 \pm 10.2$ \\
Wt gain D6-11(g)* & $30.6 \pm 7.8$ & $14.5 \pm 8.1$ & $5.1 \pm 19.4$ & $5.2 \pm 13.5$ \\
Wt gain D12-20(g)*† & $76.7 \pm 20.0^{a}$ & $94.2 \pm 17.1^{a}$ & $37.7 \pm 23.6^{b}$ & $18.7 \pm 19.5^{b}$ \\
\hline \hline
\end{tabular}

Group 1: Non-diabetic on water

Group 2: Non-diabetic on alcohol

Group 3: Diabetic on water

Group 4: Diabetic on alcohol

* Diabetic significantly different from non-diabetic, $\mathrm{p}<0.05$

$\dagger$ Significant interaction between diabetes and alcohol, $\mathrm{p}<0.05$

Values not sharing a common superscript in each row are significantly different at $\mathrm{p}<0.05$ 


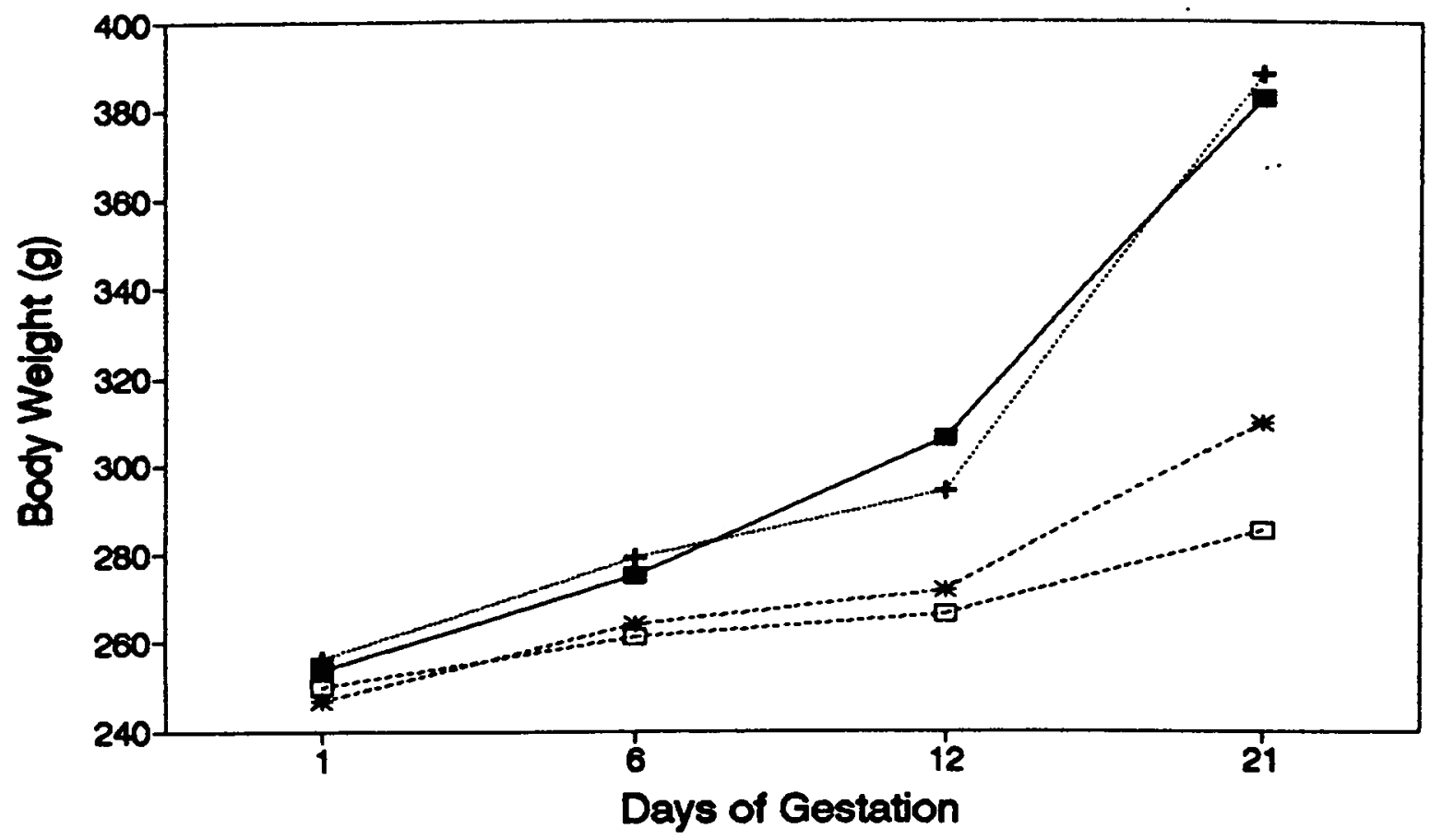

Figure 3.4: Maternal body weight changes during gestational period in 4 groups 
and alcohol on body weight gain from day 12 to day 20 of gestation, the Tests of Simple Effect were employed to identify the source of the difference. In rats not exposed to alcohol (groups 1 \& 3), diabetic rats gained less weight during this time than did nondiabetic rats $(\mathrm{p}<0.001)$. Similarly, in alcohol exposed rats (groups $2 \& 4$ ), diabetic rats gained less weight than did nondiabetic rats $(\mathrm{p}<0.001)$. On the other hand, nondiabetic rats, whether exposed to alcohol or not, had similar body weight gains. In diabetic rats, although there was a trend for alcohol exposed animals to gain less weight than animals not exposed to alcohol, the difference was not statistically significant.

This pattern of interaction between diabetes and alcohol on body weight gain from day 12 to 20 is shown in Figures 3.5 and 3.6. Figure 3.5 indicates that the difference in body weight gain from day 12 to 20 between diabetic and nondiabetic rats was greater in alcohol exposed group than in non-alcohol exposed group $(\mathrm{p}<0.05)$. Figure 3.6 shows a trend that the direction of alcohol effect on weight gain from day 12 to 20 in nondiabetic rats is opposite to that in diabetic rats. This means when rats are not diabetic, alcohol exposure tends to facilitate weight gain compared to controls and contrarily, whereas when rats are diabetic, alcohol exposure tends to result in less weight gain compared to diabetic rats not exposed to alcohol. However, the differences of weight gains from day 12 to 20 between alcohol and water exposed groups, either in nondiabetic rats or diabetic rats, were not significant.

\subsection{Blood glucose concentrations}

In groups 1 and 2 (non-diabetic), blood glucose concentrations on day 21 of gestation did not differ from those on day 1 , confirming the continued nondiabetic state throughout gestation. In groups 3 and 4 , blood glucose concentrations by one week after STZ administration were significantly higher than those before STZ administration, which were 


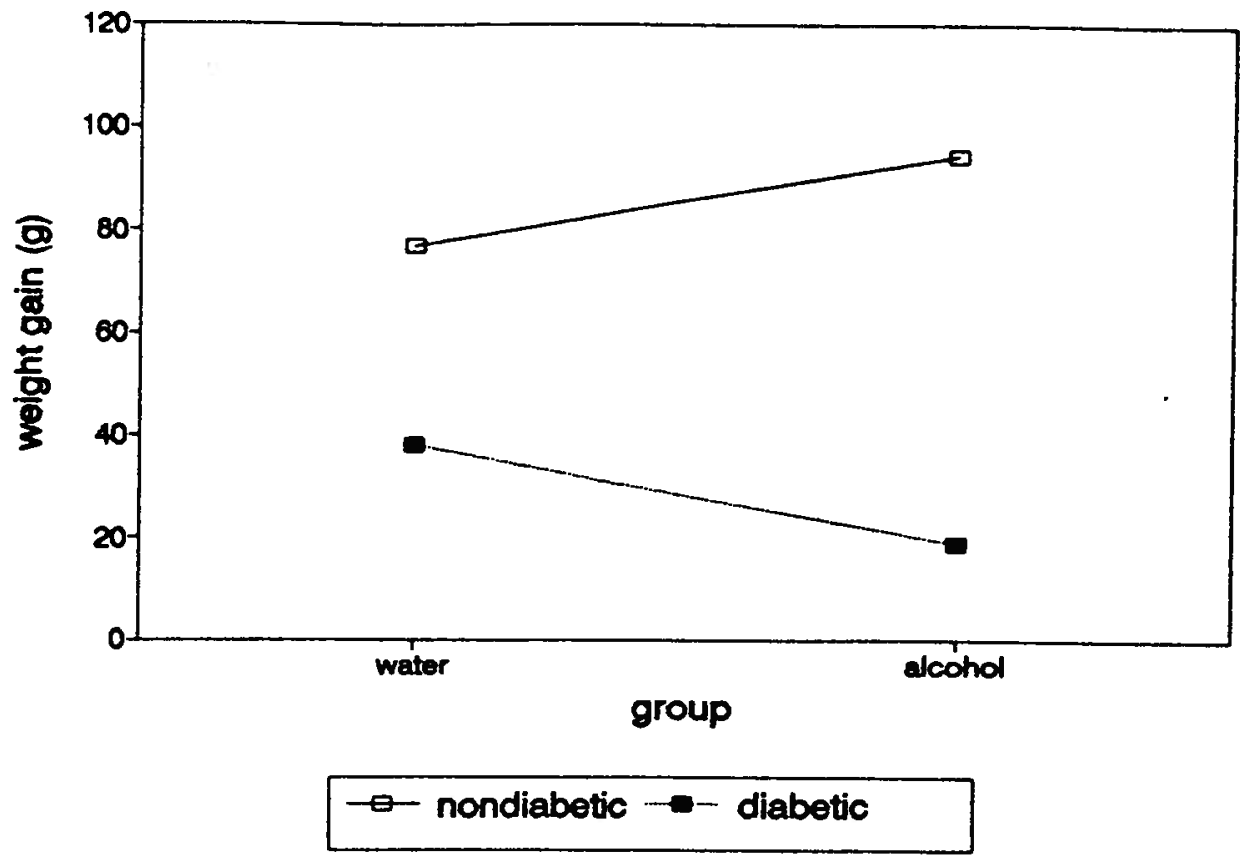

Figure 3.5: Interaction of diabetes at alcohol on maternal weight gain during D12-21

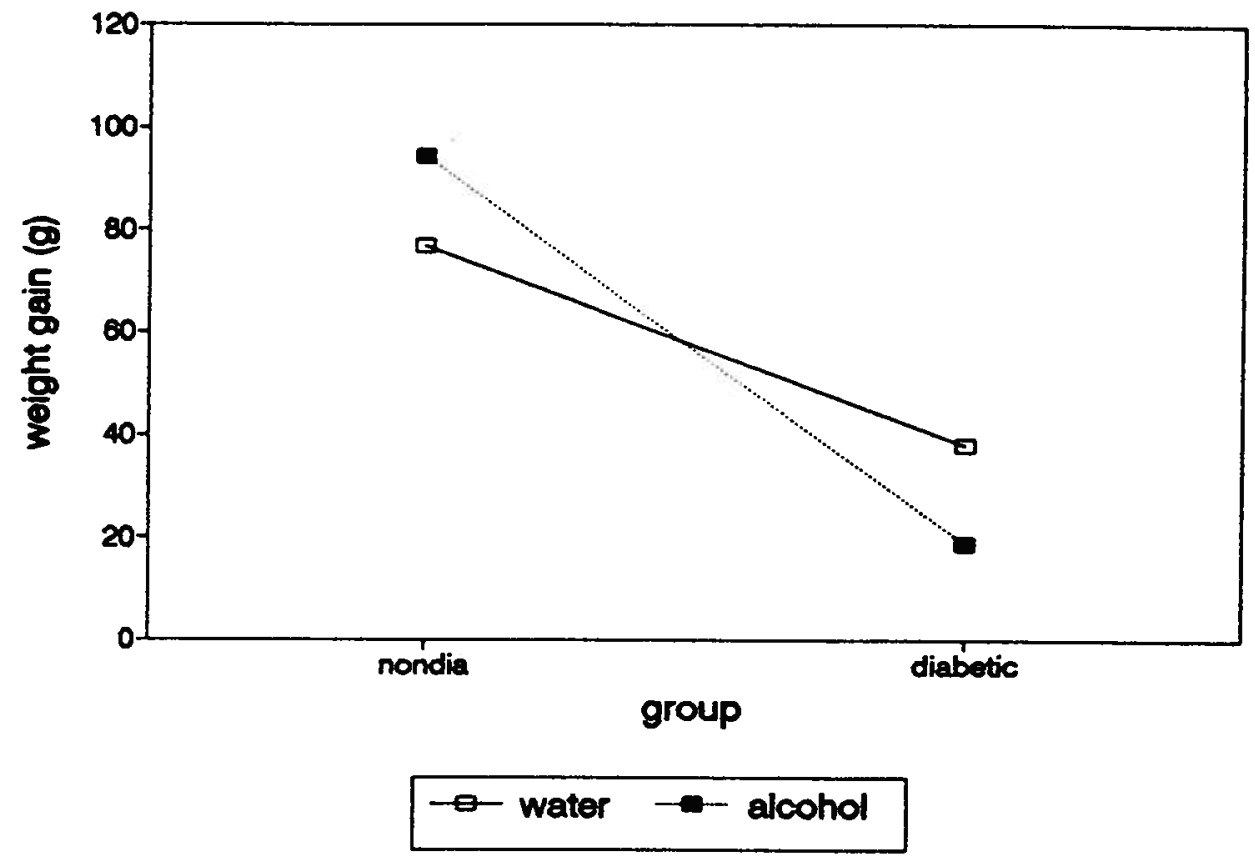

Figure 3.6: Interaction of alcohol at diabetes on maternal weight gain during D12-21 (Reference: Kimmel, H.D. Simple and factorial experiments. In: Experimental principles and design in psychology. New York. The Ronald Press Co. pp 153-177, 1985) 
Table 3.6: Blood glucose concentration of dams at different times during the experiment, in each treatment group $(\mathrm{mmol} / \mathrm{L})$

\begin{tabular}{|c|c|c|c|c|c|c|c|c|c|c|c|c|c|c|c|c|}
\hline \multirow{2}{*}{$\begin{array}{l}\text { Rat } \\
\text { No }\end{array}$} & \multicolumn{2}{|c|}{ Group 1} & \multicolumn{2}{|c|}{ Group 2} & \multicolumn{6}{|c|}{ Group 3} & \multicolumn{6}{|c|}{ group 4} \\
\hline & D1 & D21 & D1 & D21 & $\overline{\mathbf{B F}}$ & Af & D2 & D7 & D12 & D21 & $\overline{B f}$ & $\overline{A f}$ & D2 & D7 & D12 & D21 \\
\hline 1 & 3.9 & 4.8 & 4.7 & 2.9 & 3.6 & 18.4 & 16.9 & 23.6 & 23.3 & 21.1 & 4.6 & 21.3 & 26.6 & $>27$ & 16.0 & $>27$ \\
\hline 2 & 3.7 & 5.9 & 3.6 & 4.1 & 4.9 & 15.2 & 17.9 & 21.8 & 18.1 & 21.9 & 4.7 & $\mathbf{> 2 7}$ & $\mathbf{> 2 7}$ & 16.9 & $\mathbf{1 8 . 0}$ & $\overline{16.4}$ \\
\hline 3 & 3.8 & 3.8 & 4.8 & 7.6 & 2.8 & 18.3 & 22.5 & 16.7 & 19.3 & 26.6 & 4.3 & 22.0 & 18.4 & 22.3 & $\mathbf{1 7 . 5}$ & 18.8 \\
\hline 4 & 4.8 & 3.5 & 3.4 & 4.1 & 5.7 & $>27$ & 24.8 & 19.2 & 16.9 & $>27$ & 4.9 & 25.0 & $>27$ & 23.1 & 21.0 & 17.3 \\
\hline$\overline{5}$ & 2.8 & 2.4 & 2.9 & 3.9 & 4.3 & 21.9 & 19.9 & 22.3 & 24.3 & 15.0 & 5.1 & $>27$ & $>27$ & $>27$ & 18.7 & 24.0 \\
\hline 6 & 4.3 & 7.8 & 2.9 & $\overline{3.7}$ & 4.7 & 23.1 & 17.8 & 21.2 & 18.8 & 22.0 & 5.0 & 16.6 & 25.0 & $\overline{17.9}$ & 17.3 & 19.9 \\
\hline 7 & 6.8 & 4.0 & 3.7 & 3.7 & 2.9 & 19.0 & 26.4 & 18.5 & 15.7 & 22.5 & 4.3 & 25.2 & $\mathbf{1 8 . 6}$ & 24.3 & 20.1 & 25.5 \\
\hline 8 & 3.7 & 6.2 & 4.5 & 3.3 & 4.4 & $\overline{16.7}$ & 25.2 & 17.4 & 23.1 & 22.5 & 3.7 & $>27$ & $>27$ & 25.2 & 21.0 & 21.3 \\
\hline 9 & 6.8 & 4.4 & & & 5.5 & 15.8 & 26.1 & 17.7 & 18.0 & 22.0 & & & & & & \\
\hline 10 & & & & & 3.8 & 18.8 & 19.6 & 20.0 & 18.4 & $>27$ & & & & & & \\
\hline 11 & & & & & 7.2 & $\overline{23.4}$ & - & - & 22.0 & 21.7 & & & & & & \\
\hline
\end{tabular}

Group 1: Nondiabetic on water

Group 2: Nondiabetic on alcohol

Group 3: Diabetic on water

Group 4: Diabetic on alcohol

† Blood glucose level before STZ injection

$\ddagger$ Blood glucose level one week after STZ injection

not different from those of nondiabetic rats. After STZ administration, blood glucose concentrations of all rats in groups 3 and 4 were above $15 \mathrm{mmol} / \mathrm{L}$ and remained above this level throughout gestation, confirming the continued diabetic state (table 3.6).

\subsection{Peak blood alcohol levels}

On day 11 of gestation (the last day of alcohol administration to groups 2 and 4), the mean peak blood alcohol concentration was $73.3 \pm 13.6 \mathrm{mg} / \mathrm{dl}$.

\subsection{Outcome of pregnancy}

Table 3.7 shows the outcome of pregnancy by treatment group. The mean number of implantation sites per dam and mean number of live fetuses per litter did not differ between diabetic and nondiabetic rats or between alcohol exposed and non-alcohol exposed 
Table 3.7: Reproductive variables on day 21 of gestation in each treatment group

\begin{tabular}{|c|c|c|c|c|}
\hline Group & 1 & 2 & 3 & 4 \\
\hline No of rats examined & 9 & 8 & 11 & 8 \\
\hline Total No of implantation sites & 128 & 117 & 131 & 111 \\
\hline No of implantation sites/litter & $14.2 \pm 4.3 \star$ & $14.6 \pm 3.8$ & $11.9 \pm 4.3$ & $13.9 \pm 3.8$ \\
\hline Total No of live fetuses & 118 & 108 & 112 & 100 \\
\hline No of live fetuses/litter & $13.1 \pm 4.2$ & $13.5 \pm 3.8$ & $10.2 \pm 3.8$ & $12.5 \pm 3.5$ \\
\hline Total No of resorption sites & 9 & 7 & 16 & 11 \\
\hline \% resorptions & 7.0 & 6.0 & 12.2 & 9.9 \\
\hline Mean litter arcsine & $15.9 \pm 7.7$ & $14.8 \pm 7.6$ & $21.1 \pm 8.9$ & $17.9 \pm 9.5$ \\
\hline No of resorptions/litter & $1.0 \pm 1.1$ & $0.9 \pm 1.0$ & $1.5 \pm 1.7$ & $1.4 \pm 1.5$ \\
\hline No of litters with resorptions & 5 & 4 & 8 & 5 \\
\hline \% litters with resorptions & 55.6 & 50.0 & 72.7 & 62.5 \\
\hline \multicolumn{5}{|l|}{$\begin{array}{l}\text { Group 1: Non-diabetic on water } \\
\text { Group 2: Non-diabetic on alcohol } \\
\text { Group 3: Diabetic on water } \\
\text { Group 4: Diabetic on alcohol } \\
\star \text { mean } \pm \text { SD }\end{array}$} \\
\hline
\end{tabular}

rats. The number of resorptions expressed either as the mean number of resorptions per litter or as the percentage of resorptions in each group was not significantly different among the four treatment groups (both chi-square test and 2-way ANOVA). There were no differences among treatment groups with respect to number of litters with one or more resorptions.

\subsection{Fetal weight, placental weight and fetal weight/placental weight ratio}

The mean fetal weight, mean placental weight and the mean ratio of fetal weight/placental weight (f/p ratio) for each treatment group are shown in table 3.8. Photo 1 (see Appendix A) shows the relative sizes of two fetuses from a control dam (right) and a diabetic-alcohol dam (left) respectively. 
Table 3.8: Fetal and placental weights on day 21 of gestation in each treatment group $($ mean \pm SD)

\begin{tabular}{lcccc}
\hline \hline Group & 1 & 2 & 3 & 4 \\
\hline No of animals & 9 & 8 & 11 & 8 \\
Mean fetal weight/litter (g)*† & $3.38 \pm 0.63^{a}$ & $3.79 \pm 0.30^{a}$ & $2.56 \pm 0.49^{b}$ & $2.27 \pm 0.41^{b}$ \\
Mean placental weight/litter (g)* & $0.50 \pm 0.07$ & $0.45 \pm 0.04$ & $0.64 \pm 0.18$ & $0.54 \pm 0.10$ \\
Mean f/p ratio/litter $+\ddagger \ddagger$ & $6.83 \pm 1.52^{a}$ & $8.42 \pm 0.94^{b}$ & $4.14 \pm 0.89^{c}$ & $4.29 \pm 0.60^{c}$ \\
\hline \hline
\end{tabular}

Group 1: Non-diabetic on water

Group 2: Non-diabetic on alcohol

Group 3: Diabetic on water

Group 4: Diabetic on alcohol

f/p ratio: ratio of fetal weight/placental weight

* Diabetic significantly different from non-diabetic, $\mathrm{p}<0.05$

$\ddagger$ Alcohol significantly different from water, $\mathrm{p}<0.05$

† Significant interaction between diabetes and alcohol, $\mathrm{p}<0.05$

Values not sharing a common superscript in each row are significantly different at $p<0.05$

The mean fetal weight was significantly less $(\mathrm{p}<0.001)$ in litters of diabetic rats compared to nondiabetic animals, but a significant difference was not seen between alcohol and water exposed groups. However, there was a significant interaction between diabetes and alcohol on fetal weight (2-way ANOVA, $\mathrm{p}<0.05)$.

Because the overall two-way ANOVA indicated a significant interaction between diabetes and alcohol exposure on fetal weight, the Tests of Simple Effect were carried out. In the non-alcohol exposed group, fetuses of diabetic dams weighed significantly less than did fetuses of nondiabetic dams $(\mathrm{p}<0.001)$. Similarly, in alcohol exposed groups, diabetes had a very strong effect on fetal weight $(\mathrm{p}<0.001)$. As a result, fetuses of diabetic dams were lighter than fetuses of nondiabetic dams. However, in both diabetic and nondiabetic groups, the differences in fetal weight with or without alcohol treatment were not significant. 
The pattern of interaction between diabetes and alcohol on fetal weight is demonstrated in Figures 3.7 and 3.8. Figure 3.7 indicates that the difference in fetal weight between diabetic and nondiabetic rats was greater in alcohol exposed rats than in rats not exposed to alcohol $(\mathrm{p}<0.05)$. Figure 3.8 shows the directions of alcohol's effect on fetal weight in diabetic and nondiabetic rats. However, the difference of fetal weight between alcohol and water exposed rats was not significant either in diabetic or nondiabetic rats as demonstrated in Tests of Simple Effect.

Placental weights were significantly different $(p<0.01)$ when diabetic and nondiabetic rats were compared, with diabetic rats tending to have bigger placentas than nondiabetic rats. However, a significant difference in placental weight between alcohol and water exposed groups was not found.

In terms of the ratio of fetal weight/placental weight (f/p ratio), 2-way ANOVA showed that both diabetes and alcohol had very strong effects $(p<0.001$ and $p<0.05$ respectively) on the $f / p$ ratio and there was also an interaction between diabetes and alcohol $(\mathrm{p}<0.05)$.

The subsequent Tests of Simple Effect gave the following results for comparisons between different pairs of groups. In non-alcohol exposed rats, the $\mathrm{f} / \mathrm{p}$ ratio of diabetic rats was significantly lower than was that of nondiabetic rats $(p<0.001)$. Similarly, in alcohol exposed rats, diabetic rats had lower $f / p$ ratio compared to nondiabetic rats $(p<0.001)$. In nondiabetic rats, alcohol had a significant effect on $f / p$ ratio $(p<0.01)$, but the direction is interesting. Alcohol exposed rats had a higher $f / p$ ratio than did non-alcohol exposed rats. In contrast, alcohol had no effect on $f / p$ ratio in diabetic rats. As a result, all diabetic rats had a similar $f / p$ ratio.

The pattern of interaction between diabetes and alcohol on $f / p$ ratio is shown in Figures 3.9 and 3.10. Figure 3.9 shows again that the difference in $f / p$ ratio between diabetic and nondiabetic rats was greater in alcohol exposed rats than in non-alcohol exposed rats 


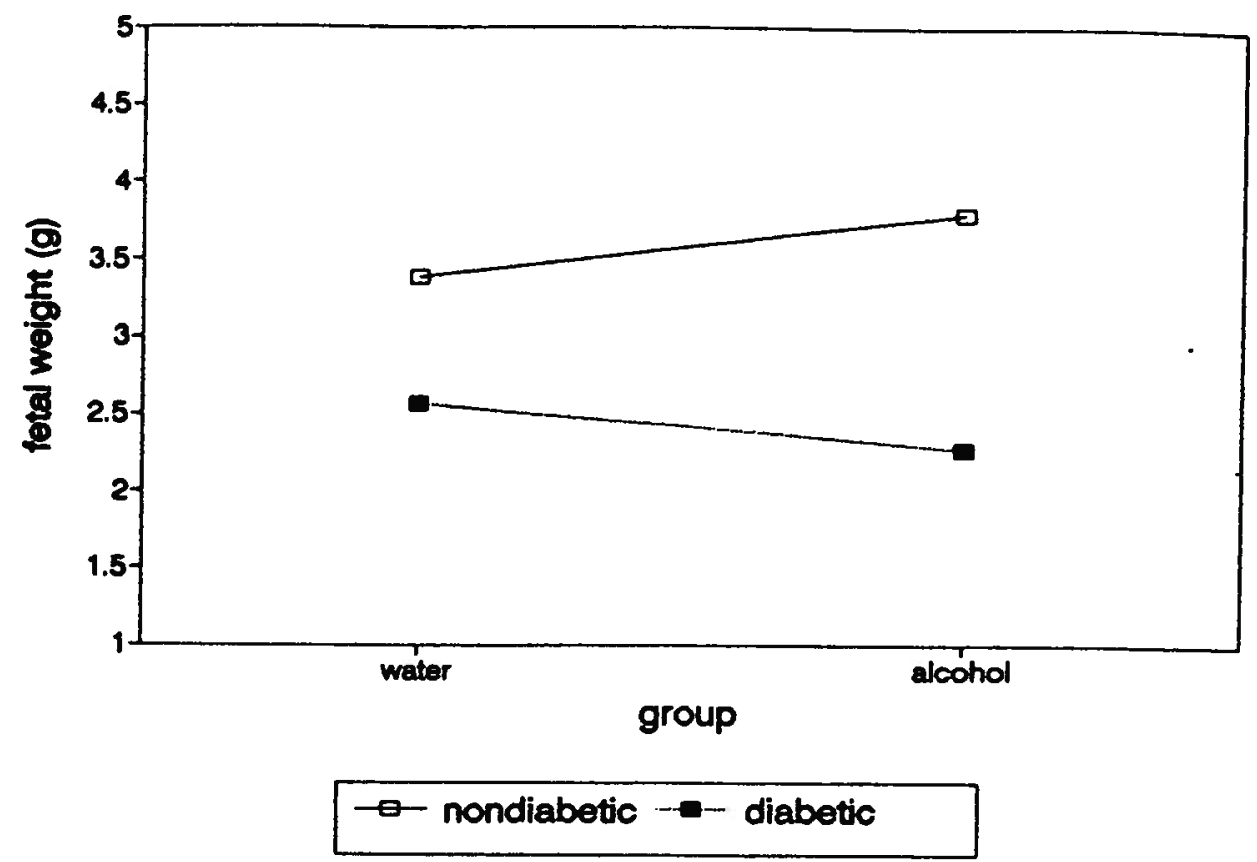

Figure 3.7: Interaction of diabetes at alcohol on fetal weight

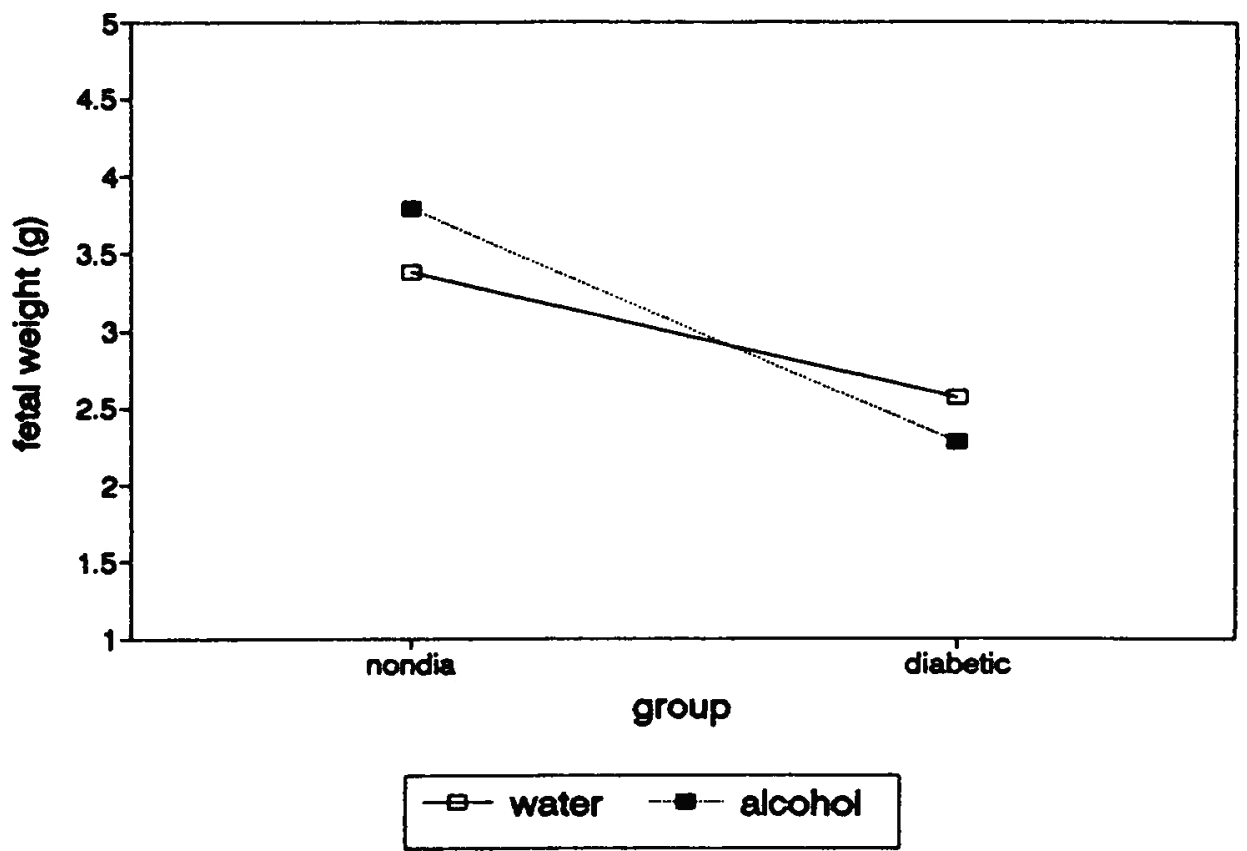

Figure 3.8: Interaction of alcohol at diabetes on fetal weight 
$(\mathrm{p}<0.05)$. Figure 3.10 demonstrates that in nondiabetic rats, alcohol exposure raised the $f / p$ ratio, however, in diabetic rats, alcohol exposure did not show any effect on $f / p$ ratio.

\subsection{External malformations}

A wide variety of external malformations were found in diabetic rats, but none were found in nondiabetic rats regardless of whether the animals were exposed to alcohol or water (table 3.9). The malformations observed include: a variety of facial defects, characterized by smaller lower jaw, no lower jaw, no mouth, tongue protruding, otocephaly (see Appendix A, photo 2), and distorted face; missing tail (see Appendix A, photo 3); umbilical hernia or gastroschisis (see Appendix A, photo 4); severe edema; and ectrodactyly. Some affected fetuses had more than one malformation, such as severe edema together with absence of the lower jaw.

Although both groups of diabetic animals (those on water and those given alcohol) had malformed fetuses, those on alcohol had a greater percentage of fetuses with all types of external malformations compared to those on water (chi-square test, $\mathrm{p}<0.05$ ), with 5 malformed fetuses out of $112(4.5 \%)$ occurring in group 3, and 12 out of $100(12 \%)$ in group 4.

In terms of the number of litters with malformed fetuses, the difference between groups 3 and 4 was not significant, although there was a trend for diabetic animals on alcohol to have more affected litters (27.3\% in group 3 vs $75 \%$ in group 4$)$. The means of the litter frequencies of external malformations (transformed to Freeman-Tukey arcsines) were not different between groups 3 and 4 (t-test, $\mathrm{p}>0.05$ ). 


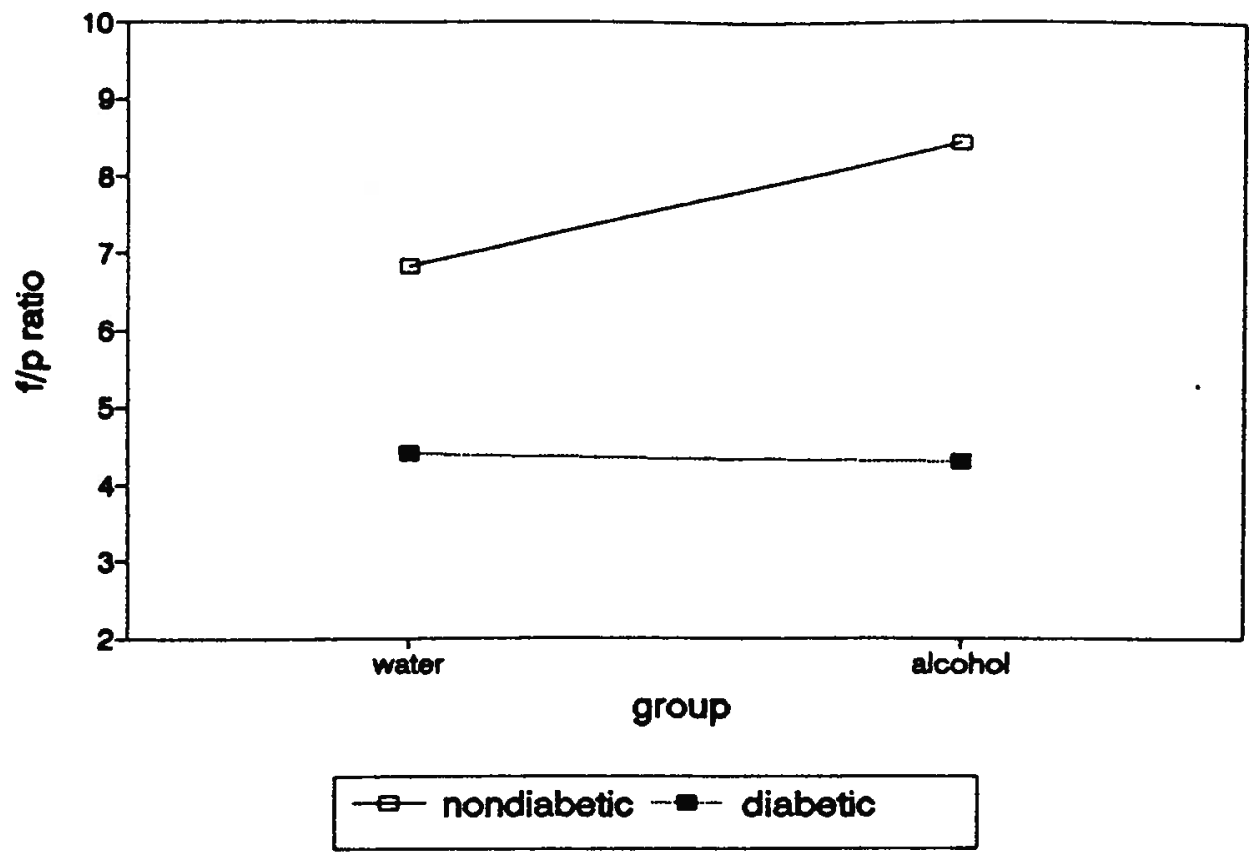

Figure 3.9: Interaction of diabetes at alcohol on $\mathrm{f} / \mathrm{p}$ ratio

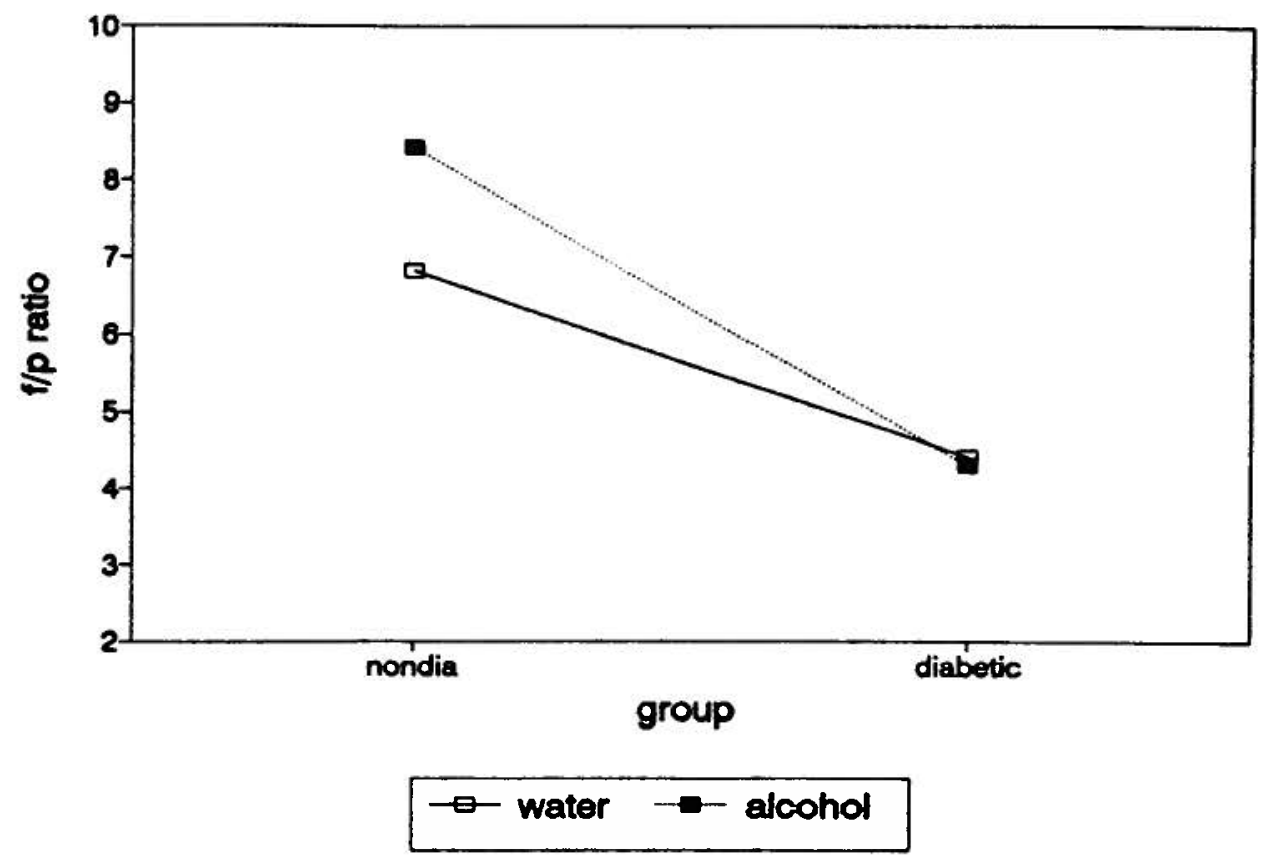

Figure 3.10: Interaction of alcohol at diabetes on $\mathrm{f} / \mathrm{p}$ ratio 
Table 3.9: Numbers of fetuses with external malformations in each treatment group

\begin{tabular}{lcccc}
\hline \hline Group & 1 & 2 & 3 & 4 \\
\hline No of litters examined & 9 & 8 & 11 & 8 \\
No of fetuses examined & 118 & 108 & 112 & 100 \\
No of fetuses with & & & & \\
$\quad$ facial defects & 0 & 0 & 3 & 8 \\
$\quad$ absent tail & 0 & 0 & 1 & 1 \\
umbilical hernia/gastroschisis & 0 & 0 & 0 & 2 \\
$\quad$ edema & 0 & 0 & 1 & 2 \\
$\quad$ ectrodactyly & 0 & 0 & 1 & 1 \\
No of fetuses with external malformations & 0 & 0 & 5 & 12 \\
Malformed fetuses as \% of live fetuses & 0 & 0 & $4.5^{a}$ & $12^{b}$ \\
Mean litter arcsine of malformed fetuses & - & - & $13.28 \pm 9.27 *$ & $17.27 \pm 8.79$ \\
No of litters with malformed fetuses & $0 / 9$ & $0 / 8$ & $3 / 11$ & $6 / 8$ \\
\% of litters with malformed fetuses & 0 & 0 & 27.3 & 75 \\
\hline \hline
\end{tabular}

Group 1: Non-diabetic on water

Group 2: Non-diabetic on alcohol

Group 3: Diabetic on water

Group 4: Diabetic on alcohol

A single fetus may have more than one malformations

Values not sharing a common superscript in each row are significantly different at $\mathrm{p}<0.05$

$*$ mean $\pm \mathrm{SD}$ 
Table 3.10: Numbers of fetuses with skeletal malformations in each treatment group

\begin{tabular}{lcccc}
\hline \hline Group & 1 & 2 & 3 & 4 \\
\hline No of litters examined & 9 & 8 & 11 & 8 \\
No of fetuses examined* & 103 & 84 & 101 & 79 \\
No of fetuses with & & & & \\
$\quad$ malformed sternum & 0 & 0 & 7 & 2 \\
$\quad$ malformed ribs & 0 & 0 & 1 & 2 \\
malformed vertebrae & 0 & 0 & 3 & 3 \\
malformed skull & 0 & 0 & 0 & 1 \\
$\quad$ malformed limb & 0 & 0 & 0 & 1 \\
No of fetuses with skeletal malformations & 0 & 0 & 11 & 9 \\
\% of malformed fetuses & 0 & 0 & 10.9 & 11.4 \\
No of litters with malformed fetuses & $0 / 9$ & $0 / 8$ & $5 / 11$ & $4 / 8$ \\
\% of litters with malformed fetuses & 0 & 0 & 45.5 & 50 \\
\hline \hline
\end{tabular}

Group 1: Non-diabetic on water

Group 2: Non-diabetic on alcohol

Group 3: Diabetic on water

Group 4: Diabetic on alcohol

* Fetuses with external malformations and fetuses which were dried out during fixation in alcohol were excluded from skeletal examination

\subsection{Skeletal malformations}

Fetuses with external malformations were excluded from skeletal examination. All fetuses without gross malformations were stained with alizarin red S and alcian blue 8GS and skeletal morphology was examined.

Skeletal malformations were not seen in fetuses of nondiabetic dams, whether on water or alcohol. However, a variety of skeletal malformations were found in diabetic animals on water and in diabetic animals on alcohol (table 3.10).

Malformed sternum was found relatively frequently among fetuses with skeletal malformations. In the 9 fetuses with malformed sternums this was expressed as cleft sternum (see Appendix A, photo 5). 
Three fetuses showed malformed ribs. One fetus, from a diabetic dam on alcohol, had the 1st left rib bifurcated and fused with the 7th vertebrae. Another fetus, from the same group, had fusion of the 7th and 8th ribs. The third fetus, from a diabetic animal on water, had an extra right rib fused distally with the 1st rib.

In the 6 fetuses with vertebral malformations, the defects occurred at different levels, i.e. cervical, thoracic or lumbar vertebrae. Two fetuses from the diabetic-alcohol group had abnormal cervical vertebrae. In one, there were 5 cervical arches on the left with the 4th arch in a vertical position, and 6 arches on the right; while in the other fetus, two extra pieces of cartilage were seen on top of the 5th and 6th cervical arches and crossed each other. The other fetus, from the diabetic-water group had the 5th left cervical arch bifurcated (see Appendix A, photo 5). In 2 fetuses with lumbar vertebral malformations, one, from diabetic-alcohol group, had an extra lumbar vertebrae, while the other, from the diabetic-water group, had more severe malformation. In this case the 1 st and 2nd lumbar vertebral right arches fused, and the 1st and 2nd lumbar vertebral bodies were ossified unilaterally and the 3rd and 4th vertebral bodies ossified unilaterally and fused together. Only one fetus, which was from the diabetic-water group, had thoracic vertebral malformation. This fetus had hemivertebrae, the 1st thoracic right and the 2nd thoracic vertebrae asymmetrically displaced and the 1 st right rib missing.

In addition, one fetus from the diabetic-alcohol group had a malformed arm joint, while another from the same group had a missing zygomatic process and zygoma bone in the skull (see Appendix A, photo 6). 


\subsection{Skeletal ossification and variants}

Four entire fetal skeletons, one from each treatment group, are shown in photo 7 (see Appendix A). A total of 367 fetuses were examined for skeletal ossification. The ossification centers in five districts including metacarpus, metatarsus, sternum, vertebrae and skull were counted in each fetus and the irregular shapes of the ossification centers were also recorded.

\subsubsection{Metacarpus, metatarsus}

No ossification centers were observed in the anterior and posterior phalanges of fetuses in any group.

Table 3.11 shows the frequency of ossification centers in the fetuses of each group, according to the number of ossification centers, as well as the average number of ossification centers. For the metacarpus (both left and right sides), all fetuses in groups 1 and 2 had either 3 or 4 ossification centers, while most fetuses in groups 3 and 4 had a maximum of 3 ossification centers. Some fetuses in groups 3 and 4 had no metacarpal ossification centers, while others had only 1 or 2 . Only a few showed 4 ossification centers. As a result, the average number of ossification centers in the metacarpus (both sides) were significantly less in the diabetic groups than in the nondiabetic groups $(p<0.001)$. However, there was no significant difference in the average number of ossification centers in metacarpus when fetuses of alcohol exposed rats are compared to those of water exposed animals.

For the metatarsus, almost all fetuses in groups 1 and 2 had 4 ossification centers on both sides. In groups 3 and 4, although large percentage of fetuses had 4 centers, quite a few had 3 centers and some did not show any ossification centers. The average number of ossification centers in the metatarsus was significantly less in groups 3 and 4 compared 
Table 3.11: Development of ossification centers in metacarpus, metatarsus, and sternum in each treatment group

\begin{tabular}{|c|c|c|c|c|c|}
\hline $\begin{array}{l}\text { Skeletal } \\
\text { district }\end{array}$ & $\begin{array}{l}\text { No. of ossification } \\
\text { centra }\end{array}$ & Group 1 & Group 2 & Group 3 & Group 4 \\
\hline \multirow[t]{6}{*}{ Metacarpus(L) } & 0 & & & 6 & 1 \\
\hline & 1 & & & 0 & 3 \\
\hline & 2 & & & 5 & 6 \\
\hline & 3 & 65 & 28 & 78 & 69 \\
\hline & 4 & 38 & 56 & 12 & \\
\hline & Ave.* & $3.43 \pm 0.43 \dagger$ & $3.68 \pm 0.39$ & $2.91 \pm 0.58$ & $2.80 \pm 0.39$ \\
\hline \multirow[t]{6}{*}{ Metacarpus(R) } & 0 & & & 5 & 0 \\
\hline & 1 & & & $\mathbf{0}$ & 3 \\
\hline & 2 & & & 6 & 7 \\
\hline & 3 & 64 & 26 & 79 & 69 \\
\hline & 4 & 39 & 58 & 11 & \\
\hline & Ave.* & $3.46 \pm 0.46$ & $3.74 \pm 0.35$ & $2.94 \pm 0.57$ & $2.83 \pm 0.35$ \\
\hline \multirow[t]{7}{*}{ Metatarsus(L) } & 0 & & & 7 & 8 \\
\hline & 1 & & & $\mathbf{0}$ & $\mathbf{0}$ \\
\hline & 2 & & & 0 & 1 \\
\hline & 3 & 1 & & 28 & 30 \\
\hline & 4 & 97 & 84 & 66 & 40 \\
\hline & 5 & 5 & & & \\
\hline & Ave.* & $4.04 \pm 0.14$ & $4.00 \pm 0.00$ & $3.49 \pm 0.83$ & $3.16 \pm 1.03$ \\
\hline \multirow[t]{7}{*}{ Metatarsus(R) } & 0 & & & 7 & 6 \\
\hline & 1 & & & 0 & $\mathbf{0}$ \\
\hline & 2 & & & $\mathbf{0}$ & 3 \\
\hline & 3 & 1 & & 25 & 31 \\
\hline & 4 & 97 & 84 & 69 & 49 \\
\hline & 5 & 5 & & & \\
\hline & Ave.* & $4.04 \pm 0.14$ & $4.00 \pm 0.00$ & $3.53 \pm 0.79$ & $3.20 \pm 0.96$ \\
\hline \multirow[t]{8}{*}{ Sternum } & 0 & & & 9 & 9 \\
\hline & 1 & & & 3 & 2 \\
\hline & 2 & & & 7 & 2 \\
\hline & 3 & 2 & & 12 & 15 \\
\hline & 4 & 39 & 7 & 14 & 26 \\
\hline & 5 & 18 & 17 & 31 & 14 \\
\hline & 6 & 44 & 60 & 20 & 9 \\
\hline & Ave.* & $5.12 \pm 0.76$ & $5.67 \pm 0.40$ & $3.92 \pm 1.85$ & $3.64 \pm 1.69$ \\
\hline $\begin{array}{l}\text { Total fetuses } \\
\text { examined }\end{array}$ & & 103 & 84 & 101 & 79 \\
\hline
\end{tabular}

Group 1: Non-diabetic on water Group 2: Non-diabetic on alcohol Group 3: Diabetic on water Group 4: Diabetic on alcohol $\dagger$ mean $\pm \mathrm{SD}$

* Diabetic significantly different from non-diabetic, $p<0.05$ 
with groups 1 and $2(p<0.01)$. Alcohol exposure alone did not have a significant effect on the average number of metatarsal ossification centers.

\subsubsection{Sternum}

Photo 8 (see Appendix A) shows the normal sternebral ossification centers in a fetus from a control litter. In groups 1 and 2, almost all fetuses had 4 to 6 ossification centers. However, in groups 3 and 4 , fetuses had numbers of ossification centers varying from none to 6 . There were a large number of fetuses with less than 4 ossification centers in the sternum (table 3.11).

The average number of ossification centers in the sternum was smaller in fetuses from diabetic rats than in fetuses from nondiabetic rats $(p<0.05)$, irrespective of whether alcohol treated or not. However, the ossified sternebral centers were not all of a normal shape. The irregular shapes of sternebral ossification centers that were observed are shown in Figure 3.11 . These include dumbbell-shaped, asymmetrically dumbbell-shaped, asymmetrical and asymmetrically dumbbell-shaped, simple asymmetrical, cleaved (bipartite), asymmetrically cleaved, unilaterally ossified. The lack of apposition refers to those asymmetrical ossification centers in cases 4,5 and 9 in Figure 3.11 . The irregular shapes are considered skeletal variants rather than malformations (table 3.12).

The overall chi-square test showed that the difference in the frequency of dumbbellshaped, cleaved, and unilaterally ossified centers (these shapes are referred as "poorly ossified centers" in the table) among groups was significant $(\mathrm{p}<0.001)$. The subsequent paired comparisons indicated that groups 1 and 2 did not differ from each other with respect to the percentage of fetuses with poorly ossified sternebral centers $(24.3 \%$ in group 1 and $20.2 \%$ in group 2). Groups 3 and 4 were significantly different from groups 1 and $2(\mathrm{p}<0.001)$, with a larger proportion of fetuses with poorly ossified centers in groups 3 and 4 ( $74.2 \%$ in group 3 and $82.3 \%$ in group 4), compared to groups 1 and 2. 


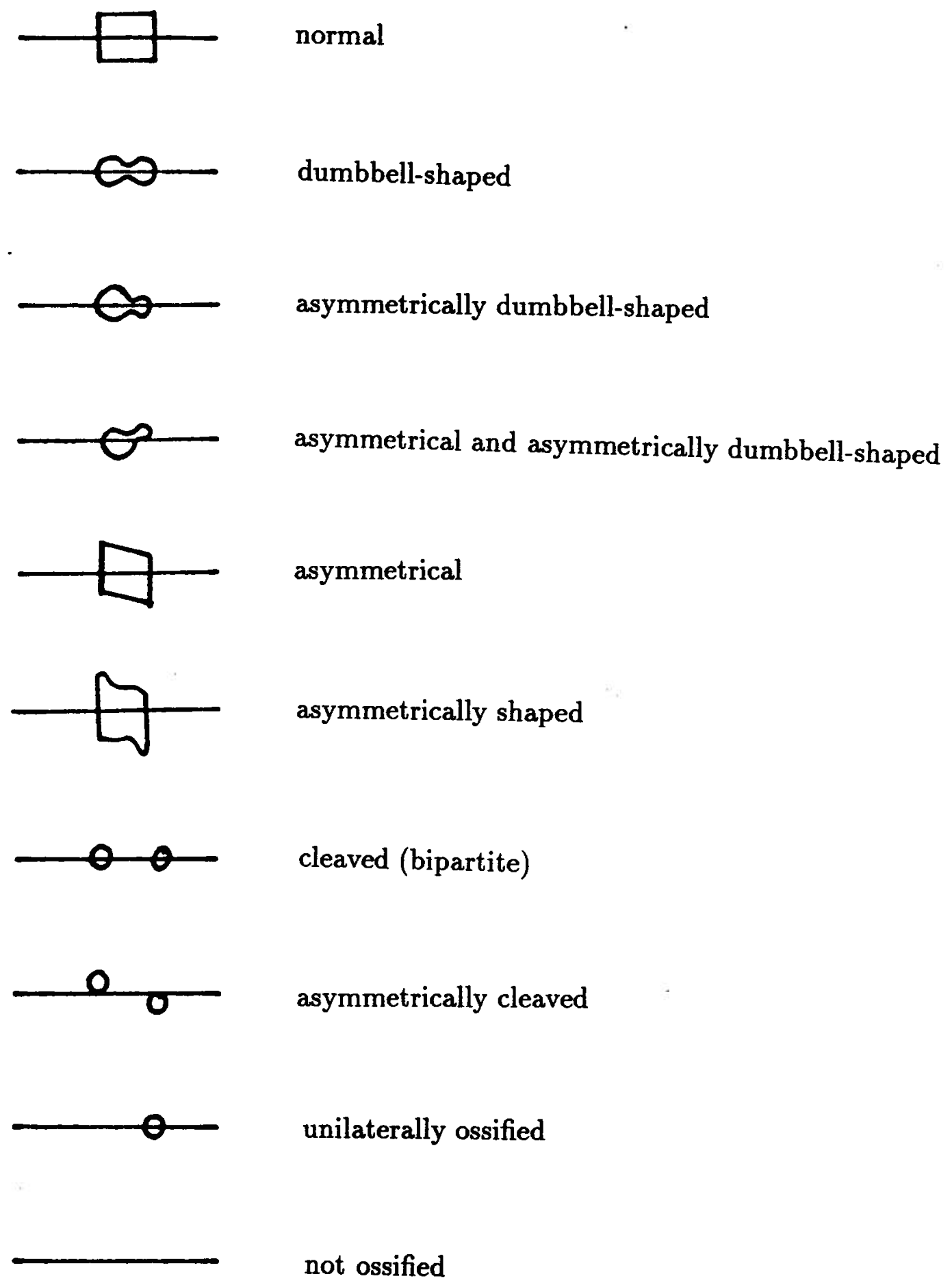

Figure 3.11: Observed irregular shapes of sternebral ossification centers 
Table 3.12: Skeletal variants observed in fetuses of each treatment group

\begin{tabular}{lcccc}
\hline \hline Group & 1 & 2 & 3 & 4 \\
\hline & 103 & 84 & 101 & 79 \\
No of fetuses examined & $0^{a}$ & $1^{a}$ & $34^{b}$ & $21^{b}$ \\
An extra rib* & $(0)$ & $(1.2)$ & $(33.7)$ & $(26.6) \dagger$ \\
& $0^{a}$ & $6^{b}$ & $0^{a}$ & $0^{a}$ \\
The 13th rib short $\ddagger$ & $(0)$ & $(7.1)$ & $(0)$ & $(0)$ \\
& $4^{a}$ & $2^{a}$ & $71^{b}$ & $68^{c}$ \\
Incomplete ossification of & $(3.9)$ & $(2.4)$ & $(70.3)$ & $(86.1)$ \\
supraoccipital bone & $5^{a}$ & $5^{a}$ & $14^{a}$ & $3^{a}$ \\
Lack of foramen & $(4.9)$ & $(6.0)$ & $(13.9)$ & $(3.8)$ \\
& $25^{a}$ & $17^{a}$ & $75^{b}$ & $65^{b}$ \\
Poorly ossified & $(24.3)$ & $(20.2)$ & $(74.2)$ & $(82.3)$ \\
sternebral centers & $13^{a}$ & $12^{a}$ & $33^{b}$ & $34^{b}$ \\
Lack of apposition & $(12.6)$ & $(14.3)$ & $(32.7)$ & $(43.0)$ \\
in sternebral centers & $7^{a}$ & $4^{a}$ & $60^{b}$ & $63^{c}$ \\
Poorly ossified & $(6.8)$ & $(4.8)$ & $(59.4)$ & $(79.7)$ \\
thoracic centers & $1^{a}$ & $0^{a}$ & $19^{b}$ & $19^{b}$ \\
Poorly ossified & $(0.97)$ & $(0)$ & $(18.8)$ & $(24.0)$ \\
lumbar centers & 0 & 0 & $44^{a}$ & $49^{b}$ \\
Poorly ossified & - & - & $(43.6)$ & $(62.0)$ \\
cervical arches & & & & \\
\hline \hline
\end{tabular}

Group 1: Non-diabetic on water

Group 2: Non-diabetic on alcohol

Group 3: Diabetic on water

Group 4: Diabetic on alcohol

Poorly ossified centers include those dumbbell-shaped, bipartite, and unilateral ossified centers

* Including cervical and lumbar extra ribs, and full or rudimentary size

$\ddagger$ Including short or rudimentary sizes

$\dagger$ Percentage

Values not sharing a common superscript in each row are significantly different 
Table 3.13: Mean numbers of poorly ossified centers in sternum, thoracic and lumbar vertebrae in each group (mean $\pm \mathrm{SD}$ )

\begin{tabular}{lcccc}
\hline \hline Group & 1 & 2 & 3 & 4 \\
\hline Sternum* & $1.28 \pm 0.54$ & $1.06 \pm 0.24$ & $2.01 \pm 1.07$ & $2.17 \pm 0.93$ \\
Thoracic* & $1.43 \pm 1.13$ & $1.00 \pm 0$ & $3.52 \pm 2.03$ & $3.81 \pm 2.19$ \\
Lumbar* & 0 & 0 & $1.42 \pm 0.77$ & $2.00 \pm 1.33$ \\
\hline \hline Group 1: Non-diabetic on water & & \\
Group 2: Non-diabetic on alcohol \\
Group 3: Diabetic on water \\
Group 4: Diabetic on alcohol \\
Means calculated among those fetuses with one or more poorly \\
ossified centers \\
* Diabetic significantly different from non-diabetic, p<0.05
\end{tabular}

The difference between groups 3 and 4 was not significant.

It is noteworthy that many fetuses had more than one poorly ossified center. The average numbers of poorly ossified centers per fetus in groups $1,2,3$, and 4 were 1.28 , $1.06,2.01$, and 2.17 respectively (table 3.13 ). The calculation of the average number of poorly ossified centers per fetus of each group did not include those fetuses with no poorly ossified centers. A significant difference in the average numbers of poorly ossified sternebral centers per fetus was only found between diabetic and nondiabetic groups $(p<0.001)$, but not between alcohol and water treated groups. Not only were there more fetuses with poorly ossified sternebral centers, but there were also more poorly ossified centers per fetus in diabetic than in nondiabetic litters.

The number of fetuses showing sternebral ossification centers with a lack of apposition was significantly different among all groups $(\mathrm{p}<0.001)$. Similarly, significant differences were found between groups 1 and $3(p=0.001)$, groups 1 and $4(p<0.001)$ and groups 2 and 4 ( $\mathrm{p}<0.001$ ), but not between groups 1 and 2 or groups 3 and 4 . The percentages of fetuses showing ossification centers with a lack of apposition were $12.6 \%, 14.3 \%, 32.7 \%$ 
and $43.0 \%$ in group 1 , group 2 , group 3 , and group 4 respectively (table 3.12).

\subsubsection{Vertebrae}

In rats, during development in utero, the ossification centers of the first cervical to the 2nd thoracic vertebral arches appear early, then ossification proceeds caudally. For the vertebral bodies, the earlier ossification centers are the fourth thoracic to sixth lumbar, then ossification extends both cephalically and caudally (Strong, 1926). Photo 9 (see Appendix A) shows the normal vertebral ossification centers and cervical arches in a fetus from a control litter.

The frequencies of fetuses by position of the most caudal vertebral arches in all 4 groups are shown in table 3.14. The results for left and right sides were similar. The overall difference among groups was significant $(\mathrm{p}<0.001)$.

The subsequent paired comparisons indicated that vertebral arches proceeded further caudally in fetuses of group 2 than in those of group $1(\mathrm{p}<0.001)$. In the control group, about $30 \%$ of fetuses had the vertebral arches ending at $\mathrm{Ca} 2$, about $40 \%$ of fetuses at $\mathrm{Ca} 1$, and the rest at a higher position. In contrast, over $50 \%$ of fetuses in group 2 had the vertebral arches ending at $\mathrm{Ca} 2$, with the rest at $\mathrm{Ca} 1$.

On the other hand, in groups 3 and 4 , vertebral arches proceeded less caudally than in group $1(\mathrm{P}<0.001)$. About $50 \%$ of fetuses in group 3 and $60 \%$ in group 4 had the vertebral arches ending at the level from S4 to S1, while only $30 \%$ of fetuses in group 1 had the vertebral arches ending at the level from S4 to S2, with more than $80 \%$ at $\mathrm{S} 4$. Again, the difference between groups 3 and 4 was not significant.

In both groups 3 and 4, poorly ossified cervical arches were found frequently, but this was not the case in groups 1 and 2. These poorly ossified cervical arches showed either as cleaved ossification centers or unilaterally ossified centers (see Figure 3.12). When this happened, it occurred more frequently in the 3rd to 7th cervical arches. Although this 
Table 3.14: Frequencies of fetuses according to the most cephalic and most caudal vertebral ossification centers and the most caudal vertebral arches

\begin{tabular}{lcccc}
\hline \hline Group & 1 & 2 & 3 & 4 \\
\hline & & & & \\
The most cephalic vertebral centrum & & & & \\
Higher than C7 & - & 12 & - & - \\
C7 & 23 & 41 & - & - \\
T1 & 73 & 31 & 35 & 22 \\
T2 & 7 & - & 38 & 33 \\
T3 & - & - & 13 & 15 \\
T4 & - & - & 8 & 6 \\
Lower than T4 & - & - & 6 & 3 \\
The most caudal vertebral centrum & & & & \\
Ca6 & 4 & 5 & - & - \\
Ca5 & 11 & 24 & 1 & - \\
Ca4 & 28 & 40 & 26 & 8 \\
Ca3 & 45 & 15 & 32 & 32 \\
Ca2 & 13 & - & 8 & 11 \\
Ca1 & 2 & - & 8 & 3 \\
Higher than Ca1 & - & - & 25 & 25 \\
The most caudal vertebral arch Left (Right) & & & & \\
Ca2 & $33(33)$ & $48(48)$ & $8(4)$ & $3(2)$ \\
Ca1 & $40(39)$ & $35(36)$ & $46(47)$ & $28(27)$ \\
S4 & $25(25)$ & $1(0)$ & $13(16)$ & $14(17)$ \\
S3 & $2(4)$ & - & $11(9)$ & $9(8)$ \\
S2 & $3(2)$ & - & $15(18)$ & $15(15)$ \\
S1 & - & - & $7(6)$ & $9(9)$ \\
L6 of lower than L6 & - & - & $1(1)$ & $1(1)$ \\
& & & & \\
\hline \hline
\end{tabular}

Group 1: Non-diabetic on water

Group 2: Non-diabetic on alcohol

Group 3: Diabetic on water

Group 4: Diabetic on alcohol 
phenomenon existed in both groups 3 and 4, it happened significantly more frequently in group $4(62 \%)$ than in group $3(43.6 \%)(\mathrm{p}<0.05)$.

Table 3.14 also shows the frequencies of fetuses according to the most cephalic and most caudal vertebral ossification centers. The frequencies of fetuses with respect to the positions of the most cephalic vertebral bodies were significantly different among groups $(\mathrm{p}<0.001)$. The paired comparisons indicated that group 2 was significantly different from group $1(\mathrm{p}<0.001)$. The majority of fetuses from group 2 had the ossified vertebral bodies ending at the 7th cervical vertebrae or higher, and the remainder had it at the 1st thoracic vertebrae, with no fetuses showing the ossification centers lower than this. In comparison, only a few fetuses from group 1 had the ossified vertebral bodies ending at C7 and most of fetuses had them at T1, with some fetuses at T2. Therefore, ossification of the vertebral centra has proceeded further cephalically in group 2 fetuses (nondiabeticalcohol) than in group 1 (the control).

In contrast, fetuses of both groups 3 and 4 had vertebral centra which extended less cephalically than did fetuses from controls $(p<0.001)$. In controls, over $90 \%$ of fetuses had ossified vertebral centers ending at $\mathrm{T} 1$, with only a few below that level, but in groups 3 and $4,1 / 3$ or less had ossified vertebral centers ending at $\mathrm{T} 1$, with the remainder below that level. However, groups 3 and 4 did not differ significantly from each other.

Similarly, the frequencies of fetuses according to the positions of the most caudal vertebral centers were significantly different among groups $(p<0.001)$. The paired comparisons indicated again that positions of caudal end vertebral centers proceeded further in group 2 than in group 1 ( $p<0.001)$. In groups 3 and 4 the caudal end of vertebral center had proceeded less than in group $1(\mathrm{p}<0.001)$. The difference between groups 3 and 4 was not significant.

In summary, ossification of the vertebral centra extended further, both cephalically and caudally, in fetuses of nondiabetic alcohol-exposed rats compared to other treatment 


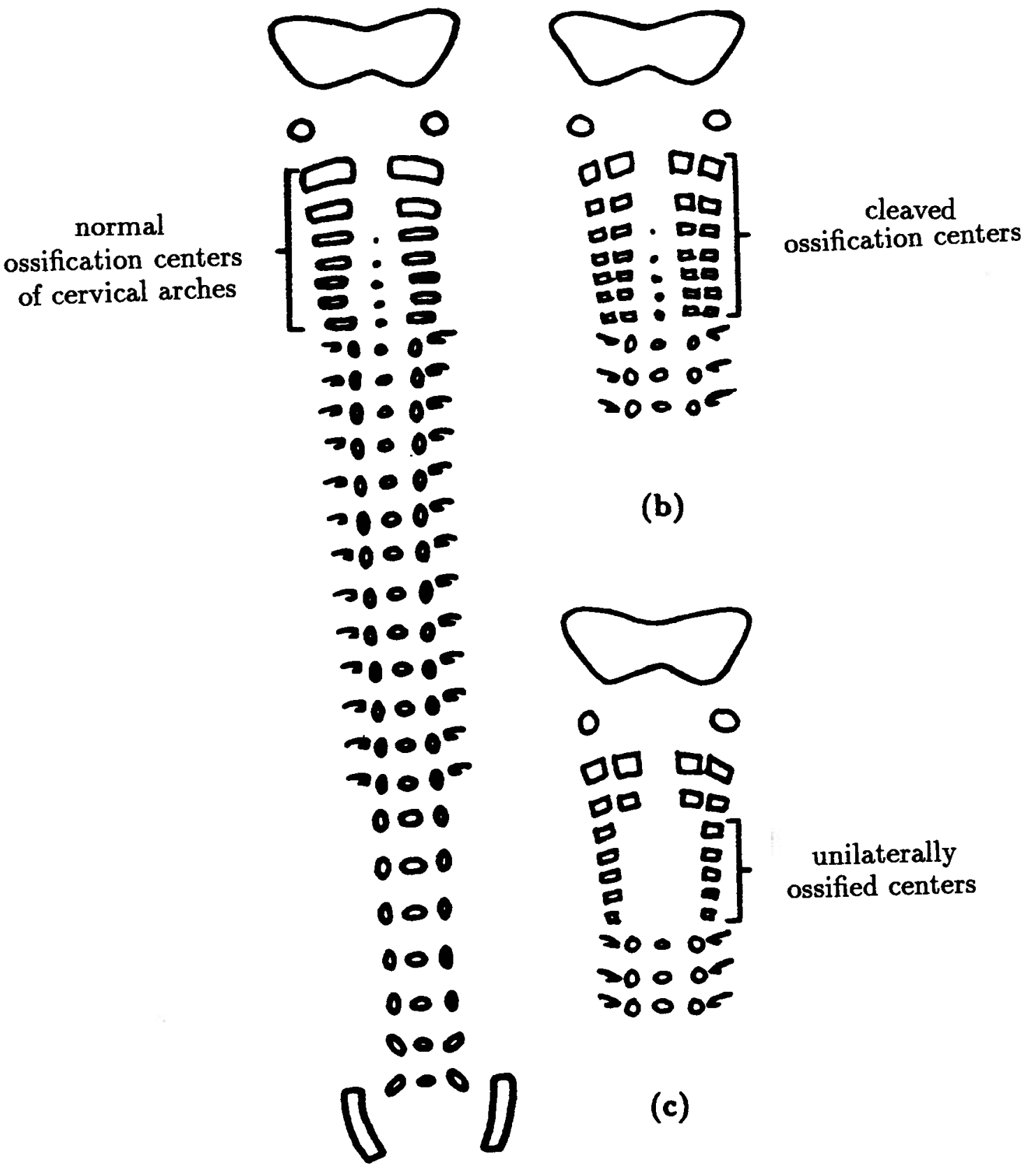

(a)

Figure 3.12: Ossification centers of cervical arches

(a) normal ossification centers

(b)(c) poor ossification centers 
groups. However, all fetuses from diabetic rats had vertebral centra which were extended less, both cephalically and caudally, compared to fetuses of controls, although group 3 (diabetic-water) did not differ from group 4 (diabetic-alcohol).

The most commonly encountered irregular shapes of vertebral ossification centra are shown in Figure 3.13 . These include asymmetrical, dumbbell-shaped, asymmetrically dumbbell-shaped, asymmetrical and asymmetrically dumbbell-shaped, cleaved (bipartite), cleaved and asymmetrically ossified, unilaterally ossified, and unossified. These irregular shaped ossification centers are referred as "poorly ossified centers" in the text. With respect to unossified vertebral centers, only those in the range between the most cephalic and the most caudal ossified centers are classified as unossified, and these are considered "poorly ossified". Photo 10 (see Appendix A) shows a fetus, from a diabetic rat exposed to alcohol, with poorly ossified vertebral ossification centers.

The proportions of fetuses with poorly ossified thoracic vertebral centers were significantly different among groups $(\mathrm{p}<0.001)$. The paired comparisons indicated that the difference between groups 1 and 2 was not significant. However, both groups 3 and 4 were significantly different from controls $(\mathrm{p}<0.001)$. In groups 3 and $4,59.4 \%$ fetuses and $79.7 \%$ fetuses respectively had poorly ossified thoracic centra, while in group $1 \mathrm{a}$ much smaller percentage of fetuses had poorly ossified thoracic centra (only $6.8 \%$ ). It should be noted that, the difference between groups 3 and 4 was significant $(p<0.005)$, with group 4 showing $20.3 \%$ more fetuses had poorly ossified thoracic centra than in group 3 (table 3.12).

The average number of poorly ossified thoracic vertebral centra was 1.43 in the 7 fetuses with poorly ossified vertebral centra in group $1 ; 1.00$ in the 4 fetuses of group 2; 3.35 in the 60 fetuses of group 3; and 3.81 in the 63 fetuses of group 4 . The average number of poorly ossified thoracic vertebral centers per fetus was significantly different between diabetic and nondiabetic groups $(p<0.001$ ), but not significantly different between alcohol 

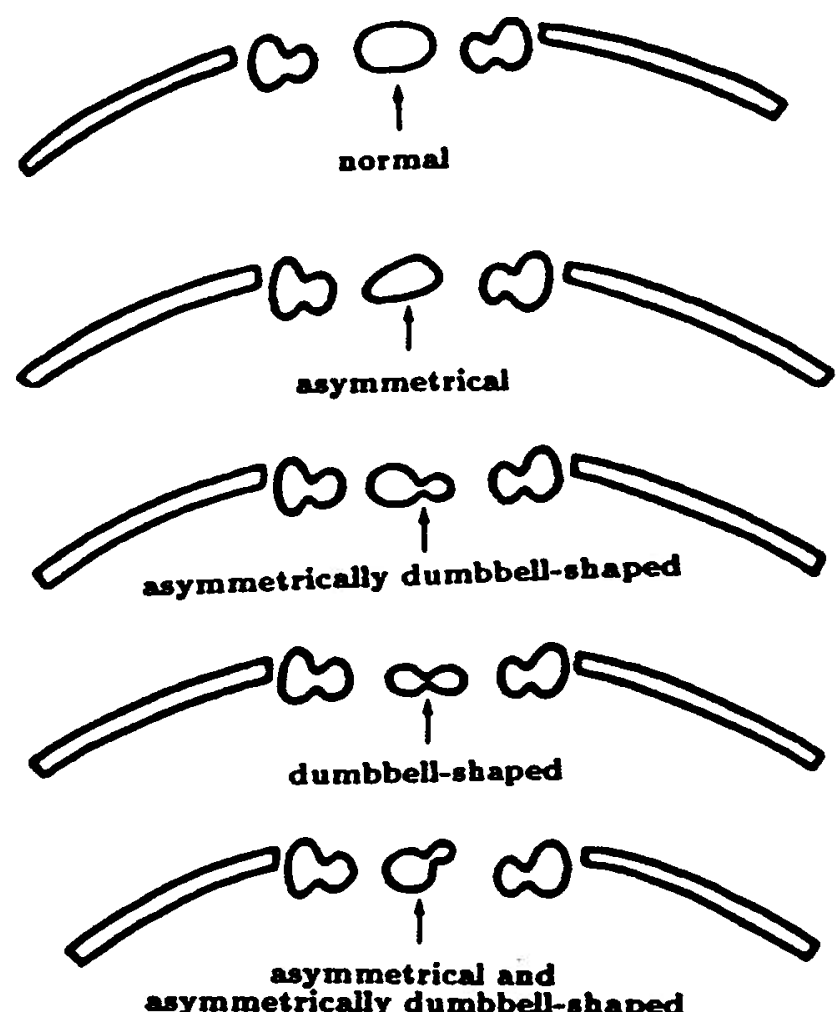

asymmetrically dumbbell-shaped
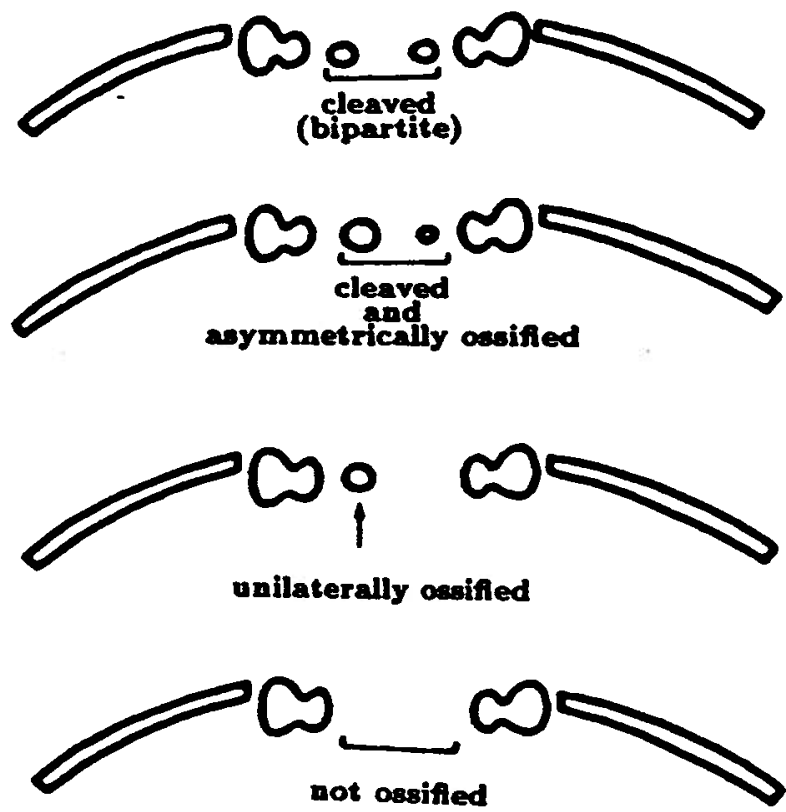

Figure 3.13: Observed irregular shapes of vertebral ossification centers 
and water treated groups (table 3.14). Thus, not only did more fetuses have poorly ossified thoracic vertebral centra in diabetic groups, but also they had a larger number of poorly ossified centers in each fetus.

The percentages of fetuses with poorly ossified lumbar vertebral centra were significantly different among groups $(\mathrm{p}<0.001)$. There was only one fetus with a single poorly ossified lumbar vertebral center in group 1 and none in group 2. However, both groups 3 and 4 had relatively large percentages of fetuses with poorly ossified lumbar vertebral centers ( $18.8 \%$ in group 3 and $24.0 \%$ in group 4$)$. The difference between groups 3 and 4 was not significant.

The average numbers of poorly ossified lumbar vertebral centra in each fetus in groups 3 and 4 were 1.42 and 2.00 respectively, which were not significantly different (table 3.14 ).

\subsubsection{Skull}

Most bones in the skull were ossified on day 21 of gestation in all experimental groups. This included the mandible, premaxilla, vomer, zygomatic process of the maxilla, alisphenoid, squamosal, medial pterygoid plate, nasal, frontal, parietal, exoccipital and incisive, and the posterior palatine foramen was completely enclosed by ossifying tissue.

Some additional bones were ossified in all but a few fetuses. These were zygoma (not ossified in 2 fetuses from group 4 and one fetus from group 3); basisphenoid (not ossified in one fetus from group 3); interparietal bone (not ossified in one fetus from group 3); and the tympanic annulus (ossified on the right side, but not on the left side in one fetus from group 4).

The bones which were frequently unossified or incompletely ossified in the skull were the hyoid bone, presphenoid bone, and the supraoccipital bone. The basisphenoid foramen was frequently incompletely enclosed by ossifying tissue (table 3.15). 
Table 3.15: Ossification centers and foramen in skull

\begin{tabular}{lcccc}
\hline \hline Group & 1 & 2 & 3 & 4 \\
\hline No of fetuses examined & 103 & 84 & 101 & 79 \\
Hyoid bone & $101(2)^{a}$ & $70(14)^{b}$ & $92(9)^{a b}$ & $71(7)^{a b}$ \\
Presphenoid bone & $102(1)^{a}$ & $84(0)^{a}$ & $86(15)^{b}$ & $69(9)^{b}$ \\
Basisphenoid foramen & $86(12)^{a}$ & $74(5)^{a}$ & $53(34)^{b}$ & $35(40)^{b}$ \\
Supraoccipital bone & $103(0)^{a}$ & $84(0)^{a}$ & $100(1)^{a}$ & $75(3)^{a}$ \\
\hline \hline
\end{tabular}

Group 1: Non-diabetic on water

Group 2: Non-diabetic on alcohol

Group 3: Diabetic on water

Group 4: Diabetic on alcohol

Figures indicate numbers of fetuses in which ossification centers were present or (not) or foramen were completely enclosed by ossifying tissue or (not)

Values not sharing a common superscript in each row are significantly different at $\mathrm{p}<0.005$

The frequencies of the presence of ossification centers in the hyoid bone were significantly different among groups $(\mathrm{p}<0.01)$. There was a larger percentage of fetuses failing to show ossification centers in the hyoid bone in group 2 than in group $1(\mathrm{p}<0.001)$. This was one of the two parameters affected only by alcohol exposure ( $16 \%$ of fetuses in group 2 did not have ossification centers in the hyoid bone, only $2 \%$ in group 1 ).

There was no difference in the frequencies of ossification centers in the hyoid bone between any other pairs of groups, although there was a trend that diabetic groups tended to have more fetuses lacking ossification centers in the hyoid bone. About $9 \%$ of fetuses in both diabetic groups did not have ossification centers in the hyoid bone.

The frequencies of presence of ossification centers in presphenoid bone were significantly different among groups $(\mathrm{p}<0.001)$. Groups 1 and 2 did not differ from each other. $15 \%$ of the fetuses in group 3 and $11 \%$ of those in group 4 lacked ossification centers in presphenoid bone, which were significantly different from group $1(\mathrm{p}<0.01)$. However, the difference between groups 3 and 4 was not significant. 
The figures in table 3.15 concerning the basisphenoid foramen show whether the foramen was completely enclosed or not (in parentheses). The frequencies of fetuses with foramen completely enclosed by ossifying tissue were significantly different among groups $(\mathrm{p}<0.001)$. Groups 1 and 2 did not differ from each other. The percentages of fetuses with completely enclosed basisphenoid foramen in groups 1 and 2 were $83.5 \%$ and $88.1 \%$ respectively. Both groups 3 and 4 were significantly different from controls $(\mathrm{p}<0.001)$ with $52.5 \%$ of fetuses in group 3 and $44.3 \%$ of those in group 4 having completely enclosed basisphenoid foramen. Again the difference between groups 3 and 4 was not significant.

The frequencies of the presence or absence of ossification center in supraoccipital bone were not different among groups. However, some fetuses did have ossification center in supraoccipital bone which were not complete. These fetuses either showed a dumbbell shaped ossification center or cleaved ossification centers in supraoccipital bone. The percentages of fetuses with incompletely ossified supraoccipital bone were significantly different among groups ( $\mathrm{p}<0.001$ ). Groups 1 and 2 did not differ from each other. Only $3.9 \%$ of fetuses in group 1 and $2.4 \%$ of fetuses in group 2 had incomplete ossification of supraoccipital bone. Both groups 3 and 4 were significantly different from controls $(\mathrm{p}<0.001)$. There were $70.3 \%$ and $86.1 \%$ of fetuses in groups 3 and 4 respectively had incompletely ossified supraoccipital bone. The difference between groups 3 and 4 was also significant $(\mathrm{p}<0.0125)$. Group 4 had a higher percentage of fetuses with incompletely ossified supraoccipital bone compared to group 3 .

In addition, some fetuses did not have the foramen structure at all. This was considered a variant (table 3.12). Differences among groups were observed $(\mathrm{p}<0.05)$, but when comparisons were made between treatment pairs, the differences were not significant. This is probably because the sample size in each group was too small. 


\subsubsection{Other skeletal variants}

The frequencies of skeletal variants are shown in table 3.13. Most of these have already been described. In addition, one of the commonest skeletal variants was the occurrence of a 14th extra rib, which either appeared at cervical or lumbar in position, and was either rudimentary or full size (see Appendix A, photo 10). The presence of a 14th rib was much more frequent in the two diabetic groups $(\mathrm{p}<0.001)$ but was not different between groups 3 and 4. The other phenomenon found in the nondiabetic-alcohol group (group 2) was a short or rudimentary 13th rib. This was not found in other groups $(p<0.001)$.

\subsubsection{Bone areas}

Although ossification centers were present in all groups, the extent of ossification was not necessarily the same among groups. Therefore, the areas of ossified bone were measured in the humerus, ulna, radius, femur, fibula, and tibia.

The areas of ossified tissue in each of these bones were significantly smaller in diabetic groups compared to those in nondiabetic groups $(\mathrm{p}<0.001)$, but did not differ between alcohol and water exposed groups (table 3.16). 
Table 3.16: Ossified tissue areas $\left(\mathrm{mm}^{2}\right)$ measured in the selected bones (mean \pm SD)

\begin{tabular}{lcccc}
\hline \hline Group & 1 & 2 & 3 & 4 \\
\hline Humerus* & $3.32 \pm 0.54$ & $3.30 \pm 0.26$ & $2.62 \pm 0.39$ & $2.45 \pm 0.46$ \\
Ulna* & $1.22 \pm 0.27$ & $1.23 \pm 0.15$ & $1.00 \pm 0.15$ & $0.91 \pm 0.19$ \\
Radius* & $2.14 \pm 0.46$ & $2.23 \pm 0.27$ & $1.64 \pm 0.33$ & $1.40 \pm 0.40$ \\
Femur* & $1.71 \pm 0.41$ & $1.83 \pm 0.37$ & $1.32 \pm 0.35$ & $1.08 \pm 0.31$ \\
Fibular* & $0.92 \pm 0.21$ & $0.90 \pm 0.13$ & $0.66 \pm 0.09$ & $0.58 \pm 0.22$ \\
Tibia* & $1.91 \pm 0.47$ & $2.02 \pm 0.35$ & $1.62 \pm 0.32$ & $1.34 \pm 0.38$ \\
\hline \hline
\end{tabular}

Group 1: Non-diabetic on water

Group 2: Non-diabetic on alcohol

Group 3: Diabetic on water

Group 4: Diabetic on alcohol

* Diabetic significantly different from non-diabetic, $\mathrm{p}<0.05$ 


\section{Chapter 4}

\section{Discussion}

The major objectives of this study were: (1) to test whether a small amount of alcohol administered during organogenesis has an effect on the outcome of pregnancy in nondiabetic rats; (2) to confirm the teratogenic effect of maternal diabetes on the fetus; (3) to establish whether there is an interaction between alcohol and diabetes on the outcome of pregnancy.

\subsection{Calorie and water consumption}

In the present study, the average daily calorie and water consumption were not significantly different between groups 1 and 2 during days 1-5 of gestation, when group 2 was not administered alcohol; days 6-11, when group 2 was given alcohol; and days 12-20, when group 2 was finished alcohol administration. These results demonstrated that the administration of small amount of alcohol $(2 \mathrm{~g} / \mathrm{kg} /$ day) during organogenesis (days 611) to nondiabetic rats (group 2) did not affect calorie and water intake. These results are different from those of previous studies (Abel and Dintcheff, 1978a; Tze and Lee, 1975; Vavrousek-Jakuba et al., 1991), in which higher doses of alcohol were administered chronically, and food and water consumption were depressed in alcohol consuming animals compared to controls. The results in the present study were also different from those of Abel's study (1978b). In that study, the daily amount of alcohol administered was the same as that of ours, but chronically, and food and water consumption were decreased. 
The average daily calorie intake and water intake of diabetic rats (groups 3 and 4) were much higher than those of nondiabetic rats (groups 1 and 2) in the present study, which is consistent with those of previous studies (Eriksson, 1984a; Giavini et al., 1986). In diabetic rats, alcohol administration significantly reduced the average daily calorie intake during the period of alcohol administration, and average daily water intake during the period of alcohol administration as well as afterwards. Nevertheless, the calorie and water intake by alcohol exposed diabetic rats were still significantly higher than those of controls.

\subsection{Reproductive performance}

There was no significant difference between diabetic and nondiabetic rats in the proportion of rats apparently breeding, as determined by the presence of vaginal plugs ( $100 \%$ in nondiabetic rats and $93.5 \%$ in diabetic rats). This is consistent with the study by Giavini et al. (1986). However, not all rats which had vaginal plugs produced litters. Of the animals with plugs, $100 \%$ of those in group 1 (controls); $90 \%$ of those in group 2 (non-diabetic, alcohol); $68 \%$ of those in group 3 (diabetic, water); and $61.5 \%$ of those in group 4 (diabetic, alcohol) produced litters on day 21 . That these differences did not attain statistical significance may be due to the small numbers of animals in each group. This is similar to the findings of previous studies (Eriksson et al., 1989a; Eriksson et al., 1982), in which it was found that more diabetic rats failed to implant despite a sperm-positive vaginal smear than was the case in nondiabetic controls.

The reason for this is not certain. However, it is clear that diabetes is not a disease with simply abnormal carbohydrate metabolism. It is characterized by multiple metabolic abnormalities, including abnormal protein and lipid metabolism. The development of the fertilized egg, embryo formation and fetal development are processes 
consisting of a high rate of cell division, requiring active protein synthesis. Altered protein synthesis in diabetes obviously will affect these processes. If the fertilized egg cannot develop properly, it possibly cannot implant later on. Therefore this may account for the observation that diabetic rats often did not produce litters despite vaginal plugs. Even in those dams with successful implantation, there may be an interference with the later processes of development, resulting in resorptions or fetal malformations.

\subsection{Weight gain}

It has been observed that although overall maternal weight gain during pregnancy may be normal, weight gain during organogenesis, or during a portion of organogenesis, may be adversely affected by experimental treatments. For this reason Black and Marks (1986) recommended that weight gain in rats be reported separately for days 6-10 of gestation (where the weight of any embryos is insignificant) and during the treatment period, in addition to the entire gestational period.

In the present study, the body weight gains were recorded separately for 3 periods of the gestation (days 1-5, 6-11, 12-20). Diabetic rats gained less weight during all 3 periods of gestation and, as a result, weighed significantly less than did the controls throughout gestation. These results corroborate previous studies in which diabetic rats gained less weight than controls during gestation (Eriksson et al., 1989a; Eriksson et al., 1989b; Eriksson and Jansson, 1984b; Sybulski and Maughan, 1971; Urir-Hare et al., 1989). However, the study by Giavini et al. (1986) was an exception, in that they found that diabetic rats had a similar weight gain during gestation and their body weights were not significantly different from controls at term. The reason for the differences in the results from different studies is not known.

On the other hand, alcohol administration to nondiabetic rats via stomach tube 
during organogenesis (days 6-11 of gestation) at the level of $2 \mathrm{~g} / \mathrm{kg}$ did not affect body weight gains during the period of administration or afterwards. At term, alcohol exposed nondiabetic rats had similar body weights to those of controls. This result differs from previous studies (Testar et al., 1986; Tze and Lee, 1975; Vavrousek-Jakuba et al., 1991), in which depressed weight gain was found during pregnancy in rats following treatment with higher doses of ethanol. Furthermore, in Abel's study (1978b), the amount of alcohol administered was the same as in the present study, and he too found a depressed weight gain in rats exposed to alcohol during gestation. In that case, the pair-fed animals also had a depressed weight gain. Abel suggested that the lower weight gain of the ethanoltreated animals was probably the result of ethanol's depressant effect on food intake rather than on the assimilation of food. Unlike Abel's study, in the present study alcohol was administered only for a short period during gestation (day 6-11 of gestation). Food and water consumption were not affected by alcohol administration; therefore, calorie and water consumption patterns were similar to those of controls. As a result, the weight gain pattern did not significantly differ from that of the controls.

In the present study, a significant interaction between diabetes and alcohol exposure on body weight gain from day 12 to day 20 of gestation was found. The difference in weight gain during this period between diabetic and nondiabetic rats was greater in alcohol exposed rats than in non-alcohol exposed rats. This difference was caused by a trend toward greater weight gain in alcohol exposed rats than in controls, while weight gain was less in the diabetic-alcohol group than in the diabetic-water group.

\subsection{Outcome of pregnancy}

Differences in the number of implantation sites per dam, litter size, mean number of resorptions per litter and percentage of resorptions in each group, as well as in the 
number of litters with one or more resorptions were not statistically significant among groups.

Our study is consistent with that of Eriksson et al. (1982) in terms of the implantation sites, in which the implantation sites per dam were as numerous in diabetic dams as in the controls.

With respect to the incidence of resorptions, our study is consistent with the study by Giavini et al. (1986). In that study the incidence of resorptions in diabetic CD rats was not different from that of the controls. However, many other studies had reported much higher frequencies of resorptions in diabetic rats than in the controls (Eriksson et al., 1989a; Eriksson et al., 1982; Eriksson, 1984a; Eriksson et al., 1989b; Urir-Hare et al., 1989).

As for litter size, findings have not been consistent among studies. Some found smaller litter size in diabetic rats (Eriksson et al., 1989a; Urir-Hare et al., 1989), while others found that the mean litter size of the control and diabetic rats did not differ from each other (Heinze and Vetter, 1987; Ornoy et al., 1984).

In the studies on alcohol exposed rats, some researchers reported no decrease in litter size (Abel, 1978b; Kahns, 1968; Pilstrom and Kiessling, 1967), while others found a decrease in litter size when rats chronically consumed large amounts of alcohol (Testar et al., 1986; Tze and Lee, 1975). Chronic consumption of lower doses $(1-2 \mathrm{~g} / \mathrm{kg})$ of alcohol throughout gestation, also has resulted in reduced litter size (Abel, 1978b).

The inconsistent findings among studies were probably due to differences in experimental conditions, such as the use of different strains of animals, or the differences in the timing of breeding after the rats becoming diabetic. The different amounts of alcohol administered and the different periods of alcohol administration may have been especially important in producing different results in experiments on alcohol treated animals. 


\subsection{Fetal and placental weights}

In the present study, diabetic rats had lighter mean fetal weights but larger placentas compared to nondiabetic rats. These are consistent with the findings of previous studies (Eriksson et al., 1989a; Eriksson et al., 1982; Eriksson et al., 1989b; Eriksson and Jansson, 1984b; Giavini et al., 1986; Urir-Hare et al., 1989) in which reduced fetal weights and heavier placentas were observed in diabetic rats.

It has been suggested that the increase in placental weight is a long-term compensatory mechanism, aiming to secure a sufficient nutrient supply to the fetuses, since a drastic reduction in placental blood flow to the diabetic fetuses had been reported by Eriksson et al. (1984b).

Similarly, the combination of decreased fetal and increased placental weights has also been reported in the fetuses of alcohol-treated rats (Gallo and Weinberg, 1986; Gordon et al., 1985; Jones et al., 1981; Weinberg et al., 1990; Weinberg, 1985; Wiener et al., 1981). It has been suggested that placental hyperplasia and hypertrophy may be adaptive mechanisms brought into play to maintain normal placental function in alcoholconsuming females (Gallo and Weinberg, 1986; Weinberg, 1985). In those studies, rats were all chronically exposed to high doses of alcohol. However, in our study, a low dose of alcohol was administered and the exposure time was only from days 6-11 of gestation. We did not find a decrease in fetal weight, nor an increase in placental weight in the nondiabetic, alcohol exposed group.

It is noteworthy that a significant interaction between diabetes and alcohol on fetal weight was found in the present study. The difference in fetal weight between diabetic and nondiabetic rats was greater when rats were given alcohol than when given water. This difference was caused by the trend that alcohol-exposed nondiabetic rats (group 2) had bigger fetuses than controls (group 1) and alcohol-exposed diabetic rats (group 4) 
had smaller fetuses than diabetic rats not exposed to alcohol (group 3).

In addition, the ratio of fetal weight/placental weight was calculated in this study. This ratio reflects the relationship of a fetus to its corresponding placenta. For example, two fetuses with different birth weights may have the same placental weight. If the comparison were simply done between the two placentas without considering the corresponding fetuses, we would have not seen any difference. However, when fetal weight is considered, the smaller fetus would have a relatively larger placenta, compared to the bigger fetus. Therefore, the smaller ratio represent a relatively bigger placenta for the size of fetus.

In the present study, whether exposed to alcohol or not, diabetic rats had lower $\mathrm{f} / \mathrm{p}$ ratio compared to nondiabetic rats. Interestingly, in nondiabetic rats, this low dose of alcohol consumption raised the $\mathrm{f} / \mathrm{p}$ ratio compared to controls. However, in diabetic rats the same level of alcohol consumption did not have an effect on $f / p$ ratio.

Similar observations in rats treated with low dose of alcohol have not been reported. Low doses of alcohol during short periods of pregnancy have not been used in previous studies.

It is difficult to explain the significant difference in $\mathrm{f} / \mathrm{p}$ ratios between groups 1 and 2. As neither fetal weight nor placental weight differed significantly between groups 1 and 2 , the difference in ratios can not be ascribed to "better" placental development or to retarded fetal development. Fetal weight tended to be greater in group 2 and placental weight tended to be less in group 2 , compared to group 1 . It may be that the ratio is a more sensitive parameter than either of its components. 


\subsection{Malformations}

A wide variety of external malformations were found in fetuses of diabetic rats, but none were found in those of nondiabetic rats regardless of whether the animals were exposed to alcohol or not. The malformations observed included: a variety of facial defects, characterized by smaller lower jaw, no lower jaw, no mouth, tongue exposure, otocephaly, and distorted face; missing tail; umbilical hernia/gastroschisis; severe edema; and ectrodactyly. Malformed fetuses from diabetic dams have frequently been reported in rats (Eriksson et al., 1989a; Eriksson, 1984a; Giavini et al., 1986; Giavini et al., 1990; Urir-Hare et al., 1989). The malformations found in those studies included subcutaneous edema, micrognathia, hepatomphalocoele, exencephaly, absence of the tail (Eriksson et al., 1989a; Eriksson, 1984a; Giavini et al., 1986). The results from those studies together with those of the present study indicate that a variety of external malformations occur in experimental diabetic animals and there was no specific malformation consistently observed across studies. This is in agreement with the observations in other studies, summarized by Eriksson et al. (1982).

Similarly, a variety of skeletal malformations were observed in both diabetic groups in the present study. These included: cleft sternum, malformed ribs (bifurcated or fused ribs), vertebral malformations (arch or center), malformed arm joint, missing bone in skull, etc. A wide spectrum of skeletal malformations was also found in other studies with diabetic rats (Baker et al., 1981; Eriksson et al., 1989a; Giavini et al., 1986; Giavini et al., 1990; Urir-Hare et al., 1989), including fused ribs, malformed vertebrae, scoliosis, absence of the tail together with caudal vertebrae (i.e. sacral dysgenesis), a failure of neural tube fusion, and split sternum.

The lack of consistent malformations observed in different studies may be caused by different timing of inducing diabetes in the animals. The different strains used in 
studies may be another possible factor which caused the observations of a wide variety of malformations. There may be genetic differences in susceptibility, and vulnerability may be different at different time points during organogenesis.

Unlike studies in mice, malformations were not found frequently in most studies of alcohol treated rats (Abel and Dintcheff, 1978a; Abel, 1978b; Abel, 1979a; Lee and Leichter, 1983; Testar et al., 1986), especially in study of low dose alcohol consumption (Abel, 1978b), except for the study by Tze and Lee (1975).

In the present study, all malformed fetuses were from diabetic dams. However, the frequency of external malformations was significantly higher when diabetic rats exposed to alcohol were compared to diabetic rats not exposed to alcohol. This indicates that low dose of alcohol administered during organogenesis may act synergistically with maternal diabetes to produce external malformations in the fetuses. However, the mechanism is not known at present.

\subsection{The proposed mechanisms for malformations}

The search for a teratogenic agent in diabetes is complicated by the fact that diabetes is not simply a disorder of carbohydrate regulation. Diabetes is responsible for a loss of normal homeostasis not only of carbohydrate but of fat and protein metabolism as well. Vascular complications may lead to additional metabolic changes such as hypoxia or impaired renal clearance of toxins. In short, there are multiple factors in the disordered milieu of the pregnant diabetic which could be teratogenic (Mills, 1982).

Although the precise etiology of malformations in diabetic pregnancy is obscure, maternal hyperglycemia is one suspected etiology. In some in vitro rodent embryo culture systems, it has been confirmed that severe malformations can be caused merely by increasing the glucose concentration of the culture medium $(12$ to $15 \mathrm{mg} / \mathrm{ml}$, which is 8 to 
10 times the level of glucose present in normal rat serum (Cockroft and Coppola, 1977), or 5 or $8 \mathrm{mg} / \mathrm{ml}$, which are very close to the level of glucose present in severe diabetic rat serum (Sadler, 1980)).

The study by Eriksson et al. (1989b), demonstrated the importance of well regulated glucose homeostasis during pregnancy. It was shown in this study that diabetic animals with continuous insulin treatment gained weight at normal rate, and the fetuses showed few resorptions and no malformations. When insulin treatment was interrupted, the pregnant animals lost weight, and congenital malformations were found. The marked clustering of malformations were found in fetuses of diabetic rats with insulin-interruption between days 6 and 10 of gestation.

However, abnormal glucose metabolism may not explain all malformations. Eriksson et al. (1989b) observed that rats that produced malformed offspring were not markedly different from those that did not give birth to malformed offspring. The maternal weight losses during the period of interrupted insulin therapy were similar, and resorption rates were also similar in the litters with and without malformed offspring. Serum levels of glucose, cholesterol, urea, and creatine did not differ between the pregnant rats. On the other hand, the marked elevation of $\beta$-hydroxybutyrate and triglycerides in the serum of animals with malformed offspring may indicate that the teratogenic environment also includes a severe disturbance of maternal lipid metabolism in addition to glucose dysregulation (Eriksson et al., 1989b).

Trace metal imbalances is another possible etiology of congenital malformations in diabetic pregnancy. One trace metal which may be important is zinc. Although the etiological relationship between congenital malformations in diabetic pregnancy and fetal zinc deficiency is so far obscure, there is ample evidence to indicate that zinc deficiency in itself may cause a number of disturbances in the feto-maternal development. A variety of external as well as skeletal malformations have been demonstrated in the fetuses of 
zinc deficient rats (Da Cunha Ferreira et al., 1989; Hurley and Swenerton, 1966; Hurley, 1981). The external malformations found in fetuses of zinc deficient rats include: cleft palate; exencephaly; meningoencephalocele; meningocele; hydrocephaly; microphthalmia; micrognathia; umbilical hernia; gastroschisis; syndactyly; shortening of limbs; limb dysplasia; oligodactyly; short, angulated, wavy, and curly tails; heart abnormalities; lung abnomalities; urogenital abnormalities; spina bifida, etc. Skeletal malformations in fetuses of zinc deficient rats occurred in almost all skeletal districts, such as skull, spine, tail, ribs, sternum, and limbs. Most of these malformations described above have also been found in fetuses of diabetic rats.

It should be noted that a zinc deficiency has been demonstrated in diabetic rats (Eriksson, 1984a). It has been suggested that zinc deficiency is an important cause of growth retardation and congenital malformations also in the offspring of diabetic mothers. On the other hand, in the study by Eriksson (1984a), there were no differences in trace metal concentrations between normal and malformed fetuses. This finding, however, might imply that fetal trace metal disturbances do not always become manifest as malformations and that zinc deficiency in particular may play a permissive role in the etiology of malformations in the offspring.

Fetal hyperinsulinism, which is secondary to the hyperglycemia, was considered to be the causative factor, since Laadauer and Duraswami (Giavini et al., 1986) had shown that high concentrations of insulin provoked vertebral anomalies in chick embryos (Giavini et al., 1986). In addition, the low molecular weight somatomedin inhibitors have proved to be teratogenic (Giavini et al., 1986).

Genetic factors might also play a role in the genesis of malformations. In a substrain of Spraque-Dawley rats that is prone to fetal malformations, there is the interaction between genetic factors and the metabolic derangement of diabetes that is necessary for the induction of skeletal malformation (Eriksson, 1988), but the nature of the genetic 
predisposition is not yet clear. It is, however, noteworthy that diabetes exacerbates changes in proteoglycan metabolism in cartilage that are more severe in this substrain than in other Spraque-Dawley substrains (Eriksson et al., 1986).

With respect to the mechanism of teratogenic effect of alcohol, it is still unclear. Ethanol appears to be the principal agent responsible for fetal alcohol syndrome, however, a growing body of evidence suggests that acetaldehyde, with its inhibiting effect on DNA synthesis, placental amino acid transport, and morphologic alterations in the CNS of the developing mammalian embryo, could explain most of the abnormalities seen in fetal alcohol syndrome. The varying effects seen in the offspring of chronic alcoholic mothers ingesting a similar amount of alcohol may be due to differences in the ability to metabolize alcohol. Deficiencies of zinc, which is involved in a variety of metalloenzymes including alcohol dehydrogenase (ADH) and protein synthesis, may also be contributory (Kumar, 1982).

In the present study, diabetes combined with alcohol consumption during pregnancy increased the frequency of external malformations compared to the solely diabetic pregnancy (almost tripled the malformation frequency, 12 vs $4.5 \%$ ). It seems that the two factors may synergistically act together. However, the mechanism whereby they act together is not understood at present.

\subsection{Skeletal ossification}

The toxic effects of a drug on the fetal development may manifest itself not only in terms of malformations but also in terms of retarded ossifications. It has been demonstrated that the stage of fetal skeletal development can provide an additional, reliable index of retarded fetal development, in addition to fetal weight (Aliverti et al., 1979). Therefore, evaluation of the stage of ossification attained by the fetus is important in studies on 
teratogenesis.

Aliverti et al. (1979) have suggested that certain 'districts' of the skeleton provide particularly sensitive indices of the stage of fetal ossification. These are: metacarpus, metatarsus, sternum, cervical and caudal vertebrae, and anterior and posterior proximal phalanges. All of these districts of the skeleton were examined in the present study. In addition, the thoracic, lumbar, and sacral vertebrae, and skull were also examined.

\subsubsection{Number of ossification centers}

The ossification centers were counted in the districts mentioned above except the proximal phalanges, which did not yet show ossification centers either in control or other treatment groups. As in my study, the studies of Lee and Leichter (1983) and Eriksson et al. (1989a) showed that the anterior and posterior proximal phalanges of control and treated rats were not ossified.

Studies have consistently shown that fetuses from diabetic mothers have fewer ossification centers in most locations (Eriksson et al., 1989a; Eriksson et al., 1982; Urir-Hare et al., 1989). It has also been reported that fetuses from rats consuming chronic high doses of alcohol have fewer ossification centers compared to those from control and pair-fed rats (Lee and Leichter, 1983).

In the present study, fetuses from diabetic rats had fewer ossification centers than those of nondiabetic rats in the districts of metacarpus, metatarsus and sternum. Some fetuses of diabetic rats had no ossification centers in these districts. Fetuses of diabetic dams had vertebral ossification centers which extended less cephalically and caudally and had ossified vertebral arches which extended less caudally, compared to the fetuses of nondiabetic dams. These results indicated that fetuses of diabetic dams had retarded skeletal development relative to those of nondiabetic rats, which is consistent with previous studies (Eriksson et al., 1989a; Eriksson et al., 1982; Urir-Hare et al., 1989). It 
is noteworthy that the fetuses of diabetic dams weighed significantly less than those of nondiabetic dams. This means that the development of the whole fetus was retarded, and the retarded skeletal development does not seem to be specific.

Alcohol exposure did not have an effect on the average number of ossification centers in the metacarpus, metatarsus, and sternum. Interestingly, in nondiabetic rats, fetuses of alcohol-exposed rats had vertebral ossification centers which extended more cephalically and caudally and had ossified vertebral arches which extended further caudally compared to those of non-alcohol exposed rats. However, the same effect of alcohol exposure was not found in diabetic rats. This indicates that small amounts of alcohol may enhance fetal development in fetuses of nondiabetic rats, but not in those of diabetic rats.

\subsubsection{Skeletal variations}

Abnormally shaped skeletal elements, though a spontaneous phenomenon, can be increased in frequency in rat and mouse fetuses following maternal administration of drugs, such as thalidomide, salicylate, retinoic acid, diphenylhydantoin, and etc (Fritz and Hess, 1970).

In the present study, the irregular shapes observed in the sternum includes dumbbellshaped, asymmetrically dumbbell-shaped, asymmetrical and asymmetrically dumbbellshaped, simple asymmetrical, cleaved (bipartite), asymmetrical and cleaved, unilaterally ossified. Those observed in vertebrae includes: asymmetrical, dumbbell-shaped, asymmetrically dumbbell-shaped, asymmetrical and asymmetrically dumbbell-shaped, cleaved, cleaved and asymmetrically ossified, unilaterally ossified, and unossified. Whether the bipartite ossified centers occur as part of the usual sequence of the development is not clear. It has been noticed that in the rat and mouse, some "bipartite" and dislocated sternebra may remain permanently altered (Fritz and Hess, 1970). Findings of this sort are usually listed under the heading of skeletal anomalies and can be shown to vary in 
frequency depending on the stock or strain of animal concerned. However, it has been found that dumbbell-shaped thoracic vertebral centers or bipartite sternebral centers can be completely ossified after term (Fritz and Hess, 1970). Therefore, it is difficult to tell at the time of examination whether an irregularly shaped center will become "normal" or not later on. This caused trouble for categorizing the findings.

In the present study, these irregular shapes were considered to have no significant biologic effect on animal health or on body conformity and represented only slight deviations from normal (Fujinaga et al., 1989), as these may happen in control group. Therefore, they were categorized as developmental variants.

The dumbbell-shaped, cleaved and unilaterally ossified centers were pooled together and referred as "poorly ossified centers" in this study. It has been found that not only there were more fetuses with poorly ossified sternebral centers, thoracic and lumbar vertebral centers but there were also more poorly ossified centers per fetus in these districts in diabetic than in nondiabetic litters. Also, more fetuses of diabetic dams had sternebral ossification centers with lack of apposition than fetuses of nondiabetic dams.

Alcohol exposure itself did not have an effect on the shape of sternebral ossification centers. It should be noted, however, that diabetic rats exposed to alcohol had significantly more fetuses with poorly ossified thoracic centers than diabetic rats not exposed to alcohol. Similarly, more fetuses of diabetic rats had poorly ossified cervical arches compared to those of nondiabetic rats. Diabetic rats exposed to alcohol had more fetuses with poorly ossified cervical arches than diabetic rats not exposed to alcohol. These results indicate that the administration of small amounts of alcohol during organogenesis may exacerbate the toxic effect of maternal diabetes on the formation of thoracic centers and cervical arches, although alcohol itself did not show this effect. However, how maternal diabetes and alcohol administration act together is not clear at this time. It has been observed that the fetuses with more bone retardation are those very small ones. 
And there is a trend that the average fetal weight in diabetic-alcohol group was smaller (table 3.8). More skeletal retardation could be secondary to more retardation overall.

The presence of the 14th extra rib was much more frequent in the two diabetic groups. Only one fetus in group 2 had a 14th rib and none in the control group. The occurrence of an accessory rib structure is not considered to be a malformation, but it is thought that an increase in their incidence during teratogenicity tests, if not already associated with increased malformations, indicates that the embryotoxic range of dosage is being approached (Wilson, 1973). In the present study, the occurrence of the 14th rib significantly increased in fetuses of diabetic rats, while malformations were also increased in fetuses of diabetic rats. Therefore, the presence of the 14 th rib probably indicates the embryotoxic effect of maternal diabetes.

The other variation observed in this study was the short or rudimentary 13th rib, which specifically occurred only in the alcohol treated group (group 2). Whether this indicates retarded fetal development is not established. If so, it is contrary to the findings that fetuses of nondiabetic alcohol-exposed rats had vertebral ossification centers extended more cephalically and caudally and had ossified vertebral arches extended more caudally compared to those of non-alcohol exposed rats, which suggested that small amounts of alcohol may enhance fetal development.

\subsubsection{Ossification of the skull}

In a study by Fritz et al. (1970), it was found that the bones of the skull were completely ossified on day 21 , with the exception of the supraoccipital bone, which was dumbbellshaped in a few fetuses.

Our findings in control rats are consistent with those of Fritz et al. In our controls, only 2 fetuses had unossified hyoid bones, one fetus had unossified presphenoid bone and 4 fetuses had dumbbell-shaped supraoccipital bone. The rest of bones in the skull were 
completely ossified in all fetuses of controls.

However, in the diabetic groups significantly more fetuses had a total absence of ossification in presphenoid bone compared to nondiabetic groups. There was no difference between the alcohol exposed group and the water exposed group. The most impressive finding is the ossification of supraoccipital bone. In both diabetic groups, except for a few fetuses with a complete lack ossification of supraoccipital bone, most fetuses had supraoccipital centers which were either dumbbell-shaped or bipartite. This higher frequency of incompletely ossified supraoccipital bone in diabetic rats compared to nondiabetic rats obviously demonstrated a retarded skull development in the fetuses of diabetic dams. It should be noted that when diabetic rats were exposed to alcohol, the frequency of incompletely ossified supraoccipital bone in the fetuses was significantly higher than that in diabetic rats not exposed to alcohol.

Significantly more fetuses in the nondiabetic, alcohol exposed group (group 2) failed to show ossification centers in hyoid bone, compared to controls. Similar results were also reported by Lee and Leichter (1983). In that study, they reported that most fetuses in alcohol exposed group did not show ossification centers in hyoid bone, but did in controls. However, unossified centers were also found in other bones of the skull. In that study, the amount of alcohol administered was high, and administration was chronic compared to that of the present study. At the low dose of alcohol administration, why the hyoid bone was affected but not other bones is difficult to understand.

\subsubsection{Bone areas}

The number of ossification centers can only tell whether the bone has ossified or not, but not the extent of the ossification. Therefore, the ossified tissue areas were measured in humerus, ulna, radius, femur, fibula and tibia of the fetuses. Fetuses of diabetic groups (groups $3 \& 4$ ) had significantly smaller areas for all these bones, compared to nondiabetic 
groups. This provided further evidence that the fetuses of diabetic dams had retarded skeletal development.

To summarize the findings in the skeletal examination, we have demonstrated that: (1) the fetuses of diabetic dams had a retarded skeletal development as follows: The fetuses of diabetic dams had a smaller number of ossification centers in metacarpus, metatarsus, and sternum, and had vertebral arches and centers which extended less cephalically and/or caudally. Not only were there more fetuses with poorly ossified sternebral, thoracic vertebral and lumbar vertebral centers but there were also more poorly ossified centers per fetus in these districts. More fetuses had sternebral ossification centers with lack of apposition. More fetuses had poorly ossified cervical arches. For the skull, more fetuses had an absence of presphenoid bone, incompletely enclosed foramen, and poorly ossified supraoccipital bone. The 14th extra rib occurred frequently in fetuses of diabetic dams compared to those of nondiabetic dams. Fetuses of diabetic dams had smaller bone areas in humerus, ulna, radius, femur, fibula and tibia; (2) alcohol exposure alone seemed to enhance skeletal development with vertebral ossification centers extended more cephalically and caudally and ossified vertebral arches extended more caudally. On the other hand, significantly more fetuses had absence of ossification centers in the hyoid bone and a 13th short rib, possibly indicating retarded skeletal ossification; (3) interaction between diabetes and alcohol on several parameters was observed. More fetuses had poorly ossified thoracic vertebral centers, poorly ossified cervical arches, and poorly ossified supraoccipital bone in alcohol exposed diabetic rats than in nonalcohol exposed diabetic rats. This possibly indicates that small amount of alcohol administration during organogenesis could exacerbate the toxic effect of maternal diabetes on the fetuses. 


\subsection{The effect of alcohol consumption}

In the present study, alcohol was administered at the level of $2 \mathrm{~g} / \mathrm{kg} /$ day, which is approximately equivalent to $4 \mathrm{oz}$ absolute alcohol ( 8 average-sized drinks per day) consumed by a $60 \mathrm{~kg}$ woman. The peak blood alcohol level was $73.3 \mathrm{mg} / \mathrm{dl}$ which was comparable to a level at which some adverse effects of alcohol on the offsprings of both human and animals were observed.

However, the alcohol administration alone did not have any adverse effects on the fetuses of group 2 rats. This may be caused by the transient blood alcohol level and short period of alcohol exposure in this experiment.

Although alcohol consumption alone did not show any visible effects in this study, we did observe an interaction between alcohol and diabetes. However, we can not tell whether the observed interaction was the direct or indirect effect of alcohol, since the alcohol exposed diabetic rats significantly reduced their calorie and water consumption compared to the non-alcohol exposed diabetic rats. Without pair-fed controls, it is hard to say whether the undernutrition in alcohol exposed diabetic rats interacted with diabetes, which caused the more severe adverse effect in this group.

\subsection{Summary and conclusion}

To summarize, the results of this investigation support the view of previous studies that maternal diabetes is teratogenic to the offspring in terms of significantly increased malformation rate, retarded fetal development (small fetal weight, big placenta, and retarded skeletal ossification).

Consumption of small amount of alcohol $(2 \mathrm{~g} / \mathrm{kg})$ during organogenesis (days 6-11 of gestation) did not seem to intoxicate the dams. Body weight gain was at a normal rate, and there was a larger $\mathrm{f} / \mathrm{p}$ ratio compared to controls. In terms of skeletal development, 
alcohol exposure seemed to enhance bone development, with the exception of a few fetuses with absence of ossification centers in the hyoid bone and the short 13th rib, possibly indicating retarded skeletal development.

A significant interaction between maternal diabetes and alcohol administration during organogenesis was observed. Fetal external malformation rate was significantly increased in alcohol exposed diabetic rats compared to nonalcohol exposed diabetic rats. Furthermore, more fetuses had poorly ossified thoracic vertebral centers, poorly ossified cervical arches, and poorly ossified supraoccipital bone in alcohol exposed diabetic rats than in nonalcohol exposed diabetic rats. These observations suggested that a small amount of alcohol consumption during organogenesis can exacerbate the embryotoxic effects of maternal diabetes. 
Appendix A

Photographs 
Photo 1: Fetuses on day 21 of gestation, fixed in $95 \%$ alcohol. The right fetus, which is from a control dam, is about 2 times bigger than the left one, which is from a diabetic dam exposed to alcohol.

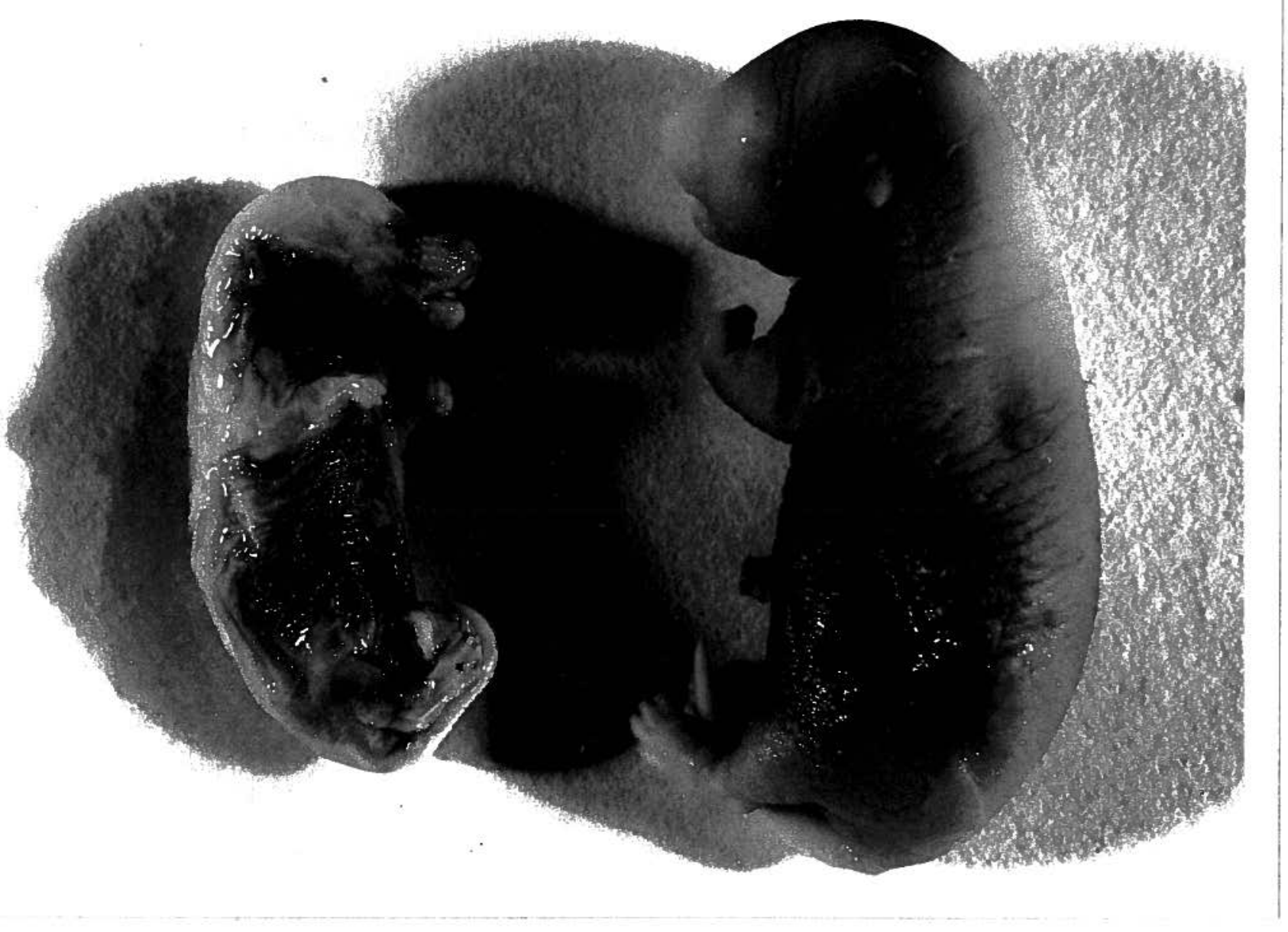


Photo 2: A fetus from a diabetic rat exposed to alcohol, showing otocephaly.

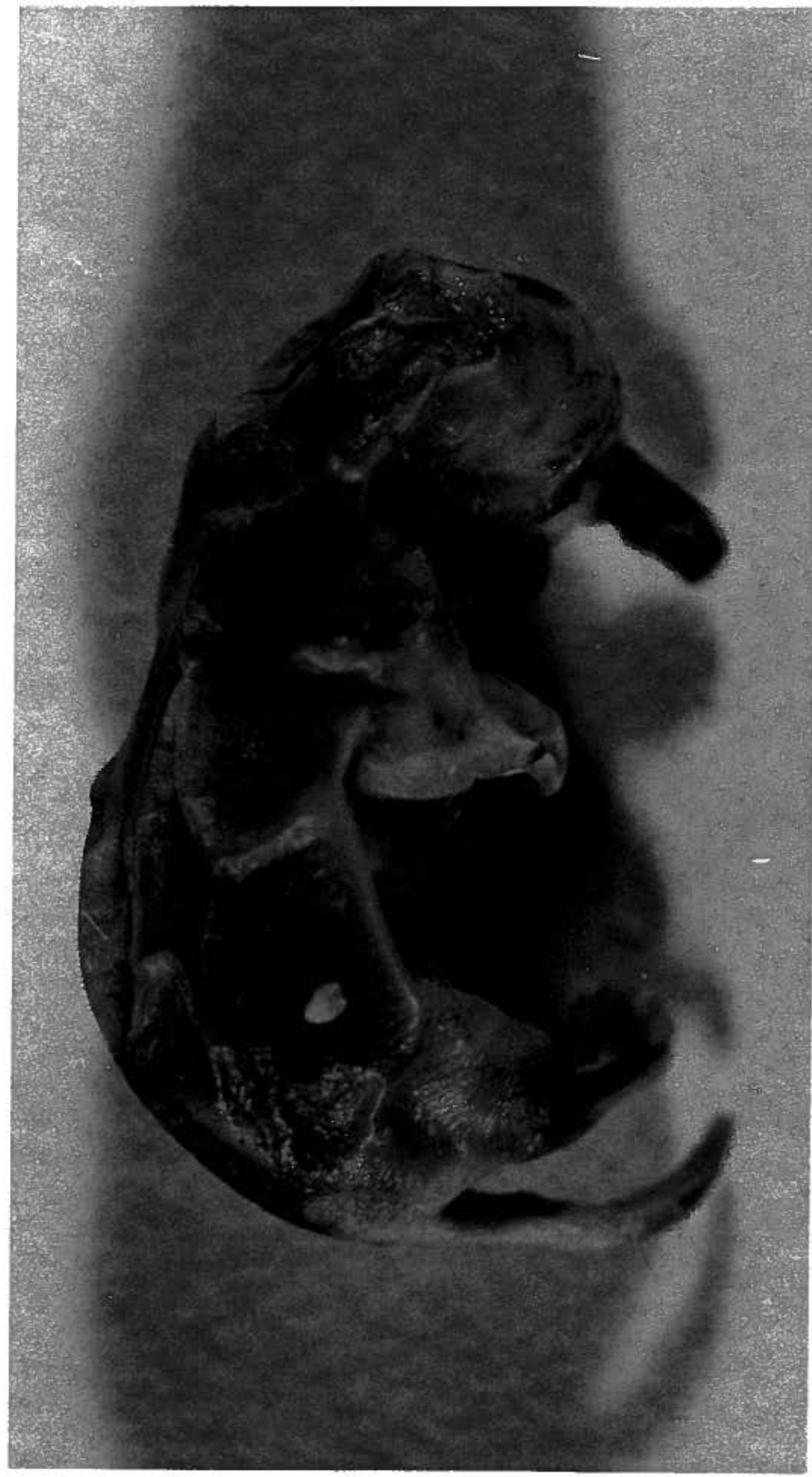


Photo 3: A fetus from a diabetic rat exposed to alcohol, showing an absence of tail.

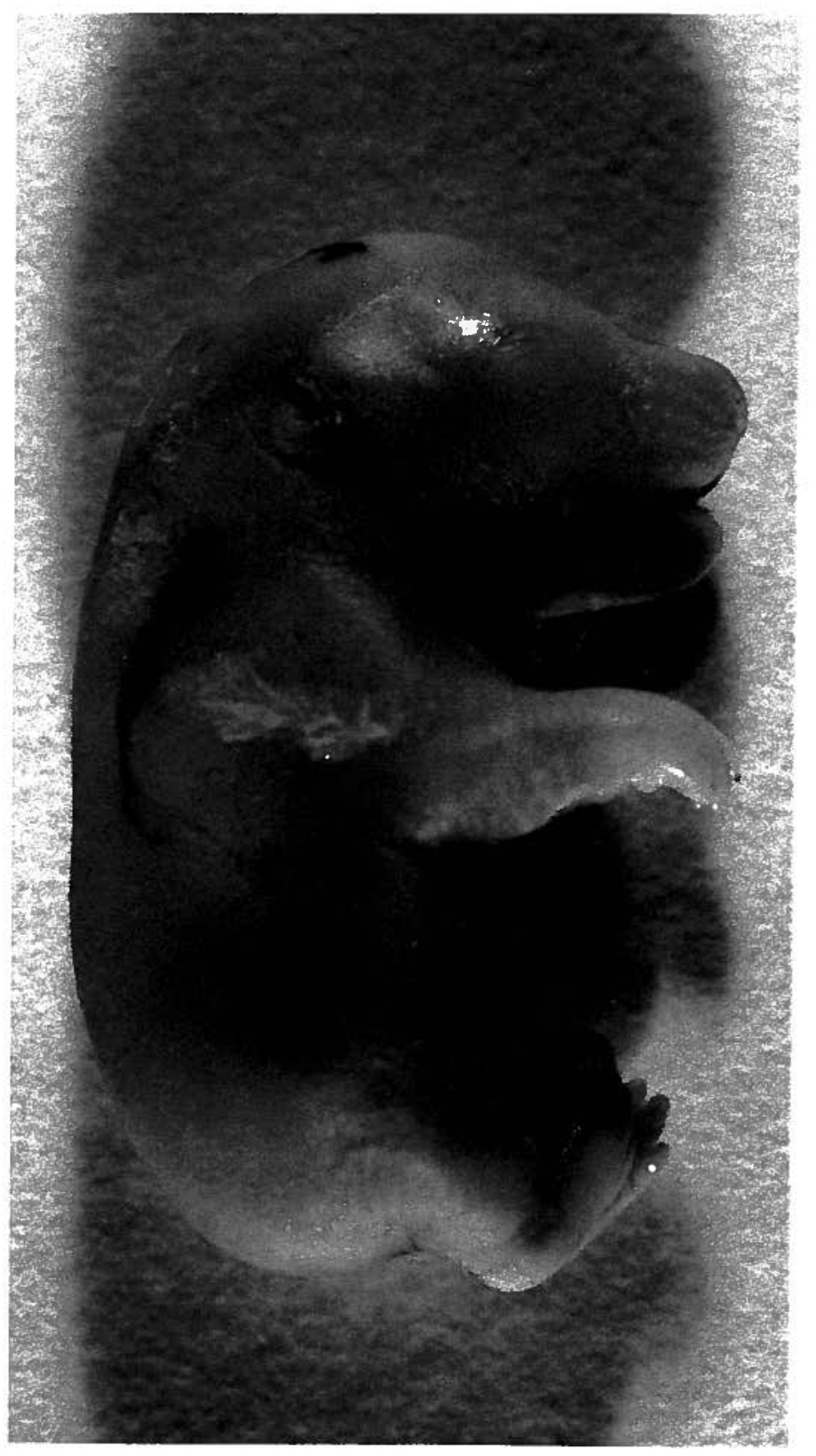


Photo 4: A fetus from a diabetic rat exposed to alcohol, showing a gastroschisis.

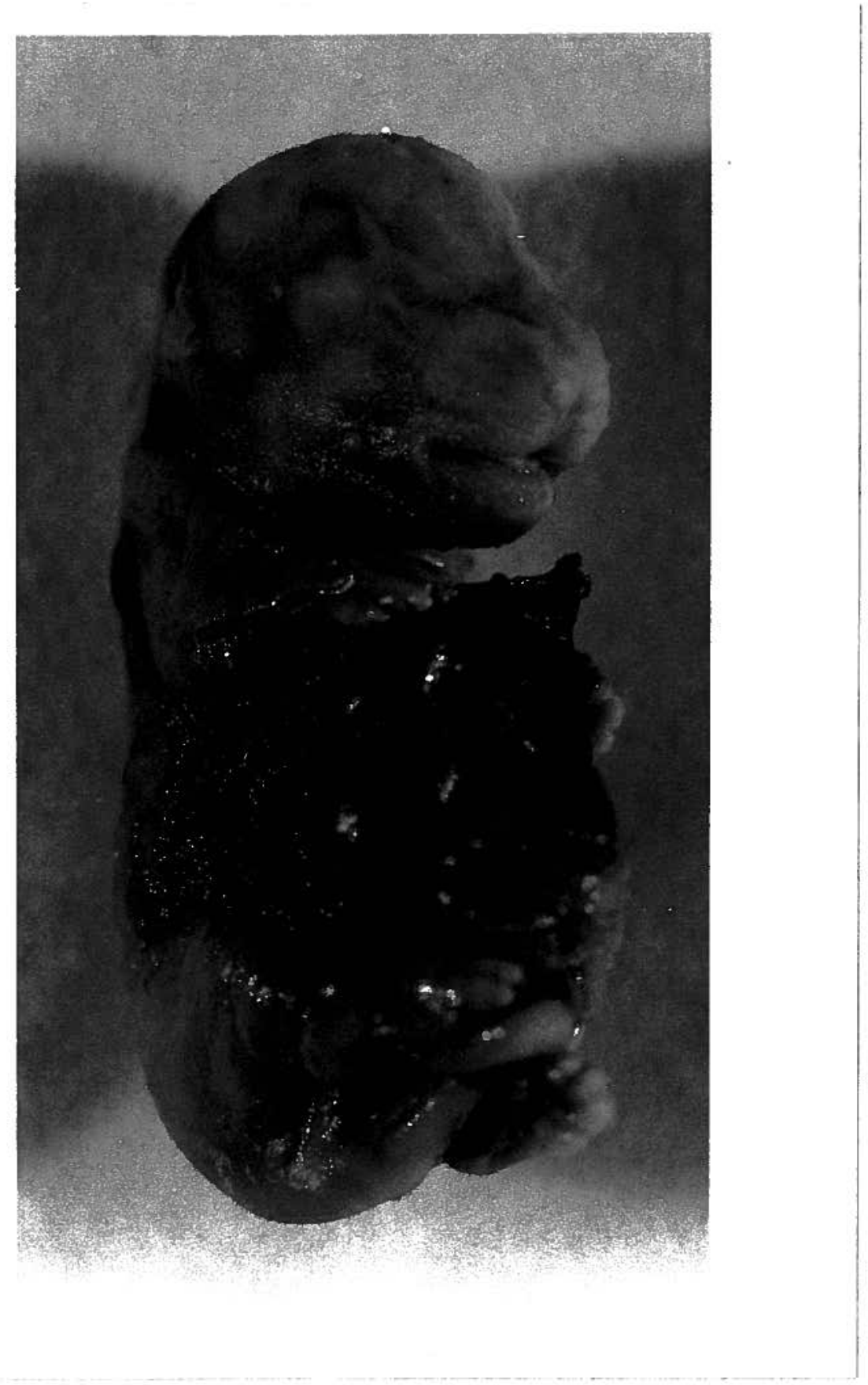


Photo 5: A fetal skeleton from a diabetic rat, showed the 5th left cervical arch bifurcated and a cleft sternum. 
Photo 6: Ventral view of the fetal skulls on day 21 of gestation. Left skull is from a fetus of control dam; right one is from a fetus of diabetic dam exposed to alcohol. Except for the smaller size, the right skull is less ossified and has a missing zygomatic process and zygoma bone.

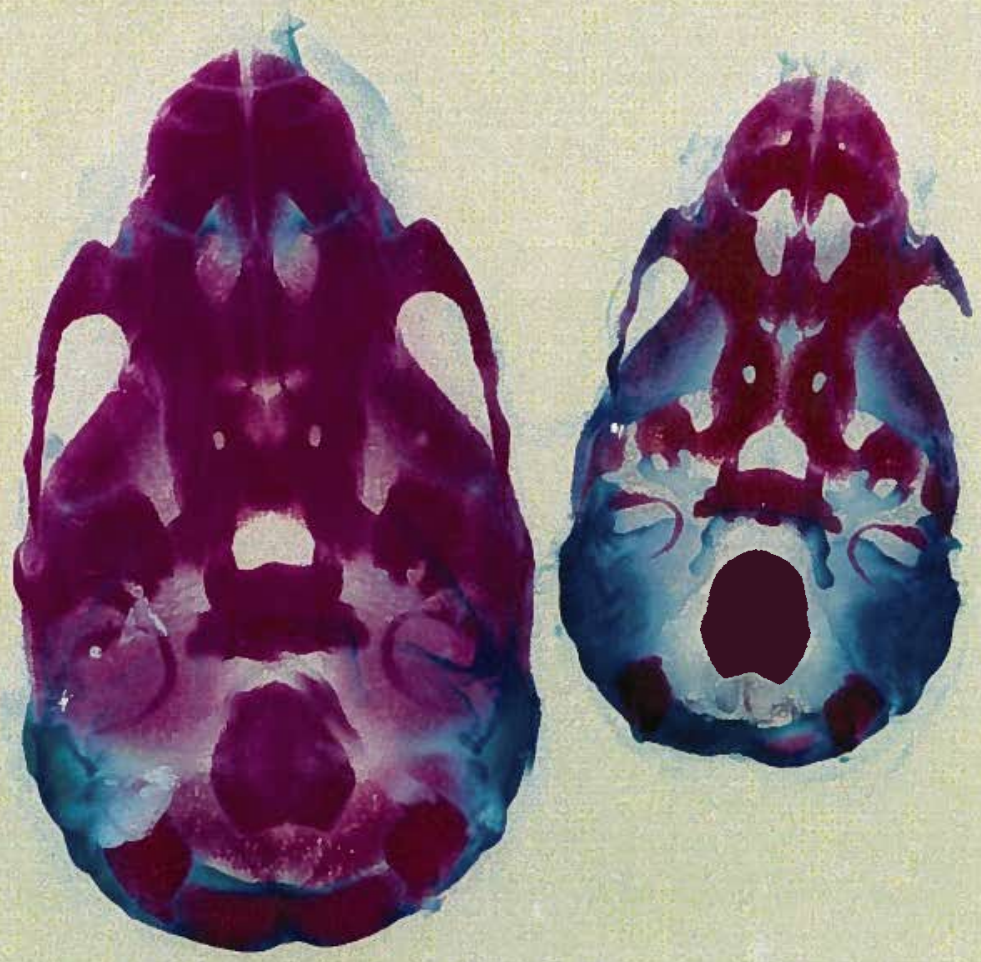


Photo 7: Fetal skeletons on day 21 of gestation stained with alizarin red S and alcian blue 8GS. From left to right, control (group 1); non-diabetic on alcohol (group 2); diabetic on water (group 3); diabetic on alcohol (group 4). In addition to the smaller size of the fetuses from diabetic dams, the skeletons are less ossified (more blue color).
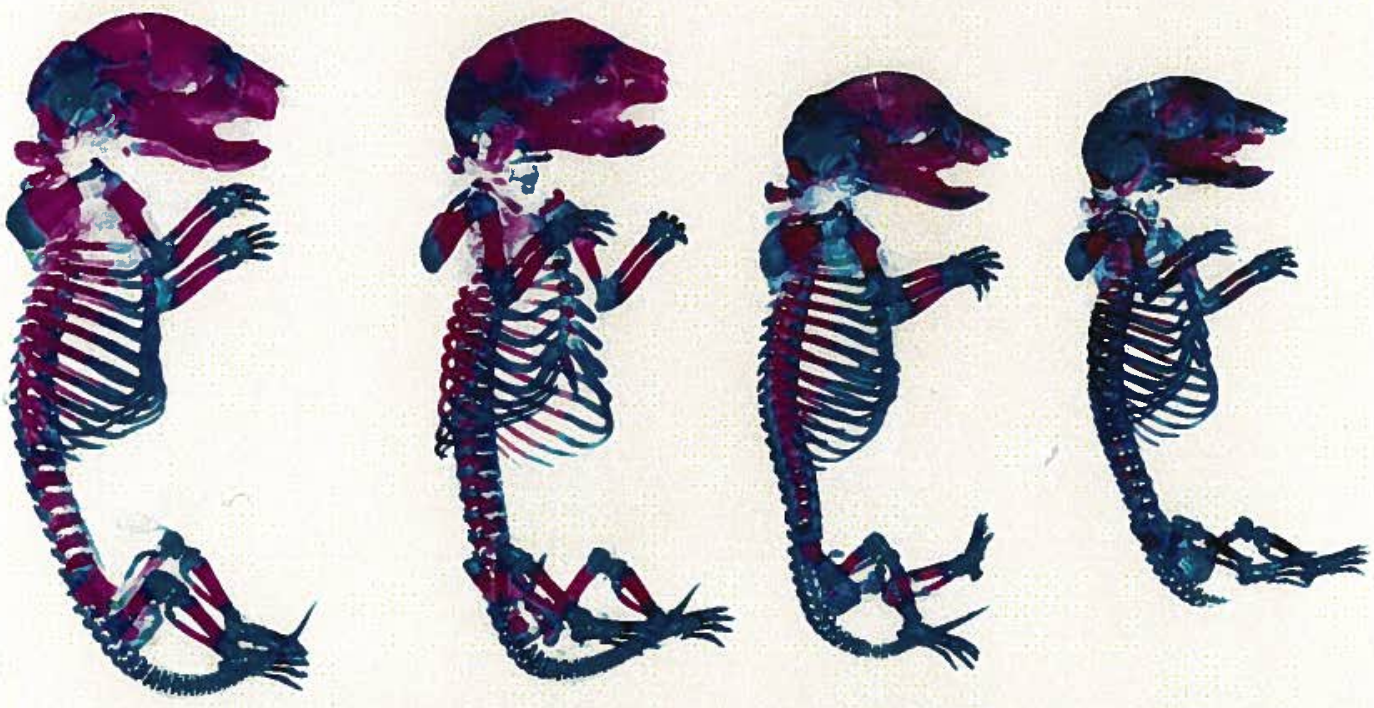
Photo 8: A fetal skeleton from a control litter (skull removed). The focus is the normal sternebral ossification centers.

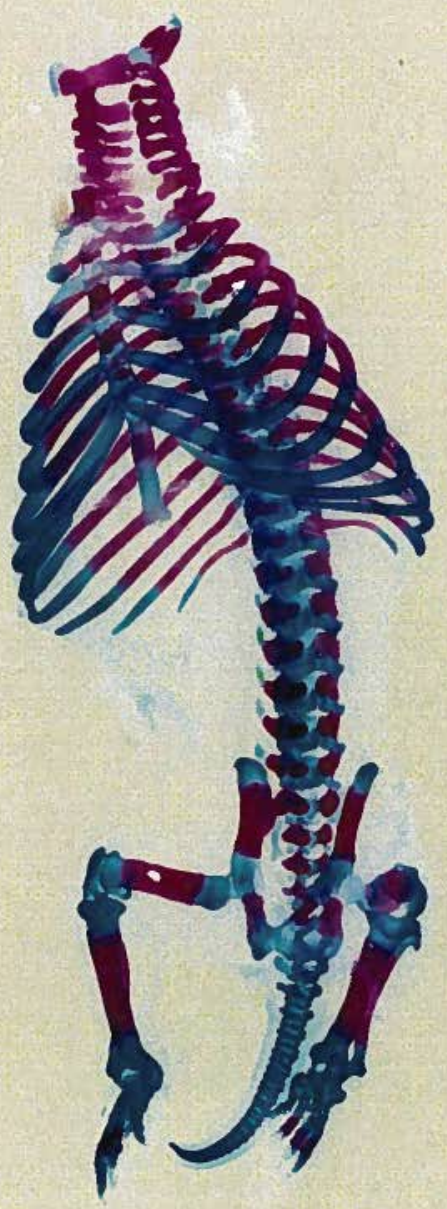


Photo 9: A fetal skeleton from a control litter (skull removed). The focus is the normal vertebral ossification centers and cervical arches.

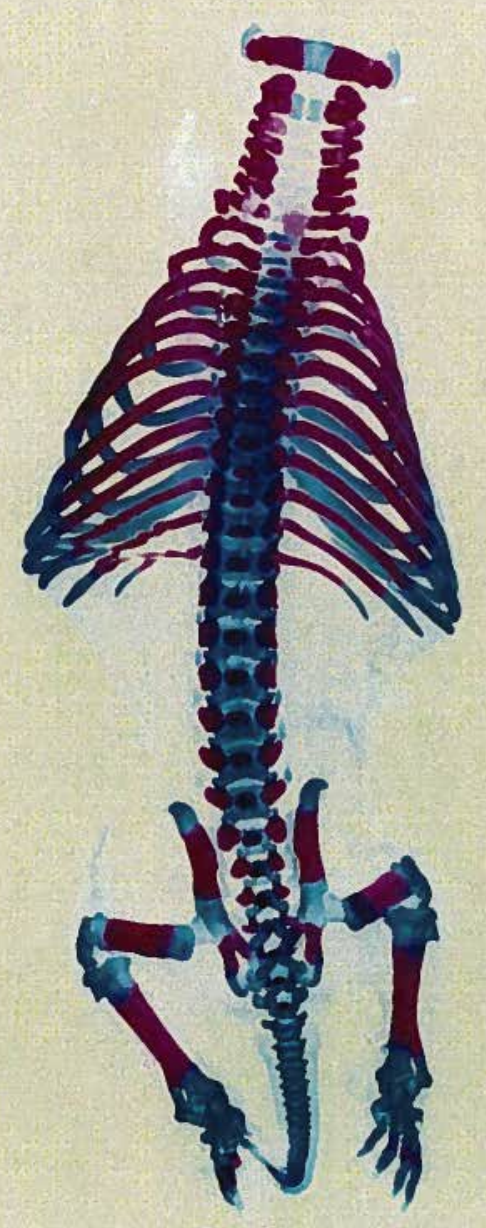


Photo 10: A fetal skeleton from a diabetic rat exposed to alcohol, showed a rudimentary extra rib on the left, and a short extra rib on the right. These extra ribs appeared at lumbar position. In addition, this fetus showed a few poorly ossified vertebral ossification centers.

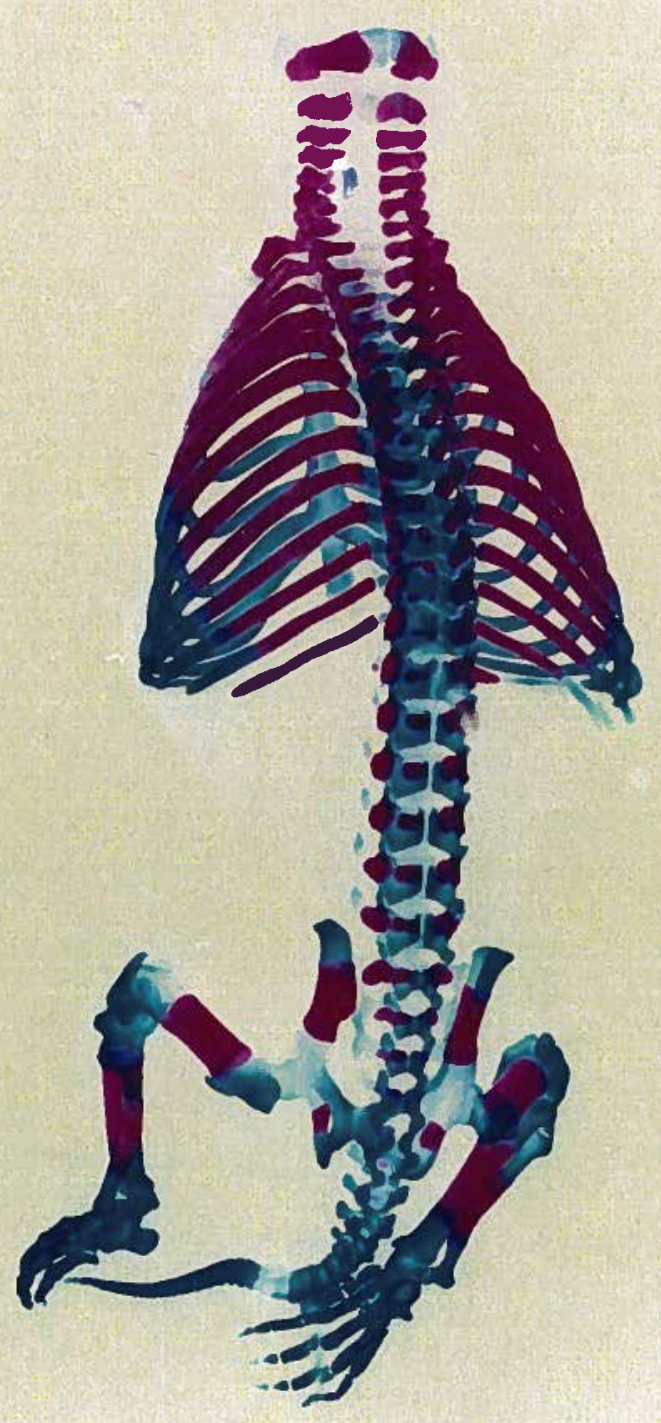




\section{Appendix B}

Chi-square tests, $P$ values 


\begin{tabular}{|c|c|c|c|c|c|c|c|}
\hline & Overall & 1 vs 2 & 1 vs 3 & 1 vs 4 & 2 vs 3 & 2 v8 4 & 3 vs 4 \\
\hline Breeding rate & NS & - & - & - & - & - & - \\
\hline Pregnant rate & NS & - & - & - & - & - & - \\
\hline \% resorptions & NS & - & - & - & - & - & - \\
\hline$\%$ litters with resorptions & NS & - & - & - & - & - & - \\
\hline$\%$ external malformed fetuses & - & - & - & - & - & - & $<0.05$ \\
\hline $\begin{array}{l}\text { \% litters with external } \\
\text { malformed fetuses }\end{array}$ & - & - & - & - & - & - & NS \\
\hline $\begin{array}{l}\text { \% malformed fetuses } \\
\text { (external \& skeletal) }\end{array}$ & - & - & - & - & - & - & NS \\
\hline $\begin{array}{l}\text { \% litters with malformed } \\
\text { fetuses (external \& skeletal) }\end{array}$ & - & - & - & - & - & - & NS \\
\hline $\begin{array}{l}\text { The most cephalic vertebral } \\
\text { center }\end{array}$ & $<0.001$ & $<0.001$ & $<0.001$ & $<0.001$ & $<0.001$ & $<0.001$ & NS \\
\hline $\begin{array}{l}\text { The most caudal vertebral } \\
\text { center }\end{array}$ & $<0.001$ & $<0.001$ & $<0.001$ & $<0.001$ & $<0.001$ & $<0.001$ & NS \\
\hline $\begin{array}{l}\text { The most caudal vertebral } \\
\text { arch (Left) }\end{array}$ & $<0.001$ & $<0.001$ & $<0.001$ & $<0.001$ & $<0.001$ & $<0.001$ & NS \\
\hline $\begin{array}{l}\text { The most caudal vertebral } \\
\text { arch (Right) }\end{array}$ & $<0.001$ & $<0.001$ & $<0.001$ & $<0.001$ & $<0.001$ & $<0.001$ & NS \\
\hline Hyoid & $<0.01$ & $<0.001$ & NS & NS & NS & NS & NS \\
\hline Presphenoid & $<0.001$ & NS & $<0.001$ & 0.002 & $<0.001$ & 0.001 & NS \\
\hline Foramen & $<0.001$ & NS & $<0.001$ & $<0.001$ & $<0.001$ & $<0.001$ & NS \\
\hline Supraoccipital & NS & - & - & - & - & - & - \\
\hline Extra rib & $<0.001$ & - & - & - & - & - & NS \\
\hline The 13th short rib & $<0.001$ & - & - & - & - & - & - \\
\hline $\begin{array}{l}\text { Incomplete ossification of } \\
\text { supraoccipital bone }\end{array}$ & $<0.001$ & NS & $<0.001$ & $<0.001$ & - & - & 0.0118 \\
\hline Lack of foramen & $<0.05$ & NS & NS & NS & NS & NS & NS \\
\hline $\begin{array}{l}\text { Poorly ossified stemebral } \\
\text { centers }\end{array}$ & $<0.001$ & NS & $<0.001$ & $<0.001$ & $<0.001$ & $<0.001$ & NS \\
\hline $\begin{array}{l}\text { Lack of apposition in } \\
\text { sternebral centers }\end{array}$ & $<0.001$ & NS & 0.001 & $<0.001$ & 0.0040 & $<0.001$ & NS \\
\hline $\begin{array}{l}\text { Poorly ossified thoracic } \\
\text { centers }\end{array}$ & $<0.001$ & NS & $<0.001$ & $<0.001$ & $<0.001$ & $<0.001$ & 0.0039 \\
\hline $\begin{array}{l}\text { Poorly ossified lumbar } \\
\text { centers }\end{array}$ & $<0.001$ & NS & - & - & - & - & NS \\
\hline $\begin{array}{l}\text { Poorly ossified cervical } \\
\text { arches }\end{array}$ & $<0.001$ & - & - & - & - & - & 0.0133 \\
\hline
\end{tabular}




\section{Appendix C}

Two way ANOVA statistical effects diabetes vs alcohol, $P$ values 


\begin{tabular}{|c|c|c|c|}
\hline & Diabetic & Alcohol & Interaction \\
\hline Water D1-5 ave. & $<0.001$ & NS & NS \\
\hline Water D6-11 ave. & $<0.001$ & $<0.01$ & $<0.01$ \\
\hline Water D12-20 ave. & $<0.001$ & $<0.05$ & $<0.05$ \\
\hline Calorie D1-5 ave. & $<0.001$ & NS & NS \\
\hline Calorie D6-11 ave. & $<0.001$ & $<0.01$ & $<0.01$ \\
\hline Calorie D12-20 ave. & $<0.001$ & NS & NS \\
\hline Body wt D1 & NS & NS & NS \\
\hline Body wt D6 & $<0.01$ & NS & NS \\
\hline Body wt D12 & $<0.001$ & NS & NS \\
\hline Body wt D21 & $<0.001$ & NS & NS \\
\hline Wt gain D1-5 & $<0.05$ & NS & NS \\
\hline Wt gain D6-11 & $<0.001$ & NS & NS \\
\hline Wt gain D12-20 & $<0.001$ & NS & $<0.05$ \\
\hline Implantation & NS & NS & NS \\
\hline Resorption & NS & NS & NS \\
\hline Live fetuses & NS & NS & NS \\
\hline Fetal wt & $<0.001$ & NS & $<0.05$ \\
\hline Placental wt & $<0.01$ & NS & NS \\
\hline f/p ratio & $<0.001$ & $<0.05$ & $<0.05$ \\
\hline Metacarpus (L) & $<0.001$ & NS & NS \\
\hline Metacarpus (R) & $<0.001$ & NS & NS \\
\hline Metatarsus (L) & $<0.01$ & NS & NS \\
\hline Metatarsus (R) & $<0.01$ & NS & NS \\
\hline Sternum & $<0.01$ & NS & NS \\
\hline \multicolumn{4}{|l|}{ Bone areas } \\
\hline Humerus & $<0.001$ & NS & NS \\
\hline Ulna & $<0.001$ & NS & NS \\
\hline Radius & $<0.001$ & NS & NS \\
\hline Femur & $<0.001$ & NS & NS \\
\hline Fibular & $<0.001$ & NS & NS \\
\hline Tibia & $<0.01$ & NS & NS \\
\hline $\begin{array}{l}\text { Mean no. of poorly ossified } \\
\text { sternebral centers }\end{array}$ & $<0.001$ & NS & NS \\
\hline $\begin{array}{l}\text { Mean no. of poorly ossified } \\
\text { thoracic centers }\end{array}$ & $<0.001$ & NS & NS \\
\hline
\end{tabular}




\section{Appendix D}

Tests of Simple Effect, $P$ values 


\begin{tabular}{lcccc}
\hline & $\begin{array}{c}\text { Dia at water } \\
(1 \text { vs 3) }\end{array}$ & $\begin{array}{c}\text { Dia at alc } \\
(2 \text { vs } 4)\end{array}$ & $\begin{array}{c}\text { Alc at non-dia } \\
(1 \text { vs })\end{array}$ & $\begin{array}{c}\text { Alc at dia } \\
(3 \text { vs } 4)\end{array}$ \\
\hline & & & & \\
Water D6-11 ave. & $<0.001$ & $<0.001$ & NS & $<0.001$ \\
Water D12-20 ave. & $<0.001$ & $<0.001$ & NS & $<0.01$ \\
Calorie D6-11 ave. & $<0.001$ & $<0.001$ & NS & $<0.001$ \\
Wt gain D12-20 & $<0.001$ & $<0.001$ & NS & NS \\
Fetal wt & $<0.001$ & $<0.001$ & NS & NS \\
f/p ratio & $<0.001$ & $<0.001$ & $<0.01$ & NS \\
& & & & \\
\hline
\end{tabular}




\section{Bibliography}

[1] Abel, E.L., and Dintcheff, B.A. (1978a) Effects of prenatal alcohol exposure on growth and development in rats. J. Pharmacol. Exp. Ther. 207: 916-921.

[2] Abel, E.L. (1978b) Effects of ethanol on pregnant rats and their offspring. Psychopharmacology 57: 5-11.

[3] Abel, E.L. (1979a) Prenatal effects of alcohol on adult learning in rats. Pharmacol. Biochem. Behav. 10: 239-243.

[4] Abel, E.L. (1979b) Effects of ethanol exposure during different gestation weeks of pregnancy on maternal weight gain and intrauterine growth retardation in the rat. Neurobehav. Toxicol. 1: 145-151.

[5] Aliverti, V., Bonanomi, L., Giavini, E., Leone, V.G., and Mariani, L. (1979) The extent of fetal ossification as an index of delayed development in teratogenic studies on the rat. Teratology 20: 237-242.

[6] Ariyuki, F., Higaki, K., and Yasuda, M. (1980) A study of fetal growth retardation in teratological tests: An examination of the relationship between body weight and ossification of coccygeal vertebrae in mouse and rat fetuses. Teratology 22: 43-49.

[7] Aufrere, G., and Lebourhis, B. (1987) Effect of alcohol intoxication during pregnancy on fetal and placental weight: Experimental studies. Alcohol and Alcoholism 22: 401-407.

[8] Baird, J.D., and Aerts, L. (1987) Research priorities in diabetic pregnancy today: The role of animal models. Biol. Neonate 51: 119-12\%.

[9] Baker, L., Egler, J.M., Klein, S.H.,and Goldman, A.S. (1981) Meticulous control of diabetes during organogenesis prevents congenital lumbosacral defects in rats. Diabetes 30: 955-959.

[10] Black, D.L., and Marks, T.A. (1986) Inconsistent use of terminology in animal developmental toxicology studies: a discussion. Teratology 33: 333-338.

[11] Brownscheidle, C.M., Wootten, V., Mathieu, M.H., Davis, D.L., and Hofman, I.A. (1983) The effects of maternal diabetes on fetal maturation and neonatal health. Metabolism 32 (Suppl. 1): 148-155. 
[12] Chernoff, G.F. (1975) A mouse model of the fetal alcohol syndrome. Teratology 11: $14 A$.

[13] Chernoff, G.F. (1977) The fetal alcohol syndrome in mice: An animal model. Teratology 15: 223-230.

[14] Chernoff, G.F. (1980) The fetal alcohol syndrome in mice: maternal variables. Teratology 22: 71-75.

[15] Clarren, S.K., and Smith, D.W. (1978) The fetal alcohol syndrome. N. Engl. J. Med. 298: 1063-1067.

[16] Chung, C.S., and Myrianthopoules, W.C. (1975) Factors affecting risks of congenital malformations. Report from the collaborative perinal project. In: Birth defects original article series (ed Bergsma D). The National Foundation-March of Dimes, Vol. 11, Symposia Specialists, Miami, pp. 23-38.

[17] Cockroft, D.L., and Coppola, P.T. (1977) Teratogenic effects of excess glucose on headfold rat embryos in culture. Teratology 16: 141-146.

[18] Da Cunha Ferreira, R.M.C., Monreal Marquiegui, I., and Villa Elizaga, I. (1989) Teratogenicity of zinc deficiency in the rat: study of the fetal skeleton. Teratology 39: $181-194$.

[19] Driscoll, C.D., Streissguth, A.P., and Riley, E.P. (1990) Prenatal alcohol exposure: Comparability of effects in humans and animal models. Neurotoxicol. Teratol. 12: 231-237.

[20] Ellis, F.W., and Pick, J.R. (1976) Beagle model of the fetal alcohol syndrome. Pharmacologist 18: 190.

[21] Elton, R.H., and Wilson, M.E. (1977) Changes in ethanol consumption by pigtailed macaques. J. Stud. Alc. 38: 2181-2183.

[22] Eriksson, U., Dahlstrom, E., Larsson, K.S., and Hellerstrom, C. (1982) Increased incidence of congenital malformations in the offspring of diabetic rats and their prevention by maternal insulin therapy. Diabetes 30: 1-6.

[23] Eriksson, U.J. (1984a) Diabetes in pregnancy: Retarded fetal growth, congenital malformations and feto-maternal concentrations of zinc, copper and manganese in the rat. J. Nutr. 114: $477-484$.

[24] Eriksson, U.J., and Jansson, L. (1984b) Diabetes in pregnancy: Decreased placental blood flow and disturbed fetal development in the rat. Pediatric Research 18: 735738. 
[25] Eriksson, U.J., Unger, E., and Kjellen, L. (1986) Decreased levels of high molecular weight cartilage proteoglycans in diabetic rats of a malformation-prone strain. Diabetologia 29: 534A.

[26] Eriksson, U.J. (1988) Importance of genetic predisposition and maternal environment for the occurrence of congenital malformations in offspring of diabetic rats. Teratology 37: 365-374.

[27] Eriksson, U.J., Bone, A.J., Turnbull, D.M., and Baird, J.D. (1989a) Timed interruption of insulin therapy in diabetic $\mathrm{BB} / \mathrm{E}$ rat pregnancy: effect on maternal metabolism and fetal outcome. Acta Endocrinol. 120: 800-810.

[28] Eriksson, R.S.M., Thunberg, L., and Eriksson, U.J. (1989b) Effects of interrupted insulin treatment on fetal outcome of pregnant diabetic rats. Diabetes 38: 764-772.

[29] Fisher, S.E., Atkinson, M., Burnap, J.K., Jacobson, S., Sehgal, P.K., Scott, W. and Van Thiel, D.H. (1982) Ethanol-associated selective fetal malnutrition: A contributing factor in the fetal alcohol syndrome. Alcohol.: Clin. Exp. Res. 6: 197-201.

[30] Fisher, S.E., Inselman, L.S., Duffy, L., Atkinson, M., Spencer, H., and Chang, B. (1985) Ethanol and fetal nutrition: effect of chronic ethanol exposure on rat placental growth and membrane associated folic acid receptor binding activity. $J$. Pediatr. Gastroenterol. Nutr. 4: 645-649.

[31] Freinkel, N. (1980) The Banting lecture 1980: Of pregnancy and progeny. Diabetes 29: $1023-1035$.

[32] Freinkel, N. (1988) Diabetic embryopathy and fuel-mediated organ teratogenesis: Lessons from animal models. Horm. Metabol. Res. 20: $463-475$.

[33] Fritz, H., and Hess, R. (1970) Ossification of the rat and mouse skeleton in the perinatal period. Teratology 3: 331-338.

[34] Fujinaga, M., Baden, J.M., and Mazze, R.I. (1989) Susceptible period of nitrous oxide teratogenicity in sprague-dawley rats. Teratology 40: 439-444.

[35] Gallo, P.V., and Weinberg, J. (1986) Organ growth and cellular development in ethanol-exposed rats. Alcohol 3: 261-267.

[36] Giavini, E., Broccia, M.L., Prati, M., Roversi, G.D., and Vismara, C. (1986) Effects of streptozotocin-induced diabetes on fetal development of the rat. Teratology 34: 81-88. 
[37] Giavini, E., Prati, M., and Roversi, G. (1990) Congenital malformations in offspring of diabetic rats: Experimental study on the influence of the diet composition and magnesium intake. Biol. Neonate 5\%: 207-21\%.

[38] Glasgow, A.C.A., Harley, J.M.G., and Montgomery, D.A.D. (1979) Congenital malformations in infants of diabetic mothers. Ulster. Med. J. 48: 109-117.

[39] Goldman, A.S., Baker, L., Piddington, R., Marx, B., Herold, R., and Egler, J. (1985) Hyperglycemia-induced teratogenesis is mediated by a functional deficiency of arachidonic acid. Proc. Natl. Acad. Sci. USA 82: 8227-8231.

[40] Gordon, B.H.J., Streeter, M.L., Rosso, P., and Winick, M. (1985) Prenatal alcohol exposure: abnormalities in placental growth and fetal amino acid uptake in the rat. Biol. Neonate 47: 113-119.

[41] Greizerstein, H.B. and Aldrich, L.K. (1983) Ethanol and diazepan effects on intrauterine growth of the rat. Develop. Pharmacol Ther. 6: 409-418.

[42] Hadden, D.R. (1986) Diabetes in pregnancy 1985. Diabetologia 29: 1-9.

[43] Heinze, E., and Vetter, U. (1987) Skeletal growth of fetuses from streptozotocin diabetic rat mothers: in vivo and in vitro studies. Diabetologia 30: 100-103.

[44] Henderson, G.I., Turnter, D., Patwardhan, R.V., Lumeng, L., Hoyumpa, A.M., and Schenker, S. (1981) Inhibition of placental valine uptake after acute and chronic maternal ethanol consumption. J. Pharmacol. Exp. Ther. 216: 465-472.

[45] Henderson, G.I., Patwardhan, R.V., McLeroy, S., and Schenker, S. (1982) Inhibition of placental amino acid uptake in rats following acute and chronic ethanol exposure. Alcohol.: Clin. Exp. Res. 6: 495-505.

[46] Hill, E.P., and Longo, L.D. (1980) Dynamics of maternal-fetal nutrient transfer. Fed. Proc. 39: 239-244.

[47] Horii, K., Watanabe, G., and Ingalls, T.H. (1966) Experimental diabetes in pregnant mice: prevention of congenital malformations in offspring by insulin. Diabetes 15: 194-204.

[48] Hurley, L.S., and Swenerton, H. (1966) Congenital malformations resulting from zinc deficiency in rats. Proc. Soc. Exp. Biol. Med. 123: 692-696.

[49] Hurley, L.S. (1981) Teratogenic aspects of manganese, zinc, and copper nutrition. Physiol. Rev. 61: 249-295. 
[50] Jones, K.L., and Smith, D.W. (1973a) Recognition of the fetal alcohol syndrome in early infancy. Lancet 2: 999-1001.

[51] Jones, K.L., Smith, D.W., Ulleland, C.N., and Streissguth, A.P.S. (1973b) Pattern of Malformation in offspring of chronic alcoholic mothers. Lancet 1: 1267-1271.

[52] Jones, P.J.H., Leichter, J., and Lee, M. (1981) Placental blood flow in rats fed alcohol before and during gestation. Life Sci. 29: 1153-1159.

[53] Kahns, A.J. (1968) Effect of ethanol exposure during embryogenesis and neonatal period on the incidence of Lepatoma in $\mathrm{C}_{3} \mathrm{H}$ male mice. Growth 32: 311-316.

[54] Kennedy, L.A. (1984) Changes in the term mouse placenta associated with maternal alcohol consumption and fetal growth deficits. Am. J. Obstet. Gynecol. 149: 518-522.

[55] Keppen, L.D., Pysher, T., and Rennert, O.M. (1985) Zinc deficiency acts as a co-teratogen with alcohol in fetal alcohol syndrome. Pediatric Res. 19: 944-947.

[56] Kimmel, H.D. (1985) Simple and factorial experiments. In: Experimental principles and design in psychology. New York: The Ronald Press Co. pp. 153-177.

[57] Kitzmiller, J.I., Cloherty, J.P., Younger, M.D., Tabatabaii, A., Rothchild, S.B., Sosenko, I., Epstein, M.F., Singh, S., and Neff, R.K. (1978) Diabetic pregnancy and perinatal morbidity. Am. J. Obstet. Gynecol. 131: 560-580.

[58] Kucera, J. (1971) Rate and type of congenital anomalies among offspring of diabetic women. J. Reprod. Med. 7: 61-70.

[59] Kumar, S.P. (1982) Fetal Alcohol Syndrome. Mechanisms of Teratogenesis. Annal Clin. Lab. Sci. 12: 254-257.

[60] Lee, M., and Leichter, J. (1983) Skeletal development in fetuses of rats consuming alcohol during gestation. Growth 47: 254-262.

[61] Leichter, J., and Lee, M. (1979) Effect of maternal ethanol administration on physical growth of the offspring in rats. Growth 43: 288-297.

[62] Leichter, J., and Lee, M. (1984) Does dehydration contribute to retarded fetal growth in rats exposed to alcohol during gestation? Life Sci. 35: 2105-2111.

[63] Majewski, F., Nothjunge, J., and Bierich, J.R. (1979) Alcohol embryopathy and diabetic fetopathy in the same newborn. Helv. Paediat. Acta. 34: 135-139. 
[64] Malins, J.M. (1979) Fetal abnormalities related to carbohydrate metabolism: the epidemiological approach. In: Sutherland HW, Stowers JM (eds): Carbohydrate metabolism in pregnancy and the newborn 1978. Springer-Verlag, Berlin, Heidelberg, New York, pp. 229-246.

[65] Marquis, S.M., Leichter, J, Lee, M. (1984) Plasma amino acids and glucose levels in the rat fetus and dam after chronic maternal alcohol consumption. Biol. Neonate 46: $36-43$.

[66] Martin, J.M., Martin, D.C., Lund, C.A., and Streissguth, A.P. (1977a) Maternal alcohol ingestion and cigarette smoking and their effects on newborn conditioning. Alcohol.: Clin. Exp. Res. 1: 243-247.

[67] Martin, J.C., Martin, D.C., Sigman, G., and Radow, B. (1977b) Offspring survival, development, and operant performance following maternal ethanol consumption. Dev. Psychobiol. 10 : 435-446.

[68] Maykut, M.O. (1979) Consequences of prenatal maternal alcohol exposure including the fetal alcohol syndrome. Prog. Neuro-Psychopharmacol. 3: 465-481.

[69] Mills, J.L., Baker, L., and Goldman, A.S. (1979) Malformations in infants of diabetic mothers occur before the seventh gestational week: implications for treatment. Diabetes 28: 292-293.

[70] Mills, J.L. (1982) Malformations in infants of diabetic mothers. Teratology 25: 385394.

[71] Molsted-Pedersen, L. Tygstrup, I. and Pedersen, J. (1964) Congenital malformations in newborn infants of diabetic women. Lancet 1: 1124-1126.

[72] Molsted-Pedersen, L. (1980) Congenital malformations in the offspring of diabetic women. In: Proc. Congr. Int. Diabetes Fed., 10th, Vienna, Austria. Amsterdam, Expcerpta Med., pp. 758-62.

[73] Nelson, B.K., Brightwell, W.S., MacKenzie, D.R., Khan, A., Burg, J.R., Weigel, W.W., and Goad, P. T. (1985) Teratological assessment of methanol and ethanol at high inhalation levels in rats. Fundamental and Appl. Toxicol. 5: 727-736.

[74] Ornoy, A., Merin, B., Zusman, I., Granat, M., Barash, V., and Shafrir, E. (1984) Placental and skeletal changes in fetuses of streptozotocin-diabetic rats. In: Lessons from animal diabetes. E. Shafrir and A.E. Renold, eds. John Libbey, London, pp. 775-781.

[75] Papara-Nicholson, D., and Telford, I.R. (1957) Effects of alcohol on reproduction and fetal development in the guinea pig. Anat. Rec. 127: 438-439. 
[76] Pedersen, J. (1977) Congenital malformations. In: The pregnant diabetic and her newborn. 2nd Edition. Munkgaard, Copenhagen, pp. 191-196.

[77] Pedersen, J. (1979) Congenital malformations in newborns of diabetic mothers. In: Sutherland HW, Stowers JM (eds): Carbohydrate metabolism in pregnancy and the newborn 1978. Berlin, Springer, pp. 264-276.

[78] Pedersen, J., and Molsted-pedesen, L. (1981) Early fetal growth delay detected by ultrasound marks increased risk of congenital malformation in diabetic pregnancy. Brit. Med. J. 283: 269-271.

[79] Pedersen, J.F., and Molsted-pedesen, L. (1982) Early growth delay predisposes the fetus in diabetic pregnancy to congenital malformation. Lancet 1: 737.

[80] Pilstrom, L., and Kiessling, K.H. (1967) Effects of ethanol on the growth and on the liver and brain mitochondrial functions of the offspring of rats. Acta Pharmacol. Toxicol. 25: 225-232.

[81] Prager, R., Abramovici, A., Liban, E., and Laron, Z. (1974) Histopathological changes in the placenta of streptozotocin induced diabetic rats. Diabetologia 10: 89-91.

[82] Randall, C.L., and Anton, R.F. (1984) Aspirin reduces alcohol-induced prenatal mortality and malformations in mice. Alcohol.: Clin. Exp. Res. 8: 513-515.

[83] Randall, C.L., Taylor, W.J., and Walker, D.W. (1977) Ethanol-induced malformations in mice. Alcohol.: Clin. Exp. Res. 1: 219-224.

[84] Randall, C.L., and Taylor, W.J. (1979) Prenatal ethanol exposure in mice: Teratogenic effects. Teratology 19: 305-312.

[85] Rilely, E.P., and Meyer, L.S. (1984) Considerations for the design, implementation, and interpretation of animal models of fetal alcohol effects. Neurobehav. Toxicol. Teratol. 6: 97-101.

[86] Sadler, T.W. (1980) Effects of maternal diabetes on early embryogenesis II. Hyperglycemia-induced encephaly. Teratology 21: 349-356.

[87] Sadler, T.W., Hunter III, E.S., Wynn, R.E., and Phillips, L.S. (1989) Evidence for multifactorial origin of diabetes-induced embryopathies. Diabetes 38: 70-74.

[88] Sokol, R.J., Ager, J., and Martier, S. (1986) Significant determinants of susceptibility to alcohol teratogenicity. Annals New York Academy of Sciences 477: 87-102. 
[89] Sandor, S., and Amels, D. (1971) The action of ethanol on the prenatal development of albino rats. Rev. Roum. Embryol. 8: 105-118.

[90] Simpson, J.L., Elias, S., Martin, A.O., Palmer M.S., Ogata, E.S., and Qadvany, Q.A. (1983) Diabetes in pregnancy, Northwestern University series (1977-1981). Am. J. Obstet. Gynecol. 146: 263-268.

[91] Streissguth, A.P., Landesman-Dwyer, S., Martin, J.C., and Smith, D.W. (1980) Teratogenic effects of alcohol in humans and laboratory animals. Science 209: 353361.

[92] Snyder, A.K., Singh, S.P., and Pullen, G.L. (1986) Ethanol-induced intrauterine growth retardation: Correlation with placental glucose transfer. Alcohol.: Clin Exp. Res. 10: 167-170.

[93] Soler, N.G., Walsh, C.H., and Malins, J.M. (1976) Congenital malformations in infants of diabetic mothers. Quart. J. Med. 45: 303-313.

[94] Streissguth, A.P., Landesman-Dwyer, S., Martin, J.C., and Smith, D.W. (1980) Teratogenic effects of alcohol in humans and laboratory animals. Science 209: 353361 .

[95] Strong, R.M. (1926) The order, time, and rate of ossification of the albino rat (mus norvegicus albinus) skeleton. Am. J. Anat. 36:313-355.

[96] Styrud, J., Dahlstrim, V.E., and Eriksson, U.J. (1986) Induction of skeletal malformations in the offspring of rats fed a zinc-deficient diet. Upsala J. Med. Sci. 91: 29-36.

[97] Sybulski, S., and Maughan, G.B. (1971) Use of streptozotocin as diabetic agent in pregnant rats. Endocrinology 89: 1537-1540.

[98] Testar, X., Lopez, D., Llobera, M., and Herrera, E. (1986) Ethanol administration in the drinking fluid to pregnant rats as a model for the fetal alcohol syndrome. Pharmacol. Biochem. Behav. Diabetes 24: 625-630.

[99] Tom, C., Juriloff, D.M., and Harris, M.J. (1991) Studies of the effect of retinoic acid on anterior neural tube closure in mice genetically liable to exencephaly. Teratology 43: 27-40.

[100] Tze, W.J., and Lee, M. (1975) Adverse effects of maternal alcohol consumption on pregnancy and fetal growth in rats. Nature 25\%: 479-480. 
[101] Urir-Hare, J.Y., Stern, J.S., Reaven, G.M., and Keen C.L. (1985) The effects of maternal diabetes on trace element status and fetal development in the rat. Diabetes 34: $1031-1040$.

[102] Uriu-hare, J.Y., Stern, J.S., and Keen, C.L. (1989) Influence of maternal dietary Zn intake on expression of diabetes-induced teratogenicity in rats. Diabetes 38: 12821290.

[103] Vavrousek-Jakuba, E.M., Baker, R.A., and Shoemaker, W.J. (1991) Effect of ethanol on maternal and offspring characteristics: comparison of three liquid diet formulations fed during gestation. Alcohol.: Clin. Exp. Res. 15: 129-135.

[104] Warner, R.H., and Rosett, H.L. (1975) The effects of drinking on offspring: An historical survey of the American and British literature. J. Stud. Alcohol 36: 13951420 .

[105] Warren, K.R., and Bast, R.J. (1988) Alcohol-related birth defects: an update. Public Health Reports 103: 638-642.

[106] Weathersbee, P.S., and Lodge, J.R. (1978) A review of ethanol's effects on the reproductive process. J. Reprod. Med. 21: 63-78.

[107] Weinberg, J., D'alquen, G., and Bezio, S. (1990) Interactive effects of ethanol intake and maternal nutritional status on skeletal development of fetal rats. Alcohol 7: $383-388$.

[108] Weinberg, J. (1985) Effects of ethanol and maternal nutritional status on fetal development. Alcohol.: Clin. Exp. Res. 9: 49-55.

[109] Wiener, S.G., Shoemaker, W.J., Koda, L.V., and Bloom, F.E. (1981) Interaction of ethanol and nutrition during gestation: influence on maternal and offspring development in the rat. J. Pharmacol. Exp. Ther. 216: 572-579.

[110] Wilson, J.G. (1973) Environment and birth defects. Academic Press, New York. Chap. 9, pp. 173-193.

[111] (1988) Congenital abnormalities in infants of diabetic mothers. Lancet June 11, 1313-1315. 